\title{
ASSESSMENT OF THE TEMPORAL STABILITY OF LAND USE \\ REGRESSION MODELS FOR TRAFFIC-RELATED AIR POLLUTION
}

\author{
by \\ Rongrong Wang \\ A THESIS SUBMITTED IN PARTIAL FULFILLMENT OF THE REQUIREMENTS FOR \\ THE DEGREE OF
}

MASTER OF SCIENCE

in

The Faculty of Graduate Studies

(Occupational and Environmental Hygiene)

THE UNIVERSITY OF BRITISH COLUMBIA

(Vancouver)

December 2011

(C) Rongrong Wang, 2011 


\section{Abstract}

Background: Land-use regression (LUR) modeling is a cost-effective approach for assessing intra-urban air pollution contrasts. It has been widely used to estimate long-term exposure to traffic-related air pollution in epidemiologic studies. The application was based on the assumption that spatial patterns of pollution are stable over time so that a model developed for a particular time point could be applied to other time points. However, this assumption has not been adequately examined. This has specific relevance to cohort studies where models are developed in one particular year and then retrospectively or prospectively applied over periods of $\sim 10$ other years.

Methods: Metro Vancouver LUR models for annual average $\mathrm{NO}$ and $\mathrm{NO}_{2}$ were developed in 2003, based on 116 measurements. In 2010, we repeated these measurements; 73 were made at the same location as in 2003, while the remaining 43 sites were within $\sim 50 \mathrm{~m}$. We then developed new models using updated data for the same predictor variables, and also explored additional variables. The temporal stability of LUR models over a 7-year period was evaluated by comparing model predictions and measured spatial contrasts between 2003 and 2010.

Results: Annual average $\mathrm{NO}$ and $\mathrm{NO}_{2}$ concentrations decreased from 2003 to 2010. From the 73 sites that were identical between 2003 and 2010, the correlation between NO 2003 and 2010 measurements was $r=0.87$ with a mean (sd) decrease of 11.3 (9.9) $\mathrm{ppb}$, and between $\mathrm{NO}_{2}$ measurements was $r=0.74$ with a mean (sd) decrease of 2.4 (3.2) ppb. 2003 and 2010 LUR models explained similar amounts of spatial variation $\left(\mathrm{R}^{2}\right.$ difference of 0.01 to 0.11 ). The 2003 models explained more variability in 2010 measurements $\left(\mathrm{R}^{2}=0.52-0.65\right)$ than 2010 models did for 2003 measurements $\left(\mathrm{R}^{2}=0.38\right.$ $-0.55)$.

Conclusions: Forecasting will be more appropriate than back-casting in the case of Metro Vancouver where concentrations and their variability decreased over time. Back-casting explains nearly the same amount of variability $\left(\mathrm{R}^{2}=0.38-0.55\right)$ in measured concentrations as did the original model $\left(R^{2}=0.52-0.58\right)$. These results support the validity of applying LUR models to cohort studies over periods as long as 7 years. 


\section{Preface}

The fundamental research question to examine the temporal stability of LUR models for traffic-related air pollution was developed by Dr. Michael Brauer. Details of the specific nature of this study, as well as its scope, were engineered in discussions between Dr. Brauer and me, with suggestions from Dr Ryan Allen and Dr. Sarah Henderson. I planned the logistics of field sampling and performed the field sampling with assistance from staff and fellow students. I prepared samples for ion chromatography analysis, which was conducted by lab staff. I processed all of the geographic information and did all statistical analysis (with R codes provided by Dr. Sarah Henderson), interpreted the results and wrote the thesis. 


\section{Table of Contents}

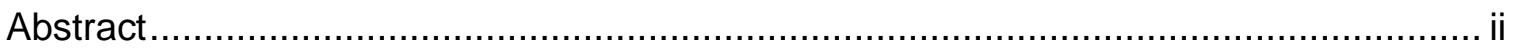

Preface

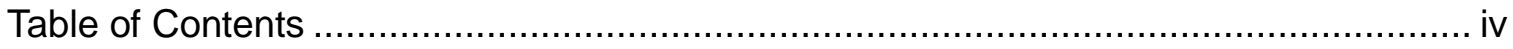

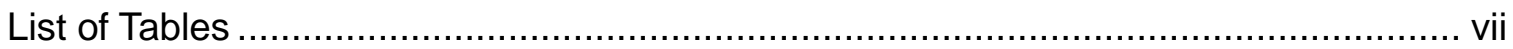

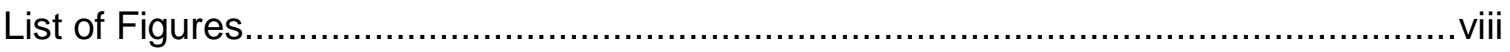

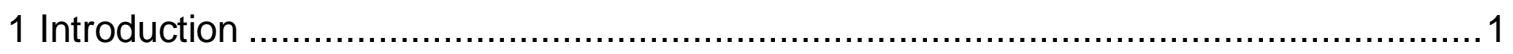

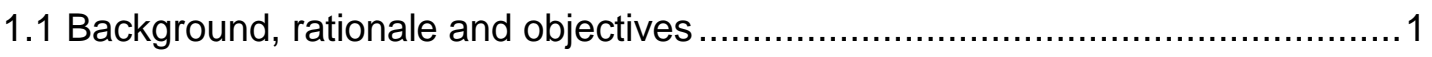

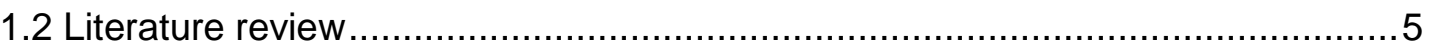

1.2.1 Conception and development of the LUR modeling approach ..................5

1.2.2 Process of constructing a LUR model.................................................

1.2.3 Application in multiple air pollutants ....................................................

1.2.4 Advancement in predictive variables................................................

1.2.5 Strengths and limitations of LUR …………..................................... 10

1.2.6 Temporal stability of LUR models. ................................................. 11

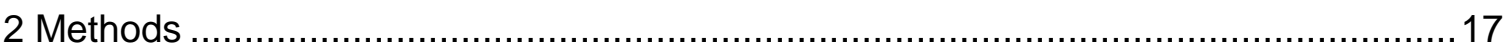

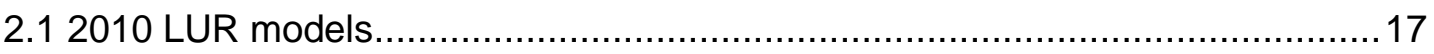

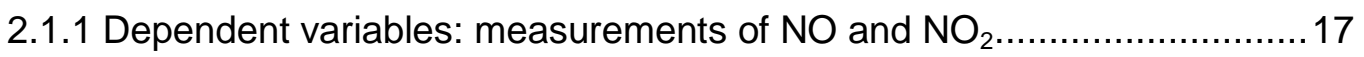

2.1.2 Independent variables: updates from $2003 \ldots \ldots \ldots \ldots \ldots \ldots \ldots \ldots \ldots \ldots \ldots \ldots \ldots \ldots . . .21$

2.1.3 Model building and validation ........................................................23

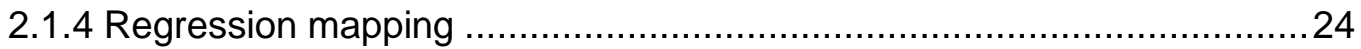

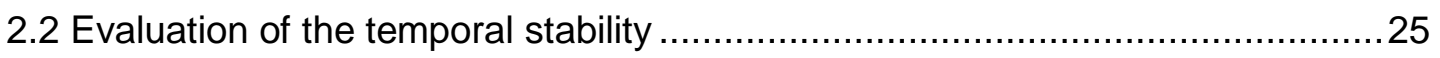

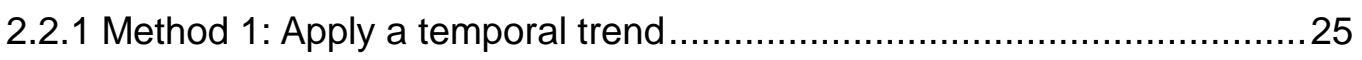

2.2.2 Method 2: Use concurrent values of predictor variables .........................25

2.2.3 Method 3: Joint method of applying temporal trend and concurrent values

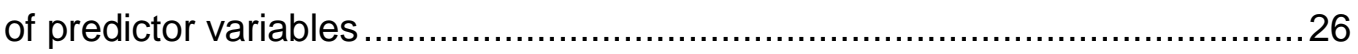

2.2.4 Method 4: Calibrating an existing model.............................................26

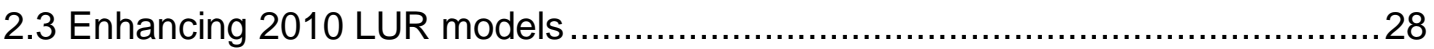

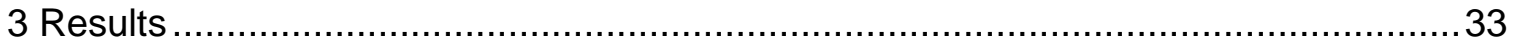

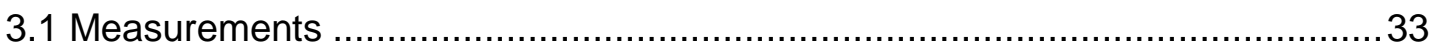

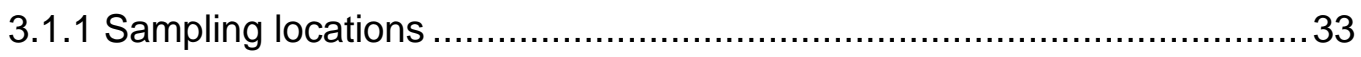




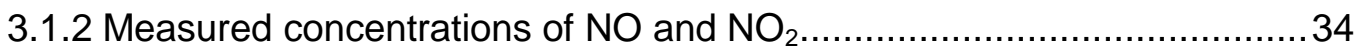

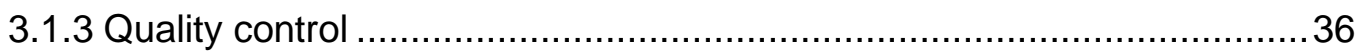

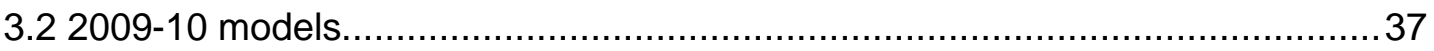

3.3 Change in $\mathrm{NO}$ and $\mathrm{NO}_{2}$ concentrations and in spatial pattern from 2003 to 201045

3.3.1 Estimated change by comparing measurements ................................. 45

3.3.2 Estimated change by comparing modeled surfaces............................... 49

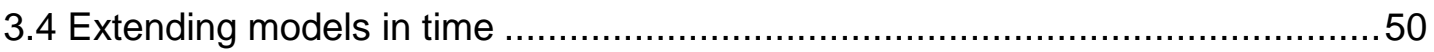

3.4.1 Method 1: applying a temporal trend ................................................52

3.4.2 Method 2: updating values of predictor variables ...................................53

3.4.3 Method 3: applying a temporal trend and updating values of predictor variables

3.4.4 Method 4: calibrating coefficients of previous models using new

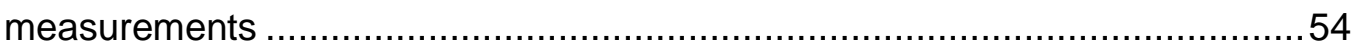

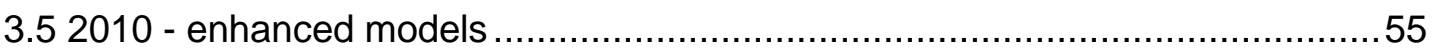

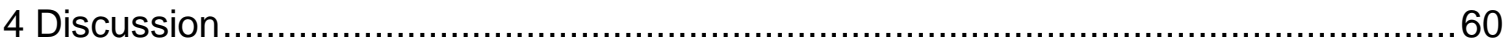

4.1 Downward trend in measured $\mathrm{NO} / \mathrm{NO}_{2}$ concentrations ...................................61

4.1.1 Near-traffic NO concentrations under-represented at monitoring stations 61 4.1.2 Overall downward trend in $\mathrm{NO}$ and $\mathrm{NO}_{2}$ concentrations from 2003 to 2010

4.1.3 Locations with increased concentrations ...............................................63

4.2 Comparison of LUR models: 2003, 2010 and 2010-enhanced.........................64

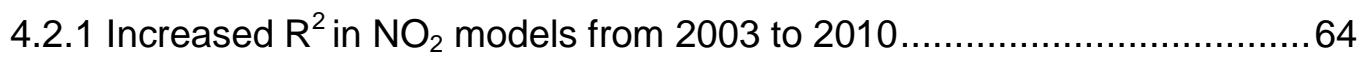

4.2.2 Two traffic metrics: road length versus traffic density .............................64

4.2.3 From 2010 to 2010 -enhanced: limited improvement from inclusion of new variables 66

4.3 Temporal stability of LUR models - exposure assessment for epidemiological studies .68

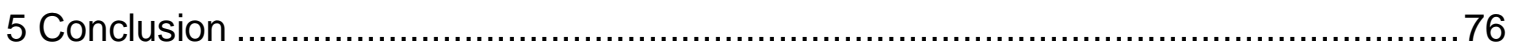

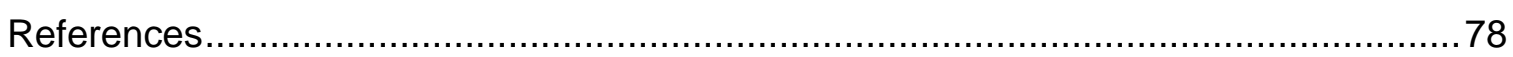

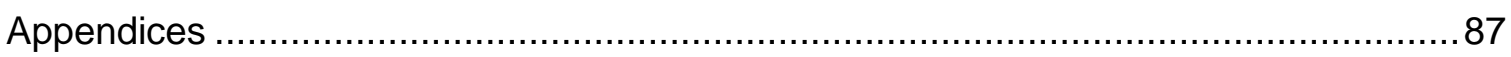

Appendix A: List of 16 Metro Vancouver monitoring stations ...............................8 88

Appendix B: SOEH Lab SOP - High Pressure lon Chromatography (IC) Conductivity and UV/VIS Analysis for Anions - Nitrite, Nitrate and Phosphate .89 
Appendix C: Calculation of ambient concentrations of $\mathrm{NO}$ and $\mathrm{NO} 2$ 96

Appendix D: R codes for LUR modeling (By Sarah Henderson) ............................97

Appendix E: Location measurements for 116 sampling sites in 2010 (in UTM) .....101

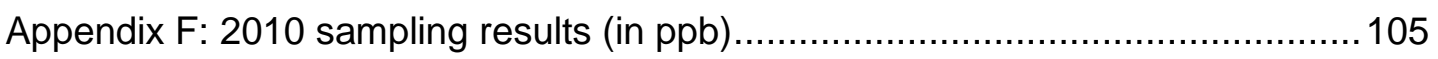

Appendix G: Quality control for 2010 measurements.......................................109

Appendix $\mathrm{H}$ : Ogawa sampling at UBC to check shelter effect............................... 114

Appendix I: Summary statistics of predictor variables at the 73 same-locating sites,

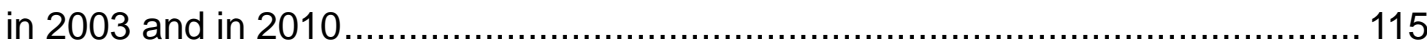




\section{List of Tables}

Table 2.1 Description of predictive variables used to develop the 2003 and 2010

LUR models (adapted from Henderson et al [24]). .....................................22

Table 2.2 Four methods of temporarily extrapolating a LUR model......................27

Table 2.3 Description of new predictive variables used to develop the 2010-enhanced LUR models..........................................................29

Table 3.1 Descriptive statistics of $\mathrm{NO}$ and $\mathrm{NO}_{2}$ measurements in 2010 (unit: ppb) 35 Table 3.2 Summary of 2010 LUR models: model parameters and validation results. Note that these only used the original pool of variables (as in 2003) so these are not the final 2010 models as those the enhanced models (Table 3.6).............40

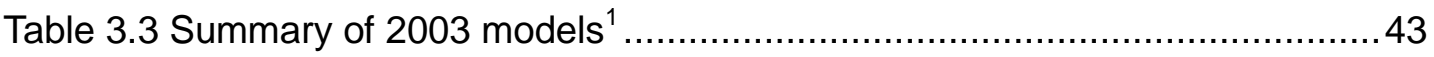

Table 3.4 Change $(\Delta)$ in $\mathrm{NO}$ and $\mathrm{NO}_{2}$ concentrations modeled by change $(\Delta)$ in LUR

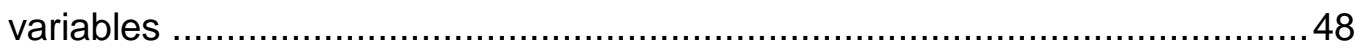

Table 3.5 Evaluation of extending LUR models over time using four methods: comparing model predictions against actual measurements at 116 sites.........51

Table 3.6 Summary of 2010-enhanced models: model parameters and validation

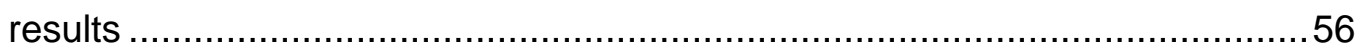

Table 3.7 Comparison of LUR models: 2003, 2010 and 2010-enhanced ................59 


\section{List of Figures}

Figure 2.1 Seasonal cycle of ambient $\mathrm{NO}_{2}$ concentrations in Metro Vancouver for the year of 2006, 2007 and 2008; black circles indicate selected sampling periods that were expected to best represent the annual average. Data source: Metro Vancouver (retrieved by personal communication with Ken Reid) 20

Figure 2.2 Reprinted with permission from: T Oke T and Hay J. The Climate of Vancouver. 2nd edition. B.C Geographical series, number 50. 1994. Page 5032 Figure 3.1 Sampling locations in 2010. 34

Figure 3.2 Distribution of $\mathrm{NO}$ and $\mathrm{NO}_{2}$ concentrations (ppb) measured at 16 Metro Vancouver (MV) monitoring stations and at 116 Ogawa sampling locations respectively; Ogawa sampling captured more variability in $\mathrm{NO}$ and $\mathrm{NO}_{2}$ concentrations. .36

Figure 3.3 Maps of modeled NO concentrations in 2003 (left) and in 2010 (right) ..41

Figure 3.4 Maps of modeled $\mathrm{NO}_{2}$ concentrations in 2003 (left) and in 2010 (right).. 42

Figure 3.5 Sampling period bias caused by seasonal fluctuation; figures show that the two 14-day sampling periods in 2009/10 underestimated the annual mean for both $\mathrm{NO}$ and $\mathrm{NO}_{2}$ 45

Figure 3.6 Histogram of change in $\mathrm{NO}$ and $\mathrm{NO}_{2}$ concentrations from 2003 to 2010, calculated as 2010 measurements minus 2003 measurements; both NO (left) and $\mathrm{NO}_{2}$ (right) approximate normal distribution $(\mathrm{n}=73)$. The few sites with increased concentrations were geographically scattered across study area....47

Figure 3.7 Change in NO2 concentrations from 2003 to 2010, estimated by subtracting two modeled surfaces (2010 surface minus 2003 surface)............50

Figure 3.8 Maps of $\mathrm{NO}$ and $\mathrm{NO}_{2}$ concentrations estimated by 2010-enhanced models 58 


\section{Introduction}

\subsection{Background, rationale and objectives}

Among many challenges in air pollution epidemiology, one has been the accurate estimation of long-term exposure to traffic related air pollution (TRAP) at the individual level across large study populations [1-3]. This is partially due to the substantial small-scale spatial variation related to traffic that routine air pollution monitoring networks fail to represent $[3,4]$. Proximity (i.e., measuring the proximity of a subject's residence to a pollution source) has been widely used as a surrogate to assess the effects of exposure to TRAP on morbidity and mortality [3, 5-9]. Other techniques, such as interpolation approaches and dispersion models, have also been applied to map air pollution at different geographic scales $[3,10]$. Interpolation methods such as kriging, relying on deterministic and stochastic geostatistical techniques [3], have mainly been used at the regional and national scales [11, 12]. However, kriging does not account for factors such as terrain or localized patterns [3], so it cannot reveal marked variation at short distances [13] and thus is not suitable for exposure assessment at very small-area scales $[13,14]$. Dispersion models have the advantage of incorporating both spatial and temporal variation without a dense monitoring network, but they are rarely used in epidemiological studies mainly due to high demands for data input and expertise $[3,10$, $15]$. 
Land use regression (LUR) models have been increasingly used as a cost-effective approach for assessing intra-urban air pollution contrasts [10, 14, 16-46]. This method uses measurements of pollutants at multiple sites, and potentially associated geographic attributes (e.g., land use, population density, traffic patterns) in a Geographic Information System (GIS), to build regression models which can be used to predict air pollution concentrations at unmeasured locations [24]. Once a LUR model is developed, exposure to TRAP can be estimated by geocoding addresses of interest (e.g. subject's homes, schools, etc.) and determining the modeled TRAP concentrations at those locations.

Application of LUR models to epidemiologic studies of chronic exposure assumes that the spatial patterns of pollution stay the same over years, so that a LUR model developed at one particular time point is applicable to other time points. In most cases, the models have been used retrospectively, with the gap between the time of individual exposure and the development of LUR ranging from 0-8 years [14, 25, 31, 47-58]. Despite a large number of LUR models being used in epidemiologic studies [16-18, 20, 22, 24, 25, 31], their temporal stability, the extent to which the spatial variability represented by these models is maintained over time, has not been adequately examined, leaving uncertainty in exposure estimates.

In Vancouver, LUR models for $\mathrm{NO}$ and $\mathrm{NO}_{2}$ were developed in 2003 [24] and have been applied in a number of epidemiological studies $[47,55,57,58]$. Briefly, ambient 
concentrations of $\mathrm{NO}$ and $\mathrm{NO}_{2}$ were sampled using Ogawa passive samplers for two 14-day periods at 116 sites in the study area. Concentrations from the sampling periods were averaged to estimate annual concentration. The sampling periods were selected to best approximate the annual average concentration by first calculating the mean $\mathrm{NO}_{2}$ concentration for every 14 consecutive day period and then selecting the combination of any two 14-day periods 26 weeks apart that best represented the annual mean. For each of the 116 measurement sites, 55 variables were generated in a GIS and linear regression models of $\mathrm{NO}$ and $\mathrm{NO}_{2}$ were built with the most predictive covariates. The final 2003 models included predictor variables describing density of road type, population density, elevation, and land use and explained $56-62 \%$ of variability in annual average concentrations [24].

As predictor variables and/or the relationships between predictors and pollution concentrations may change over time, however, the model may no longer represent the spatial patterns of TRAP in Vancouver. For example, changes in urban design (e.g. construction of new roads, changes in land use designations) and/or TRAP emissions (e.g. improvement in engine design, changes in traffic volume) may impact the spatial distribution of air pollutants and/or the predictor-concentration relationships. Epidemiologic studies in which air pollution exposure estimates for specific time periods are applied to outcome measures for other time points are only valid if spatial contrasts are stable over the exposure window of interest. Thus there was a need to evaluate the 
validity of applying LUR models to a period that is temporally distinct from the time during which the model was built.

In this study, we assessed the temporal stability of LUR models over a period of 7 years by developing an updated LUR model (2010) and comparing it with the previous 2003 model. In addition, as new techniques/variables have been explored to improve LUR model performance, we also sought to enhance the 2010 models by including new variables that were not tested previously. Specifically, the objectives of this study were:

a. To evaluate the temporal stability of the LUR model in Metro Vancouver over an approximately 7-year period by developing new LUR models of $\mathrm{NO}$ and $\mathrm{NO}_{2}$ for comparison with the previous 2003 models

b. To assess change in $\mathrm{NO}$ and $\mathrm{NO}_{2}$ concentrations from 2003 to 2010 by comparing measured concentrations over the two periods

c. To enhance 2010 models by including new potentially predictive variables

d. To provide up-to-date maps of estimated $\mathrm{NO}$ and $\mathrm{NO}_{2}$ concentrations to inform local policy/planning and for application in epidemiologic studies 


\subsection{Literature review}

\subsubsection{Conception and development of the LUR modeling approach}

Land use regression (LUR) modeling, an approach to assess intra-urban air pollution contrast, was initially introduced by Briggs et al (1997) as part of SAVIAH (Small Area Variations in Air Quality and Health) project, which focused on developing and testing methods to assess the relationship between TRAP and health at the small-area scale [16, 17]. Due to its simplicity, flexibility and successful application, the LUR approach has been widely used across Europe and North America in the past decade [10, 14, 16-36, 38-46, 59, 60], and has been recently applied in Asia [37, 61]. Most LUR models were designed for exposure assessment in specific epidemiologic studies $[10,16,18,22,25$, $26,30,31,34,35,62,63]$, or had epidemiologic studies as a rationale for developing the model [37, 43, 60, 64]. Others were used in risk assessment and in facilitating the siting of new regulatory air monitors [60]. The LUR methodology has also been evaluated and improved. For example, the inclusion of additional predictor variables has helped to improve their predictive power $[21,28,65,66]$. Evaluation of the transferability between different urban settings suggests that a LUR model may be locally calibrated to well fit another area without extensive field sampling [17, 41, 67, 68]. Also, limited evidence supports the temporal stability of models such that an existing model may be used to predict TRAP exposure in the future or estimate historical concentrations [36, 42]. 
A review of 25 LUR models, described the main components of the LUR approach (monitoring data, geographic predictors, model development and validation), its limitations and new developments, and compared LUR models with other alternatives, especially dispersion modeling [64]. It concluded that the LUR approach typically has equivalent or better performance to geo-statistical methods such as kriging and dispersion modeling in urban areas. The review also stressed the need for validation of LUR models with personal exposure monitoring, and the need to evaluate the temporal component of models used for studies focused on exposures at a finer temporal scale (e.g. average concentration per trimester of a specific pregnancy in birth cohort) [64].

The review examined the temporal aspects of LUR models with a focus on whether the measurements from temporally limited sampling periods could reliably represent the annual average. It was suggested that temporal adjustment using measurement concentrations from continuous monitoring stations is based on the assumption that the air pollutant pattern across the study area is stable over time and that data from monitoring stations are representative of the temporal variation. Thus sites for developing LUR models should be selected to reflect temporal variation [64]. However, this consideration only tackled temporal issues within the study period, rather than the temporal stability long beyond the model development period (i.e. the long-term stability of LUR models). 


\subsubsection{Process of constructing a LUR model}

Existing LUR models generally combine measurements of one or more TRAP indicators at a large number of locations within an airshed, with predictor variables (data on land use characteristics surrounding the measurement locations, e.g. road type) in a Geographic Information System (GIS). In most studies, the relationship between measured TRAP concentrations and geographic characteristics was quantified using standard multiple linear regression methods. Predictor variables were selected to develop parsimonious models with highest variability explained (i.e. highest $\mathrm{R}^{2}$ values) [64]. In other studies where LUR models were applied to larger geographical areas (such as the whole of the Netherland) rather than a metropolitan area (as the case with most studies), different predictors were used for different spatial scales [64]. A large set of predictor variables would be selected for modeling pollutant concentrations, typically including traffic, land use, population, topography, meteorology and location [64]. Selection of predictor variables depended on data availability at a particular study area, specific local conditions and choices of the investigators [64]. After a LUR model is constructed, the TRAP concentrations at any location in the study area can then be estimated from the regression model [24].

\subsubsection{Application in multiple air pollutants}

Multiple air pollutants have been modeled by the LUR method. The pioneering work of Briggs et al (1997) modeled $\mathrm{NO}_{2}$ concentrations as one of the markers of traffic-related 
air pollution[16], and $\mathrm{NO}_{2}$ has been the most modeled pollutant [10, 24, 27-30, 37, 40, $41,54,65,69-73]$, partly due to its uncomplicated and inexpensive measurements using passive samplers. Other pollutants, such as $\mathrm{PM}_{2.5}$, soot (the elemental carbon content of particulate matter), $\mathrm{PM}_{10}$ and VOCs have also been modeled in multiple studies [10, 14, $24,27,29,31,34,37,38,54,74-77]$. While most LUR models have been focused on traffic-related or industrial air pollution, the approach has also been applied to model residential wood smoke [60]. In this example, a combination of fixed and mobile monitoring along with a novel spatial buffering procedure (drainage flow/catchment-based buffering) was carried out to estimate the spatial patterns of wood smoke in the study regions.

\subsubsection{Advancement in predictive variables}

Within the LUR approach framework, new and novel techniques for generating predictive variables have been constantly explored. Major improvements include the use of meteorology [65, 69], the distance-decay regression approach [43, 66], incorporation of remote sensing data [66] and most recently, combining LUR with dispersion modeling [78].

Arain et al (2006) constructed wind direction fields from a network of 38 weather stations and incorporated them in a LUR model for greater Toronto [21]. The inclusion resulted in an increased $\mathrm{R}^{2}$ of prediction from 0.65 to 0.69 [21]. Su et al (2008) further advanced the role of meteorology by integrating wind speed, wind direction and cloud 
cover/insulation to an existing Metro Vancouver LUR model to estimate hourly NO and $\mathrm{NO}_{2}$ [65]. They combined the concepts of a box-type dispersion model and an LUR model to provide more detailed temporal resolution, and improved the prediction powers of LUR models significantly at routine sites $\left(\mathrm{R}^{2}\right.$ increased from 0.61 to 0.86 for NO, and from 0.78 to 0.92 for $\left.\mathrm{NO}_{2}\right)[64,65]$.

In the process of variable selection, an innovative method called "A Distance Decay Regression Selection Strategy (ADDRESS)" was developed by $\mathrm{Su}$ et al [43]. The ADDRESS is a multi-step process resulting in a spectrum of correlation coefficients and buffer distance decay curves at each step to select a spatial covariate of the high correlation (compared to other variables) at its optimized buffer distance. The strategy has been applied in two LUR models to maximize model performance $[43,66]$, providing an alternative in selecting predictor variable in the LUR modeling process

Another innovation has been the use of remote sensing data to include spectral reflectance of some land use types as a covariate for LUR models [66]. Remote sensing derived data such as vegetation greenness (a measure of the presence and density of green vegetation) and surface brightness (a measure of soil reflectance) have been found useful to improve the estimation of spatial variability in ambient pollutant concentrations [43, 79, 80]. In Los Angeles [43], the soil brightness was found to be significant in predicting $\mathrm{NO}$ and NOx concentrations while greenness correlated highly with $\mathrm{NO}, \mathrm{NO}_{2}$ and NOx concentrations $(r=0.4-0.5)$. Similar results were seen in Toronto LUR 
models, where the remote sensing measure had the highest correlations with VOCs and $\mathrm{NO}_{2}$ levels (it explained $>36 \%$ of the variability) [79]. In another study recently done in the city of a developing country - Ullanbaatar, Mongolia, where land use data were not available, average greenness in a $1,000 \mathrm{~m}$ buffer explained $47 \%$ of the $\mathrm{NO}_{2}$ variability and $12 \%$ of the $\mathrm{SO}_{2}$ variability, while brightness in a $2,000 \mathrm{~m}$ buffer explained $55 \%$ of the $\mathrm{SO} 2$ variance [80]. It demonstrated that remote sensing data are potential surrogates for road network and land use types [80]. With global coverage and free access, remote sensing data are valuable in deriving LUR variables where local geospatial data is not available (a likely case in developing countries) [80], as well as in improving estimation of spatial variability where remote sensing data describes actual land use better than other data source [79]. They also have the advantage of being comparable between areas with regard to land use classification [79]

Most recently, Wilton et al (2010) included a simple line source dispersion model, Caline 3, as a covariate in LUR models for NOx and $\mathrm{NO}_{2}$ in Los Angeles (LA), CA and Seattle [46]. In LA, this inclusion increased model $\mathrm{R}^{2}$ values from 0.53 to 0.71 for NOx, 0.74 to 0.79 for $\mathrm{NO}_{2}$. In Seattle, inclusion of the Caline3 variable resulted in an increase in $\mathrm{R}^{2}$ values from 0.72 to 0.81 for the $\mathrm{NO}_{2}$ model [46].

\subsubsection{Strengths and limitations of LUR}

The main strength of the LUR approach is the empirical structure of the regression process [3], making it possible to use a flexible range of inputs. For example, the 
availability of traffic data may vary from place to place. Some cities have counts and/or models of traffic volumes for transportation planning, but variables such as road types can be used where information on volume is not available[24]. In addition, the approach can also assist in planning for installation of additional stations where more intensive monitoring would be beneficial [81]. Compared with other methods such as dispersion modeling, the LUR method is relatively less expensive.

Limitations of the LUR approach include: limited ability to separate the impact of co-pollutants [48], and to represent extreme local variations that may occur near sources such as major roads [64], uncertainty in the extent to which short-term monitoring can capture long-term spatial gradients [82], and potential confounding effects from predictive variables when applied in epidemiologic studies [74]. In addition, there is uncertainty about the long-term temporal stability of LUR models, as discussed below.

\subsubsection{Temporal stability of LUR models.}

Land use regression models yield high resolution ( 10-meter) maps of the spatial patterns in air pollution, and these maps have been used in or designed for epidemiologic studies $[30,74,83-85]$. However, the temporal stability of the small-scale spatial patterns of TRAP has not been adequately examined. As the exposure period of interest might be years prior to or following the time of LUR model development, the accuracy of the estimates may decrease or the models might not even be appropriate for the time period of interest. Studies examining the temporal stability of LUR models, however, are 
limited to date. Briggs et al [16] measured pollutions concentration at a subset of 20 sites in the year after the first sampling campaign for LUR models, in Huddersfield and Amsterdam. The temporal stability of the pollution maps was estimated by comparing the newly measured data with estimates from LUR models. The correlation between the actual concentrations measured in the following year and those predicted from LUR models was high in Amsterdam $\left(\mathrm{R}^{2}=0.86\right)$ and moderate in Huddersfield $\left(\mathrm{R}^{2}=0.59\right)$. In another LUR study for the industrial city of Hamilton, Ontario [59], seasonal stability of the model was assessed by comparing measurements at a subset of 30 locations in May 2004 (spring) with estimates from a model that used measurements from Oct 2002 (fall). Results showed that the Oct 2002 model predicted $88 \%$ of the variability in pollutant concentration for the May 2004 measurements [59]. While these studies suggest that models are consistent for the following year or over different seasons in a few years, they do not account for temporal stability over longer periods, which are of interest for exposure assessment in epidemiologic studies of chronic exposure [56].

In the above studies, no temporal adjustments were made to exposure estimates. In epidemiologic applications, however, a number of methods are available to adjust concentrations estimated over long periods. Molter et al (2010) summarized three possible methods: 1) applying a temporal trend to the entire model; 2) changing the values of the model predictor variables for different time periods; 3) recalibrating the existing LUR model using new measurements [86]. 
The first method simply applies a temporal trend to LUR-predicted concentrations, accounting for the difference in background concentrations between two time periods. This approach was applied in epidemiological studies using the 2003 Metro Vancouver model where a trend was developed from the average of all (urban background) monitors in the regulatory monitoring network $[87,88]$. As the same value applies to every location, this method is only valid if the spatial pattern of pollutants does not change over time. Two studies have examined how well the original model predicted future measurements and their results suggest that application of a temporal trend would be valid. Eeftens et al (2009) tested the stability of measured and modeled spatial contrasts across the Netherlands over an approximately 10-year period and found good agreement between measured spatial contrast (relative difference between two locations) in outdoor $\mathrm{NO}_{2}$ concentrations in 1999-2000 and in $2007\left(\mathrm{R}^{2}=0.86\right)$. The LUR models produced good predictions for the past and for the future: the 2007 model explained $77 \%$ of the variability in 1999-2000 measurements $\left(2007\right.$ model $\left.\mathrm{R}^{2}=0.86\right)$ and the $1999-2000$ model explained $81 \%$ of the variability in 2007 measurements $\left(1999-2000\right.$ model $\mathrm{R}^{2}=$ 0.85) [36]. Thus the authors concluded that it was acceptable to use LUR models to predict exposure concentrations for an earlier or later time point [36]. Similarly, Porta et al (2009) compared LUR models in Rome, developed in1995/96 and 2007, in a preliminary report [42]. The two models were found to have similar predictive power $\left(\mathrm{R}^{2}=0.72\right.$ and 0.66 for $1995 / 96$ and 2007 , respectively) and to share common major 
predictor variables. However, information available from this preliminary report is insufficient for us to make firm conclusions on the validity of using these LUR models over time. Despite the promising findings that an LUR model developed at one time point may be used in other time points, these findings are location-specific. Rapid urban changes may lead to changes in spatial patterns, such that models developed in one time period may not be applicable to another period.

The second method for adapting existing LUR models to other time points is to change the values of the predictor variables. Assuming that similar predictor-concentration relationships remain, this method accounts for change in pollutant concentrations associated with changes in contributing factors over time. For example, if population density, as a predictor variable, has increased significantly over time, updating the value of population density coefficient will reflect the corresponding increase in pollutant concentrations for this period. However, this method may lead to significant error if the assumed predictor-concentration relationship does not hold. For example, traffic density may have increased over time and we may expect to see a corresponding increase in pollutant concentration (assuming that the predictor-concentration relationship does not change) while, in reality, the pollutant concentrations may have actually decreased due to vehicle emission reduction that are not reflected in the LUR models.

The third method, distinct from the previous two, involves obtaining new air quality measurements. Based on these new measurements, the model coefficients and intercept 
are recalibrated using the same predictor variables in the original model. This method was initially suggested by Briggs et al (1997) [13, 17] and recently applied by Molter et al [86]. The underlying mechanism of this method is similar to that of transferring a LUR to another location. It was found that, between cities with similar geographical features and equivalent variables, it is possible to transfer a LUR model to another location using a modest field sampling campaign for location-specific model calibration. These transferred models could be equally predictive as their source models [17, 41]. However, as cities have varying topographies and climates, transferred models may not perform as well as those developed locally [3, 67]. Along the same line, it is also possible to transfer LUR models temporally, provided that there are sufficient measurements for calibration. Molter et al (2011) successfully calibrated a set of 2005 LUR models to individual models for each year from 1996 to 2008, using measurement data obtained from an air dispersion model [86]. These calibrated models were validated by comparing model predictions with measurements of $\mathrm{NO}_{2}$ at monitoring stations, resulting in a mean error of $-0.8 \mu \mathrm{g} / \mathrm{m}^{3}$ (equal to $0.4 \mathrm{ppb}$ ) and root mean squared error (RMSE) of $6.7 \mu \mathrm{g} / \mathrm{m}^{3}$ (equal to $3.6 \mathrm{ppb}$ ) [86]. This method updated the relationship between predictor variables and pollutant concentrations. As long as the predictor variables are still dominant in the year of prediction, this method would fit every situation, regardless of whether the background level and/or spatial patterns have changed. 
In our study, we assessed the temporal stability of our Metro Vancouver LUR models using each of the three methods. In addition, we also combined the first and second method such that a temporal trend and updated predictor variables were applied simultaneously. This joint method caters to another potential situation where the urban background concentration has changed and at the same time, the relative concentration levels (spatial pattern) have shifted due to changes in the value of predictor variables. 


\section{Methods}

Measurements of outdoor $\mathrm{NO}$ and $\mathrm{NO}_{2}$ were taken at 116 locations in Metro Vancouver in 2003, and then used to develop LUR models for the region (referred to herein as the 2003 models). In fall 2009 and spring 2010 (note that while these measurements were collected in 2009 and 2010 we subsequently refer to these as 2010 measurements), we repeated $\mathrm{NO}$ and $\mathrm{NO}_{2}$ measurements again at the same locations, updated input predictive variables (Table 2.1), and constructed new models (referred to herein as the 2010 models). We then evaluated the temporal stability of LUR models over a 7-year period by comparing model predictions of outdoor $\mathrm{NO}$ and $\mathrm{NO}_{2}$ concentrations with measured spatial contrasts between the two time periods. In addition, the change in pollutant concentrations was mapped and modeled to investigate potential determinants of changes. Ultimately, we sought to enhance our 2010 models by including additional variables not tested in the 2003 models.

\subsection{LUR models}

\subsubsection{Dependent variables: measurements of $\mathrm{NO}$ and $\mathrm{NO}_{2}$}

\subsubsection{Field sampling}

We carried out our field sampling at 116 locations across Metro Vancouver from October 19 - November 2, 2009, and from April 19 - May 3, 2010. We intended to sample at as 
many of the specific 2003 sampling sites as possible. For those sites where the exact original locations (in 2003) were not accessible, samples were collected at the nearest possible location. Ogawa passive samplers were attached to lampposts or street signs at heights of $2-2.5 \mathrm{~m}$ above the ground, exposed for 14 days in the field, and taken back to lab and stored at $0-4 \circ \mathrm{C}$ until extraction and analysis. Ogawa samplers (Ogawa \& Co., USA, Inc.) are small, cylindrical samplers with 2 chambers, each containing a coated filter. We followed the company protocol $^{1}$ to prepare, store, and transport these samplers.

\subsubsection{Lab analysis}

After sampling, filters were removed from the Ogawa sampler, dissolved in $6 \mathrm{ml}$ of de-ionized water and the resulting nitrite concentration was determined by ion chromatography (Appendix B). Nitrite concentrations were converted to ambient concentration following established procedures ${ }^{1}$ (Appendix C). During the 2010 spring campaign, we used brown containers as substitutes for the regular white shelter (due to a shortage of the latter), which resulted in a systematic over-estimation of concentrations. A supplementary sampling campaign was carried out on the UBC campus to develop corrections that were then applied to all samples collected under brown containers (Appendix H).

\footnotetext{
1 Ogawa \& Co., USA, Inc, NO, NO2, NOx and SO2 Sampling Protocol Using The Ogawa Sampler http://www.ogawausa.com/pdfs/prono-noxno2so206.pdf
} 
The location (lat/log coordinates) of each sampling site was recorded by a WAAS-enabled GPS (eTrexVista ${ }^{\mathrm{TM}}$, GARMIN Ltd) during each sampling campaign and the average recorded location used in LUR modeling (described in section 2.1.2).

\subsubsection{Selection of sampling periods}

As in 2003, the two 14-day sampling periods were selected to best represent the annual average of pollutant concentrations [24]. Records of daily average concentrations of $\mathrm{NO}_{2}$ were retrieved from 15 Metro Vancouver monitoring stations for the years of 2006, 2007, 2008. Averages of two 14-day periods (spaced 26 weeks apart) were calculated for each station in each year. A combination of two 14-day periods with an average concentration that deviated the least from the annual mean were selected as the sampling periods. Deviation from annual mean was calculated as

$$
\sum_{n=3}[(\text { two } 14-\text { day average - annual average }) / \text { annual average }]^{2}
$$

We adjusted the preferred sampling periods to avoid the 2010 Winter Olympics that took place in February and March 2010, as we anticipated that changes in traffic routes and pollutant emissions during this event would affect the spatial pattern of $\mathrm{NO}$ and $\mathrm{NO}_{2}$. Figure 2.1 illustrates the seasonal cycle of ambient concentration of $\mathrm{NO}_{2}$ in Metro Vancouver and the sampling periods selected to represent annual average. 


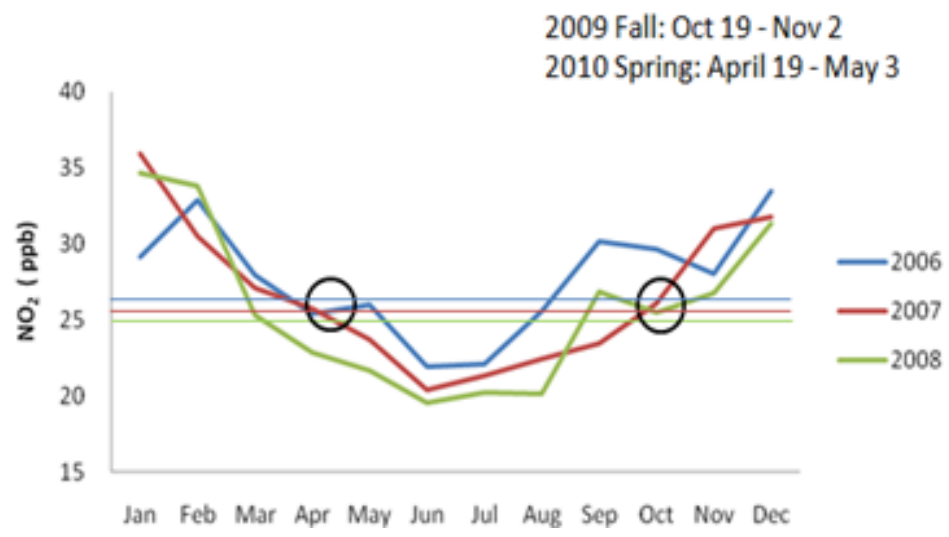

Figure 2.1 Seasonal cycle of ambient $\mathrm{NO}_{2}$ concentrations in Metro Vancouver for the year of 2006, 2007 and 2008; black circles indicate selected sampling periods that were expected to best represent the annual average. Data source: Metro Vancouver (retrieved by personal communication with Ken Reid)

\subsubsection{Quality control}

We collected duplicate samples, co-located samplers with government monitors, and deployed field blanks to assess data quality. At a subset of approximately $10 \%$ of the 116 sites (19 in 2009 fall and 17 in 2010 spring) two Ogawa samplers were attached side by side at the same height. Pearson's correlation and absolute differences were calculated between duplicates to determine measurement precision. Another set of Ogawa samplers was co-located at Metro Vancouver monitoring stations during the same period as our sampling campaign (14 stations in 2009 fall and 16 stations in 2010 spring). Results were compared with station data to assess the accuracy of measurements using Ogawa samplers (Appendix A). Meanwhile, field blanks were distributed among the monitoring stations (27 field blanks among 14 stations in 2009 fall, and 25 field blanks among 16 stations in 2010 spring). The average of field blanks was subtracted from $\mathrm{NO}$ and $\mathrm{NO}_{2}$ 
measurements to adjust for contamination from shipping and laboratory sources. The limit of detection was calculated as three times the standard deviation of the field blanks.

\subsubsection{Independent variables: updates from 2003}

For the 2010 LUR models, we used the same input variables as those used for the 2003 models, except that the input data were updated to the most recently available at the time when 2010 models were built. There were 55 variables in five categories and ten subcategories (Table 2.1). The five categories include road length, vehicle density, land use type, population density, and other geographical information. All variables were created in ArcGIS 9.2 with geographic data projected to the North American Datum 1983 (NAD 83) and expressed in units of the Universal Transverse Mercator (UTM). Details of generating these variables are described elsewhere [89]. 
Table 2.1 Description of predictive variables used to develop the 2003 and 2010 LUR models (adapted from Henderson et al [24]).

\begin{tabular}{|c|c|c|c|c|c|c|}
\hline \multirow{2}{*}{$\begin{array}{l}\text { Category } \\
\text { (N) }\end{array}$} & \multirow{2}{*}{$\begin{array}{l}\text { Description } \\
\text { (units) }\end{array}$} & \multirow{2}{*}{$\begin{array}{c}\text { Variable } \\
\text { (Sub-categories } \\
\text { ) }\end{array}$} & \multirow{2}{*}{$\begin{array}{c}\text { Buffe } \\
\text { r radii } \\
\text { (m) }\end{array}$} & \multirow{2}{*}{$\begin{array}{c}\text { Base file } \\
\text { (type) }\end{array}$} & \multicolumn{2}{|c|}{ Source } \\
\hline & & & & & 2003 & $\begin{array}{c}2009 / 201 \\
0\end{array}$ \\
\hline $\begin{array}{l}\text { Road } \\
\text { length } \\
(12)\end{array}$ & $\begin{array}{l}\text { Total length of } \\
\text { road within a } \\
\text { buffer radii } \\
\text { (in km) }\end{array}$ & $\begin{array}{l}\text { RD1 (Highways) } \\
\text { RD2 (Major } \\
\text { roads) }\end{array}$ & $\begin{array}{l}100 \\
200 \\
300 \\
500 \\
750 \\
1000\end{array}$ & $\begin{array}{c}\text { Road network } \\
\text { ( polyline) }\end{array}$ & $\begin{array}{c}\text { DMTI } \\
\text { Spatial, } \\
2001\end{array}$ & $\begin{array}{c}\text { DMTI } \\
\text { Spatial, } \\
2007\end{array}$ \\
\hline $\begin{array}{c}\text { Vehicle } \\
\text { density } \\
(12)\end{array}$ & $\begin{array}{l}\text { Density of two } \\
\text { vehicle types } \\
\text { during morning } \\
\text { rush hour } \\
\text { (in } \\
\text { vehicles/hectare } \\
\text { ) }\end{array}$ & $\begin{array}{c}\text { AD } \\
\text { (Automobiles) } \\
\text { TD (Trucks) }\end{array}$ & $\begin{array}{l}100 \\
200 \\
300 \\
500 \\
750 \\
1000\end{array}$ & $\begin{array}{l}\text { Traffic flow } \\
\text { model } \\
\text { (polyline) }\end{array}$ & $\begin{array}{l}\text { Translink } \\
\text {, } 2001 \\
\text { EMME/2 }\end{array}$ & $\begin{array}{c}\text { Translink, } \\
2008 \\
\text { EMME/2 }\end{array}$ \\
\hline $\begin{array}{l}\text { Land use } \\
\qquad(20)\end{array}$ & $\begin{array}{l}\text { Total area of } 5 \\
\text { land use types } \\
\text { (in hectares) }\end{array}$ & $\begin{array}{c}\text { RES } \\
\text { (Residential), } \\
\text { Com } \\
\text { (Commercial) } \\
\text { GOV } \\
\text { (Governmental) } \\
\text { IND (Industrial) } \\
\text { OPN (Open) }\end{array}$ & $\begin{array}{l}300 \\
400 \\
500 \\
750\end{array}$ & $\begin{array}{c}\text { Federal land } \\
\text { use } \\
\text { classification } \\
\text { (polygon) }\end{array}$ & $\begin{array}{c}\text { DMTI } \\
\text { Spatial, } \\
2001\end{array}$ & $\begin{array}{c}\text { DMTI } \\
\text { Spatial, } \\
2007\end{array}$ \\
\hline $\begin{array}{l}\text { Population } \\
\text { density } \\
\text { (6) }\end{array}$ & $\begin{array}{c}\text { Density of the } \\
\text { population } \\
\text { (in } \\
\text { persons/hectare } \\
\text { ) }\end{array}$ & POP (Persons) & $\begin{array}{c}750 \\
1000 \\
1250 \\
1500 \\
2000 \\
2500\end{array}$ & $\begin{array}{l}\text { Dissemination } \\
\text { area (polygon) } \\
\text { and census } \\
\text { population } \\
\text { data }\end{array}$ & $\begin{array}{l}2001 \\
\text { Census }\end{array}$ & $\begin{array}{l}2006 \\
\text { Census }\end{array}$ \\
\hline \multirow{2}{*}{$\begin{array}{c}\text { Geographi } \\
\text { c } \\
\text { (4) }\end{array}$} & \multirow{2}{*}{$\begin{array}{l}\text { Four additional } \\
\text { variables } \\
\text { describing the } \\
\text { geographic } \\
\text { location of each } \\
\text { site } \\
\text { ( in } \mathrm{km} \text { ) }\end{array}$} & $\begin{array}{c}\text { ELEV (Elevation) } \\
\text { X (Longitude) } \\
\text { Y (Latitude) }\end{array}$ & $n / a$ & $\begin{array}{l}\text { DEM (raster), } \\
\text { GPS } \\
\text { measurement } \\
\text { s }\end{array}$ & $\mathrm{n} / \mathrm{a}$ & $\mathrm{n} / \mathrm{a}$ \\
\hline & & $\begin{array}{c}\text { DIST (Distance } \\
\text { to the nearest } \\
\text { highway) }\end{array}$ & $n / a$ & $\begin{array}{l}\text { Road network } \\
\text { ( polyline) }\end{array}$ & $\begin{array}{c}\text { DMTI } \\
\text { Spatial, } \\
2001\end{array}$ & $\begin{array}{c}\text { DMTI } \\
\text { Spatial, } \\
2007\end{array}$ \\
\hline
\end{tabular}




\subsubsection{Model building and validation}

\subsubsection{Model building}

The relationship between pollutant concentrations and predictor variables was examined by multiple linear regression. All statistical analysis was performed in R [61]. Two response variables were modeled: the logarithm of annual average NO concentrations (as NO concentrations were best approximated by a lognormal distribution) and annual average $\mathrm{NO}_{2}$ concentration. For each of the response variables, two models were constructed independently using road length or traffic density variables as the traffic metrics, combined with the remaining 30 variables [24] (Table 2.1).

A priori assumptions were made to ensure that models did not contradict knowledge about pollution emissions and dispersion, including: 1) regression coefficients for road length and traffic density variables are positive; 2) regression coefficients for distance-to-road variables are negative.

To construct the models, univariate correlations were calculated between response variables and potentially predictive variables. Variables within each subcategory (Table $2.1)$, were ranked based on absolute correlation values; those correlated $(r \geqslant 0.6)$ with the top-ranked variable were omitted from further analysis. Remaining variables were entered into a bi-directional stepwise linear regression in which variables were further removed if 1$)$ they were not statistically significant $(p<0.05) ; 2)$ their coefficients were 
not consistent with priori assumptions; or 3 ) they contributed less than $1 \%$ to the model $\mathrm{R}^{2}$ value. $\mathrm{R}$ codes for the modeling process are included in Appendix $\mathrm{D}$.

\subsubsection{Model validation}

Models were validated by two approaches: 1) A deterministic approach, where predicted values were compared with continuous measurements at 16 Metro Vancouver stations; error was calculated as the difference between LUR predictions and station measurements; 2) A leave-one-out (LOO) cross validation, where at each sampling site, pollutant concentrations were predicted by reconstructed models based on measurements at all other sites, with the difference between measured and predicted values producing an estimate of the model error.

\subsubsection{Regression mapping}

Maps of predicted $\mathrm{NO}$ and $\mathrm{NO}_{2}$ concentrations at a resolution of $10 \mathrm{~m}$ were made based on model equations. We used Weighted Sum (ArcGIS 9.2 Spatial Analyst) to sum up raster layers representing predictor variables multiplied by their associated coefficients, as well as the model intercept. Resulting maps were further modified by setting negative estimates to zero and truncating extreme values to the maximum measured concentrations (100 ppb for $\mathrm{NO}$ and $30 \mathrm{ppb}$ for $\mathrm{NO}_{2}$, the same as in 2003). 


\subsection{Evaluation of the temporal stability}

After developing the 2010 models, we first compared 2003 and 2010 measurements to evaluate the change in $\mathrm{NO}$ and $\mathrm{NO}_{2}$ concentrations. Secondly, we evaluated the temporal stability of the LUR models by comparing model predictions with actual measurements. Four methods were applied to extend LUR models in time (described below). In each approach, an $\mathrm{R}^{2}$ value was calculated for the regression of predicted values against measurements, and an error estimate calculated by subtracting measurements from predicted values. Table 2.2 summarizes the four methods with illustrative examples.

\subsubsection{Method 1: Apply a temporal trend}

This approach adjusts model predictions by the temporal trend - in this case, the difference between annual averages of 2003 and 2010. Annual averages for $\mathrm{NO}$ and $\mathrm{NO}_{2}$ concentrations were calculated based on daily means recorded at Metro Vancouver monitoring stations $(n=16)$.

\subsubsection{Method 2: Use concurrent values of predictor variables}

In this approach, values of predictor variables of the prediction year (as opposed to model development year) were used in calculating predictions. When a 2003 model $\left(\mathrm{Y}=\mathrm{b}_{0}+\mathrm{b}_{1} \mathrm{X}_{1}+\mathrm{b}_{2} \mathrm{X}_{2}+\ldots+\mathrm{b}_{\mathrm{i}} \mathrm{X}_{\mathrm{i}}\right)$ was used to forecast 2010 concentrations, the model coefficients $\left(b_{0}, b_{1}, b_{2} \ldots b_{i}\right)$ was applied, but the values of predictors $\left(X_{1}, X_{2} \ldots X_{i}\right)$ were updated. For example, the population density within a $750 \mathrm{~m}$ buffer was 34 persons per 
hectare in 2003 at one of our sampling sites; in 2010, the number decreased to 22 at the same site. The value of 34 was used to develop the 2003 models while the value of 22 was used to predict 2010 concentrations using the 2003 model. Similarly, when a 2010 model was used to back-cast 2003 concentrations, values of predictor variables in 2003 were used to calculate 2003 concentrations.

\subsubsection{Method 3: Joint method of applying temporal trend and concurrent values of predictor variables}

This method combines the above two methods such that concentrations estimates were first calculated using concurrent values of predictor variables, and then adjusted by a temporal trend. For example, in using the 2003 model to forecast 2010 concentrations, we first applied predictor values in 2010 to the 2003 equation and further subtracted the temporal trend to estimate concentrations. This method would be suitable for an area where a change in pollutant concentrations was due to both a change in the background concentration (not captured by LUR models) and by a change in spatial patterns (explained by LUR models).

\subsubsection{Method 4: Calibrating an existing model}

In this approach, the same set of predictor variables were retained with coefficients calibrated based on measurements from the prediction year. For example, when a 2003 model was used to forecast 2010 concentrations, the 2003 model was first calibrated using 2010 measurements (i.e. 2010 measurements as dependent variable to construct an 
equation using predictor variables from the 2003 model). Then the calibrated 2003

model was used to estimate concentration levels at the 116 sites in 2010. Similarly, a 2010 model was calibrated using 2003 measurements to back-cast 2003 concentrations.

Table 2.2 Four methods of temporarily extrapolating a LUR model

\begin{tabular}{|c|c|c|c|c|}
\hline & Method 1 & Method 2 & Method 3 & Method 4 \\
\hline $\begin{array}{c}\text { Descriptio } \\
\mathrm{n}\end{array}$ & $\begin{array}{l}\text { Applying a } \\
\text { temporal trend }\end{array}$ & $\begin{array}{l}\text { Updating the } \\
\text { values of } \\
\text { variables }\end{array}$ & $\begin{array}{c}\text { Combining } \\
\text { Method } 1 \text { and } \\
\text { Method } 2 \\
\end{array}$ & $\begin{array}{l}\text { Calibrating } \\
\text { coefficients }\end{array}$ \\
\hline $\begin{array}{l}\text { Illustrative } \\
\text { equation }\end{array}$ & $\begin{array}{l}\mathrm{Y}=\mathrm{b}_{0}+\mathrm{b}_{1} \mathrm{x}_{1}+ \\
\mathrm{b}_{2} \mathrm{x}_{2}+\ldots \mathrm{b}_{\mathrm{i}} \mathrm{X}_{\mathrm{i}}+\mathrm{a}\end{array}$ & $\begin{array}{c}\mathrm{Y}=\mathrm{b}_{0}+\mathrm{b}_{1} \mathrm{x}^{\prime}{ }_{1}+ \\
\mathrm{b}_{2} \mathrm{x}^{\prime}{ }_{2}+\ldots \mathrm{b}_{\mathrm{i}} \mathrm{x}^{\prime}{ }_{\mathrm{i}}\end{array}$ & $\begin{array}{c}\mathrm{Y}=\mathrm{b}_{0}+\mathrm{b}_{1} \mathrm{x}^{\prime}{ }_{1}+ \\
\mathrm{b}_{2} \mathrm{x}^{\prime}{ }_{2}+\ldots \mathrm{b}_{\mathrm{i}} \mathrm{x}_{\mathrm{i}}+\mathrm{a}\end{array}$ & $\begin{array}{c}\mathrm{Y}=\mathrm{b}^{\prime}{ }_{0}+ \\
\mathrm{b}_{1}{ }_{1} \mathrm{x}_{1}+ \\
\mathrm{b}_{2}{ }_{2} \mathrm{x}^{\prime}{ }_{2}+\ldots \mathrm{b}^{\prime}{ }_{\mathrm{i}} \mathrm{x}^{\prime} \\
\mathrm{i}\end{array}$ \\
\hline Example* & $\begin{array}{c}\ldots 0.06 \times \text { POP. } 250 \\
0(34.6) \ldots-\mathbf{3 . 5}\end{array}$ & $\begin{array}{c}\ldots 0.06 \times \text { POP. } 250 \\
\mathbf{0}(\mathbf{3 6 . 0}) \ldots\end{array}$ & $\begin{array}{lr}\ldots 0.06 \times \text { POP.250 } \\
\text { 0 }(\mathbf{3 6 . 0}) \ldots & -\mathbf{3 . 5}\end{array}$ & $\begin{array}{c}\ldots .0 .05 \\
\times \text { POP.2500 } \\
(\mathbf{3 6 . 0}) \ldots \\
\end{array}$ \\
\hline
\end{tabular}

* Example: using $2003 \mathrm{NO}_{2}$ - length model to forecast concentrations in 2010

- 2003 Annual $\mathrm{NO}_{2}=519.54+13.59 *$ Road length within $100 \mathrm{~m}+3.66 *$ Road length within $200 \mathrm{~m}+0.06 *$ Population density within $2500 \mathrm{~m}+0.04 *$ Industrial area within $750 \mathrm{~m}-0.85 *$ Longitude $-0.86 *$ Latitude

- $\mathbf{a}=\mathbf{- 3 . 5} \mathrm{ppb}$ (decrease from 2003 to 2010)

- POP.2500 (Population density within $2500 \mathrm{~m}$ ) = 34.6 in 2003, 36.0 in 2010 (unit: people per hectare)

- (Method 4) 2010 Annual $\mathrm{NO}_{2}=-251.45+8.55^{*}$ Road length within 100m + $3.22 *$ Road length within $200 \mathrm{~m}+0.04 *$ Industrial area within $750 \mathrm{~m}+0.05^{*}$ Population density within $2500 m-0.42 *$ Longitude $+0.51 *$ Latitude 


\subsection{Enhancing 2010 LUR models}

In an effort to improve the predictive power of the LUR model, we added a total of 116 variables (Table 2.1) that were not tested in our previous LUR models. These included bus stop density, building density, intersection density, land use data retrieved from the municipality (instead of land use data from the DMTI Spatial Inc. national dataset), greenness index, wind direction, distance to port, distance to seashore, and combinations of variables (for example, use traffic density divided by distance to road as one variable). They had been used in other LUR studies and were believed to represent additional emission sources not previously considered or were believed to more closely reflect the physical properties of pollutant emission and dispersion. Following the same model building procedure (described in section 2.13), we constructed the 2010-enhanced models using independent variables as a combination of these new variables (Table 2.3) and the previous variables (Table 2.1). The following text explains the process of generating variables for intersection density, land use and wind direction. For other new variables, the generation process was straightforward and thus only noted in Table 2.3. 
Table 2.3 Description of new predictive variables used to develop the 2010-enhanced LUR models

\begin{tabular}{|c|c|c|c|c|}
\hline $\begin{array}{c}\text { Variable } \\
\text { category (unit) }\end{array}$ & Sub-category (nomenclature) & $\begin{array}{l}\text { Buffer radii } \\
\text { (in meters) }\end{array}$ & $\begin{array}{c}\text { Base file } \\
\text { (source, type) }\end{array}$ & $\begin{array}{c}\text { Spatial analysis in } \\
\text { ArcGIS v.9.2 }\end{array}$ \\
\hline $\begin{array}{c}\text { Bus stop density } \\
\text { (count per } \\
\text { hectare) }\end{array}$ & $\begin{array}{c}\mathrm{n} / \mathrm{a} \\
(\mathrm{BSD})\end{array}$ & $\begin{array}{l}100,200 \\
300,500 \\
750,1000\end{array}$ & $\begin{array}{l}\text { Translink Route } \\
\text { and Station Data, } \\
2010 \text { (Translink, } \\
\text { point) }\end{array}$ & Point density \\
\hline $\begin{array}{l}\text { Intersection } \\
\text { density } \\
\text { (count per } \\
\text { hectare) }\end{array}$ & $\begin{array}{l}\text { Highway on- and off- ramps } \\
\text { (IntRD1ramp), Highway } \\
\text { (IntRD1), Major road (IntRD2) }\end{array}$ & $\begin{array}{l}100,200 \\
300,500 \\
750,1000\end{array}$ & $\begin{array}{c}\text { CanMap } \\
\text { Streetfiles, } \\
\text { v2010.3 (DMTI, } \\
\text { line) }\end{array}$ & $\begin{array}{c}\text { Assign nodes; define } \\
\text { intersections; point density } \\
\text { (details in appendix 2.4) }\end{array}$ \\
\hline $\begin{array}{c}\text { Building density } \\
\text { (count per } \\
\text { hectare) }\end{array}$ & $\mathrm{n} / \mathrm{a}(\mathrm{BD})$ & $\begin{array}{l}750,1000 \\
1250,1500 \\
2000,2500\end{array}$ & $\begin{array}{c}\text { CanMap } \\
\text { Streetfiles, } \\
\text { v2010.3 (DMTI, } \\
\text { point) }\end{array}$ & Point density \\
\hline $\begin{array}{l}\text { Land use } \\
\text { (hectare) }\end{array}$ & $\begin{array}{c}\text { Industrial(IND), Residential } \\
\text { (RES), Open (OPEN), } \\
\text { Commercial (COMM), } \\
\text { Governmental (GOV) }\end{array}$ & $\begin{array}{l}300,400 \\
500,750\end{array}$ & $\begin{array}{c}\text { Land use } 2006 \\
\text { (Metro Vancouver, } \\
\text { polygon) }\end{array}$ & $\begin{array}{l}\text { Aggregate land use into } \\
\text { five categories; } \\
\text { "Neighborhood statistics" } \\
\text { to sum up area within a } \\
\text { search radii }\end{array}$ \\
\hline $\begin{array}{c}\text { Greenness index } \\
(\mathrm{n} / \mathrm{a})\end{array}$ & $\mathrm{n} / \mathrm{a}$ (Green) & $\mathrm{n} / \mathrm{a}$ & $\begin{array}{c}\text { Greenness index } \\
\text { (Su et al [90] } \\
\text { raster) } \\
\end{array}$ & $\mathrm{n} / \mathrm{a}$ \\
\hline $\begin{array}{l}\text { Wind direction (in } \\
\text { relation to roads) }\end{array}$ & Downwind (1), upwind (0) & $\mathrm{n} / \mathrm{a}$ & $\mathrm{n} / \mathrm{a}$ & $\begin{array}{c}\text { Manually coded (details in } \\
\text { appendix } 2.4 \text { ) }\end{array}$ \\
\hline Distance to port & n/a (Dist_port) & $\mathrm{n} / \mathrm{a}$ & $\begin{array}{c}\text { A subset of } \\
\text { industrial land use } \\
\text { layer (Metro } \\
\text { Vancouver, } \\
\text { polygon) }\end{array}$ & $\begin{array}{l}\text { Manually edited before } \\
\text { using Euclidean distance }\end{array}$ \\
\hline $\begin{array}{l}\text { Distance to } \\
\text { seashore }\end{array}$ & n/a (Dist_sea) & $\mathrm{n} / \mathrm{a}$ & $\begin{array}{l}\text { The same as used } \\
\text { in } 2003 \text { (polygon) }\end{array}$ & Euclidean distance \\
\hline $\begin{array}{c}\text { Natural logarithm } \\
\text { of distance to } \\
\text { roads }\end{array}$ & $\begin{array}{l}\text { Natural logarithm of distance } \\
\text { to highway (lnDistRD1), } \\
\text { Natural logarithm of distance } \\
\text { to major road (lnDistRD2) }\end{array}$ & $\mathrm{n} / \mathrm{a}$ & $\begin{array}{c}\text { CanMap } \\
\text { Streetfiles, } \\
\text { v2010.3 (DMTI, } \\
\text { line) }\end{array}$ & $\mathrm{n} / \mathrm{a}$ \\
\hline
\end{tabular}




\begin{tabular}{|c|c|c|c|c|}
\hline $\begin{array}{l}\text { Combination of } \\
\text { traffic density and } \\
\text { distance to roads }\end{array}$ & $\begin{array}{c}\text { Density / DistRD1, Density / } \\
\text { DistRD12 }{ }^{2} \text {, Density / } \\
\text { lnDistRD1, Density / DistRD2, } \\
\text { Density / DistRD22, Density / } \\
\text { lnDistRD2 }\end{array}$ & $\begin{array}{c}100,200, \\
300,500, \\
750,1000 \\
\text { (for traffic } \\
\text { density) }\end{array}$ & $\begin{array}{l}\text { Previous created } \\
\text { files for traffic } \\
\text { density and } \\
\text { distance to roads }\end{array}$ & $\mathrm{n} / \mathrm{a}$ \\
\hline
\end{tabular}


Intersection density variables

Intersection density variables were generated from a street network file for British Columbia distributed by DMTI Spatial. Different road types were aggregated such that RD1 included Expressways and Primary Highways (coded as Carto\#1 and Carto\#2 in original DMTI dataset) and RD2 represented Major Roads (coded as Carto \#4 ${ }^{2}$ ). We then used a script ${ }^{3}$ "Calculate Fnode Tnode 2.0 arcgis 9.2" to generate the fnode and tnode of the street network and to assign a valence value to each node. Intersections were then identified based on the valence value. For highways (RD1), we categorized points with valence value of 3 as on- and off- ramps (IntRD1ramp) and those larger than 3 as highway intersections (IntRD1). For major roads (RD2), points with valence value equal or larger than 3 were selected as major road intersections (IntRD2). Lastly, "Spatial analyst - Point density" was used to calculate the intersection density with a specified buffer radius.

\section{Land use variables}

For this variable category, DMTI data was replaced by Metro Vancouver data as the latter may be more representative of actual land use. The 17 classifications (2006 Land Use, Metro Vancouver) were aggregated into 5 categories: Industrial, Residential, Open, Governmental and Commercial ${ }^{4}$. The categories were the same as those used in 2003 and

${ }^{2}$ Carto\#3 - Secondary Highway was not found in our study area.

${ }^{3}$ downloaded from ESRI http://arcscripts.esri.com/details.asp?dbid=15188; accessed on 2011/2/25

${ }^{4}$ The aggregation: Industrial = Industrial-Extractive + Industrial + Transportation, Communication Utilities; Residential $=$ Single family + Rural + Townhouses + Low-rise apartments + High-rise apartments; Open = 
2010 models. The Metro Vancouver land use data did not cover five of our sampling sites that were located in the city of Abbotsford, as it is outside of the Metro Vancouver boundaries.

\section{Wind direction in relation to roads}

This variable for each sampling site was manually coded as upwind (0) or downwind (1) in relation to its nearest North-South roads. The dominant wind direction in our study area was identified as westward based on annual average wind direction at 16 locations in the Metro Vancouver region (Figure 2.2$)^{5}$.

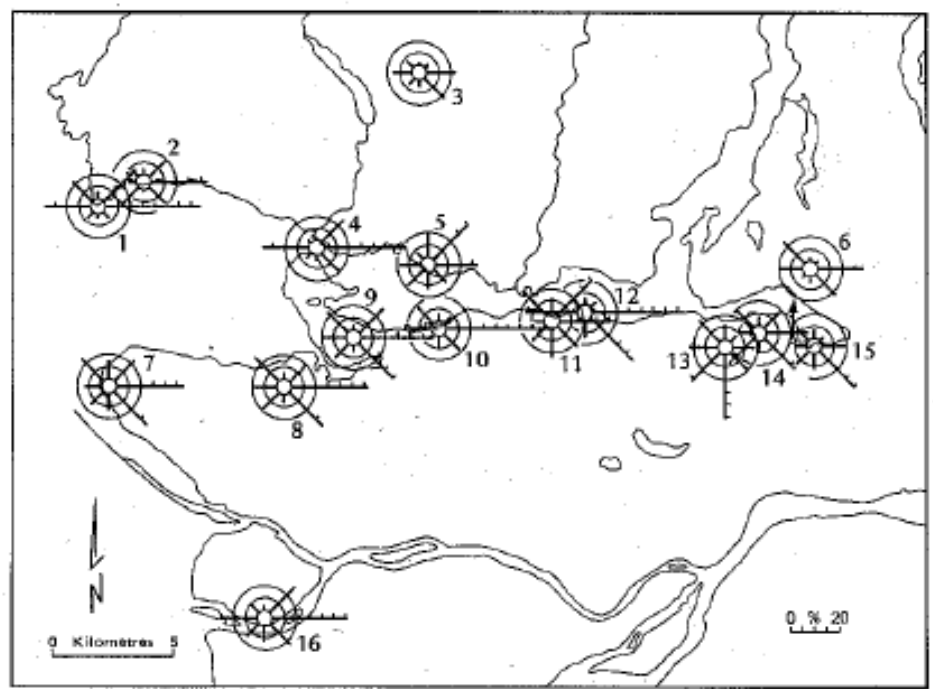

Figure 31. Annual average wind speed and direction at locations in the Greater Vancouver region. The diagram at each station is called a "wind rose" in which wind directions are plotted according to an eight-point compass. The length of each arm is proportional to the percentage frequency of winds from each direction.

Figure 2.2 Reprinted with permission from: T Oke T and Hay J. The Climate of Vancouver. 2nd edition. B.C Geographical series, number 50. 1994. Page 50

Agricultural + Harvesting and research + Open and undeveloped + Regional watershed + Recreation and protected natural areas + Lakes and water bodies; Governmental = Institutional; Commercial = Commercial + Commercial - Residential/Mixed.

5 Tim Oke and John Hay. The Climate of Vancouver. 2nd edition. B.C Geographical series, number 50. 1994. Page 50 . 


\section{Results}

\subsection{Measurements}

Of the 116 sites sampled in 2009 and 2010, 111 sites had two measurements that were averaged to estimate an annual mean. For the remaining 5 sites with only one valid measurement (either from fall or spring), the single measurement was used to estimate the annual average.

\subsubsection{Sampling locations}

Figure 3.1 presents the 116 sampling sites, with latitude/longitude coordinates recorded by GPS. In 2009 fall, the average location accuracy (standard deviation (sd)) was 11 (8) meters. Due to meteorological conditions during spring 2010 sampling, GPS recordings were not available at 8 sites and their coordinates were later manually obtained from Google Earth $^{\Theta}$; for the 108 sites with GPS-recorded coordinates, the average accuracy (sd) was 10 (3) meters. Due to unexpected events (filming, construction or sampling errors), four sites sampled in 2010 spring were 80 to $160 \mathrm{~m}$ away from their paired sites in 2009 fall (Location ID: 34, 39, 80, and 116). Based on the assumption that pollutant concentrations are proportional to the distance from site to source (primarily traffic), we averaged the lat/long coordinates. Hence, for these four sites, measured $\mathrm{NO} / \mathrm{NO}_{2}$ concentrations were estimated as an average of measurements taken at two nearby sites in fall and spring, respectively. Appendix E lists latitude/longitude coordinates 
(NAD83_UTM10) for the 116 sites.

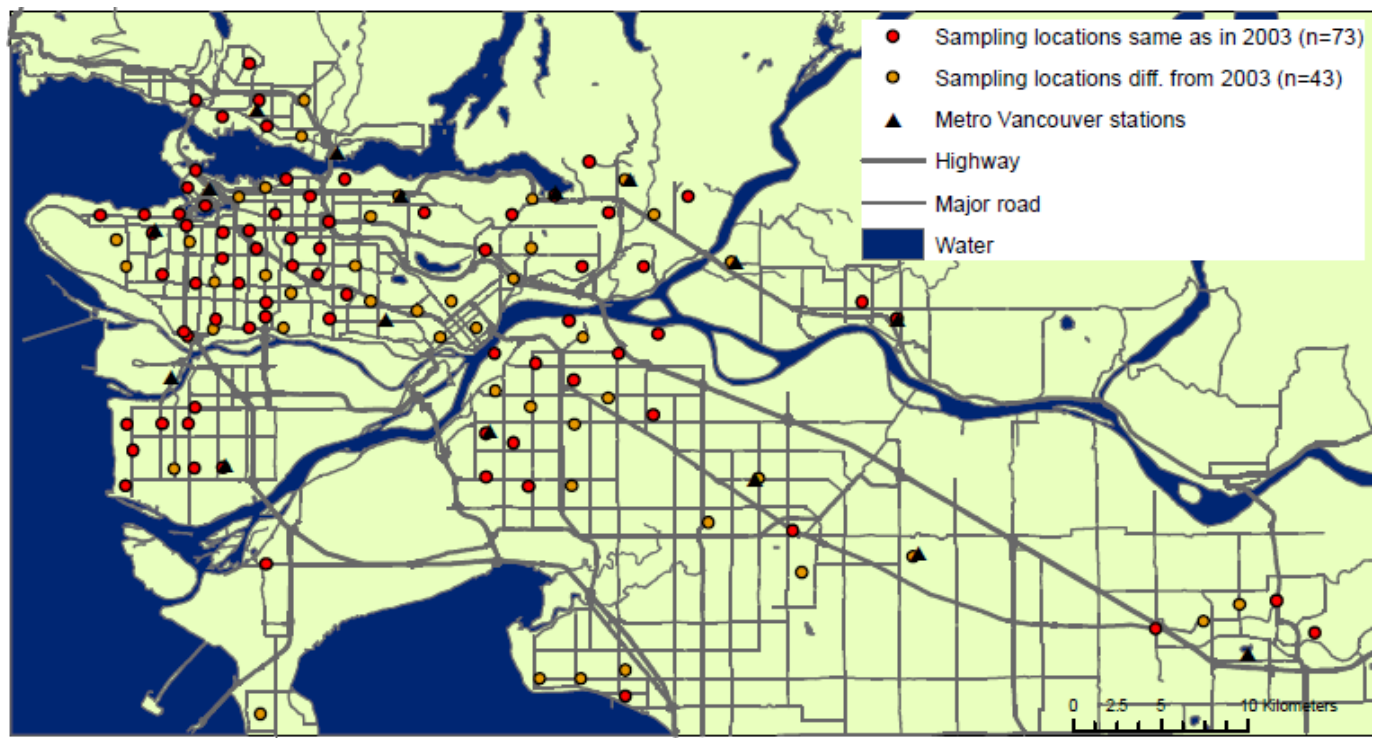

Figure 3.1 Sampling locations in 2010

\subsubsection{Measured concentrations of $\mathrm{NO}$ and $\mathrm{NO}_{2}$}

The NO concentrations approximated a lognormal distribution, with geometric mean (geometric standard deviation (gsd)) of 17.0 (2.0) ppb in 2009 fall and 10.1 (1.8) ppb in 2010 spring (Table 3.1). $\mathrm{NO}_{2}$ concentrations followed a normal distribution, with an arithmetic mean (sd) of 14.0 (3.7) ppb in fall and 7.9 (3.1) ppb in spring (Table 3.1). We originally expected to sample at the time that would best represent the annual average, but due to the 2010 Winter Olympics hosted in Vancouver, sampling periods were postponed (described in Section 2.1.1). Subsequently, the $\mathrm{NO}$ and $\mathrm{NO}_{2}$ measurements were higher in fall than in spring, in line with previous records (Figure 2.1). For NO, annual average concentrations ranged from 2.7 to $49.8 \mathrm{ppb}$, with a geometric mean (gsd) of 13.6 (1.9) ppb. For $\mathrm{NO}_{2}$, annual average concentrations ranged from 3.1 to $17.6 \mathrm{ppb}$, 
with an arithmetic mean (sd) of 10.9 (3.3) ppb. Compared with Metro Vancouver monitoring network measurements $(n=16)$, our Ogawa sampling captured more variability in $\mathrm{NO}$ and $\mathrm{NO}_{2}$ concentrations, especially for $\mathrm{NO}$ (Figure 3.2). Appendix $\mathrm{F}$ contains measurement data and annual means at each individual site.

Table 3.1 Descriptive statistics of $\mathrm{NO}$ and $\mathrm{NO}_{2}$ measurements in 2010 (unit: ppb)

\begin{tabular}{|c|c|c|c|c|c|c|}
\hline \multirow{2}{*}{ Statistics } & \multicolumn{2}{|c|}{2009 Fall } & \multicolumn{2}{|c|}{2010 Spring } & \multicolumn{2}{|c|}{ 2009-10 Average } \\
\hline & NO & $\mathrm{NO}_{2}$ & NO & $\mathrm{NO}_{2}$ & NO & $\mathrm{NO}_{2}$ \\
\hline $\mathrm{n}$ & 113 & 113 & 114 & 114 & 116 & 116 \\
\hline $\begin{array}{r}\text { Arithmetic } \\
\text { Mean }\end{array}$ & 21.3 & 14.0 & 12.1 & 7.9 & 16.6 & 10.9 \\
\hline Stdev & - & 3.7 & - & 3.1 & - & 3.3 \\
\hline $\begin{array}{c}\text { Geometric } \\
\text { Mean }\end{array}$ & 17.0 & -- & 10.2 & -- & 13.6 & -- \\
\hline $\begin{array}{c}\text { Geometric } \\
\text { Stdev }\end{array}$ & 2.0 & & 1.8 & & 1.9 & \\
\hline Median & 16.5 & 14.2 & 9.0 & 7.4 & 13.1 & 10.8 \\
\hline Min & 2.9 & 5.1 & 2.6 & 2.4 & 2.7 & 3.1 \\
\hline Max & 64.7 & 23.7 & 38.3 & 16.6 & 49.8 & 17.6 \\
\hline $25 \%$ ile - $75 \%$ ile & $10.1-30.5$ & $11.3-16.7$ & $7.2-14.9$ & $5.7-9.8$ & $8.4-22.5$ & $8.5-13.0$ \\
\hline
\end{tabular}




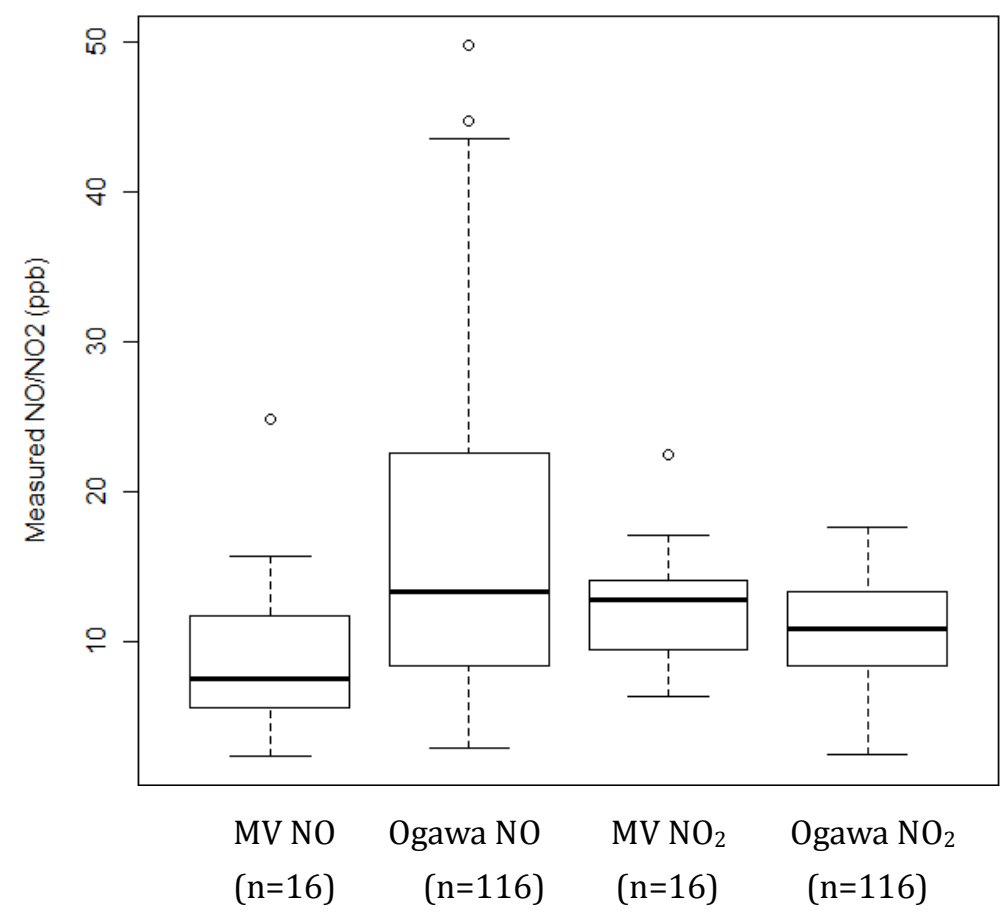

Figure 3.2 Distribution of $\mathrm{NO}$ and $\mathrm{NO}_{2}$ concentrations (ppb) measured at 16 Metro Vancouver (MV) monitoring stations and at 116 Ogawa sampling locations respectively; Ogawa sampling captured more variability in $\mathrm{NO}$ and $\mathrm{NO}_{2}$ concentrations.

\subsubsection{Quality control}

Co-located samplers: measurements from co-located Ogawa samplers (14 in fall and 16 in spring) were compared with station measurements averaged over the sampling period. Overall, the two methods were highly correlated $(r=0.87$ and 0.88 for NO in fall and spring, respectively; $\mathrm{r}=0.93$ and 0.91 for $\mathrm{NO}_{2}$ in fall and spring, respectively). $\mathrm{NO}$ had a smaller correlation value than $\mathrm{NO}_{2}$ did. This was likely caused by its greater variation over short distances. Compared with station measurements, Ogawa samplers over-estimated NO concentrations by a mean difference (sd) of 2.4 (3.4) ppb in fall and 6.5 (2.7) ppb in spring, but under-estimated $\mathrm{NO}_{2}$ concentrations, by a mean difference 
(sd) of $-1.0(1.5) \mathrm{ppb}$ in fall and -2.0 (1.3) ppb in spring. Ogawa measurements were used in analysis without adjustment for these differences.

Duplicates: Duplicate samples in the fall campaign $(n=17)$ suggested no systematic errors in Ogawa measurements $\left(\mathrm{r}=0.99\right.$ for $\mathrm{NO}$ and 0.95 for $\mathrm{NO}_{2}$; mean difference $(\mathrm{sd})$ $=1.5(1.6) \mathrm{ppb}$ for $\mathrm{NO}$ and $0.0(1.3)$ for $\left.\mathrm{NO}_{2}\right)$.

Field blanks: In fall, due to laboratory errors, 10 field blanks were not analyzed and an average of the remaining 17 blanks was applied to adjust for background contamination.

As a result, net measurements from Ogawa samples were subtracted by $0.060 \mathrm{ppb}$ for $\mathrm{NO}$ and $0.388 \mathrm{ppb}$ for $\mathrm{NO}_{2}$. In spring, most field blank samples were under the method detection limit and thus no adjustment was made to the spring Ogawa measurements.

Detailed quality control data are presented in Appendix G.

\subsection{9-10 models}

Final LUR models were developed for log-transformed NO (referred to as $\operatorname{logNO}$ hereafter) and untransformed $\mathrm{NO}_{2}$ (Table 3.2). Coefficients for all variables were statistically significant at an alpha level of 0.05 . Models explained a moderate fraction of variability in pollutant concentrations with adjusted $\mathrm{R}^{2}$ ranging from 0.53 to 0.64 . In general, there was more variability explained for $\mathrm{NO}_{2}$ than for $\mathrm{NO}$ concentrations. Models built with road length as the traffic metric explained more variability than 
models built with traffic density for NO, but the two metrics were essentially the same for the $\mathrm{NO}_{2}$ models. In all model equations, traffic variables had the highest partial $\mathrm{R}^{2}$ values (Table 3.2), indicating their primary importance in explaining the spatial variability in pollutant concentrations.

Overall, the variability at Metro Vancouver station sites was well explained by the models (as shown by the station $\mathrm{R}^{2}$ values ranging from 0.68 to 0.81 ), and more variability was explained for $\mathrm{NO}_{2}$ than for NO. Error estimates show that compared to station measurements, model predictions overestimated NO concentrations while they underestimated $\mathrm{NO}_{2}$ concentrations (Table 3.2). Leave-one-out (LOO) cross validation demonstrated that these models were robust at each individual site. Mean errors were zero for all models, with standard deviations less than those for field measurements. For each model, the LOO $\mathrm{R}^{2}$ value was close to its adjusted $\mathrm{R}^{2}$ value. These LOO validation results suggested that LUR models were not substantially affected by unusual individual sampling sites.

We mapped surfaces of estimated annual mean concentrations of NO (Figure 3.3) and $\mathrm{NO}_{2}$ (Figure 3.4) in 2010, based on road length model and traffic density models. Modeled $\mathrm{NO}_{2}$ concentrations were more homogenous on the map than those of NO. The latter had high concentrations near traffic sources, with concentrations decreasing rapidly with distance. These differences demonstrated the ability of LUR model to capture differences in spatial patterns between primary and secondary pollutants. For comparison, 
2003 maps were also included in Figure 3.3 and Figure 3.4, with accompanying model equations included in Table 3.3. 
Table 3.2 Summary of 2010 LUR models: model parameters and validation results. Note that these only used the original pool of variables (as in 2003) so these are not the final 2010 models as those the enhanced models (Table 3.6).

\begin{tabular}{|c|c|c|c|c|c|c|}
\hline $\begin{array}{c}\text { Response } \\
\text { (N) }\end{array}$ & $\begin{array}{l}\text { Traffic } \\
\text { metric }\end{array}$ & Equation $^{1}$ & $\begin{array}{c}\text { Partial } \\
\mathbf{r}^{2}\end{array}$ & $\begin{array}{c}\mathbf{R}^{2} \\
\text { Adjusted } \\
\mathbf{R}^{2}\end{array}$ & $\begin{array}{c}\text { Station } \\
\text { error } \\
\text { estimate }^{2} \\
\text { (SD) } \\
\mathbf{R}^{2} \\
\end{array}$ & $\begin{array}{l}\text { LOO error } \\
\text { estimate }^{3} \\
\text { (SD) } \\
\mathbf{R}^{2}\end{array}$ \\
\hline $\begin{array}{c}\log \mathrm{NO} \\
(116)\end{array}$ & $\begin{array}{l}\text { Road } \\
\text { length }\end{array}$ & $\begin{array}{c}7.486 \\
+1.068 \times \mathbf{R D 2 . 2 0 0} \\
+0.069 \times \mathbf{R D 1 . 1 0 0 0} \\
-0.003 \times \mathbf{E L E V} \\
+1.341 \times \mathbf{R D 1 . 1 0 0} \\
-0.101 \times \mathbf{X}\end{array}$ & $\begin{array}{l}0.39 \\
0.12 \\
0.08 \\
0.05 \\
0.12\end{array}$ & $\begin{array}{l}0.60 \\
0.58\end{array}$ & $\begin{array}{c}0.31 \\
(0.31) \\
0.70\end{array}$ & $\begin{array}{c}0.00(0.42) \\
0.54\end{array}$ \\
\hline $\begin{array}{c}\log \mathrm{NO} \\
(116)\end{array}$ & $\begin{array}{l}\text { Vehicle } \\
\text { density }\end{array}$ & $\begin{array}{c}2.285 \\
+0.053 \times \text { TD.200 } \\
+0.009 \times \text { POP.2500 } \\
-0.003 \times \text { ELEV }\end{array}$ & $\begin{array}{l}0.36 \\
0.11 \\
0.09 \\
\end{array}$ & $\begin{array}{l}0.54 \\
0.53\end{array}$ & $\begin{array}{c}0.32 \\
(0.38) \\
0.68\end{array}$ & $\begin{array}{c}0.00(0.43) \\
0.51\end{array}$ \\
\hline $\begin{array}{l}\mathrm{NO}_{2} \\
(116)\end{array}$ & $\begin{array}{l}\text { Road } \\
\text { length }\end{array}$ & $\begin{array}{c}48.777 \\
+10.319 \times \mathbf{R D 2 . 1 0 0} \\
+10.300 \times \text { RD1.100 } \\
-0.683 \times \text { DISTRD1 } \\
+0.051 \times \text { POP.2500 } \\
-0.788 \times \mathbf{X}\end{array}$ & $\begin{array}{l}0.30 \\
0.16 \\
0.14 \\
0.11 \\
0.18\end{array}$ & $\begin{array}{l}0.64 \\
0.63\end{array}$ & $\begin{array}{c}-2.76(1.87) \\
0.81\end{array}$ & $\begin{array}{c}0.01 \\
(2.12) \\
0.60\end{array}$ \\
\hline $\begin{array}{l}\mathrm{NO}_{2} \\
(116)\end{array}$ & $\begin{array}{l}\text { Vehicle } \\
\text { density }\end{array}$ & $\begin{array}{c}40.676 \\
+0.254 \times \text { TD.200 } \\
+0.044 \times \text { POP.2500 } \\
-0.457 \times \text { DISTRD1 } \\
-0.631 \times \mathbf{X}\end{array}$ & $\begin{array}{l}0.35 \\
0.08 \\
0.07 \\
0.12\end{array}$ & $\begin{array}{l}0.63 \\
0.62\end{array}$ & $\begin{array}{c}-2.05 \\
(1.91) \\
0.77\end{array}$ & $\begin{array}{c}0.00 \\
(2.11) \\
0.60\end{array}$ \\
\hline
\end{tabular}

1. Predictor variables were listed based on individual contribution to the model (from highest to lowest), measured by their respective partial $\mathrm{R}^{2}$ values. $\mathrm{X}$ (longitude) was listed in the end regardless of its partial $\mathrm{R}^{2}$ value because it is likely to be surrogate for other undefined variables. All listed variables have significant $t$-statistics $(\alpha=0.05)$.

2. Models were used to predict concentrations at 16 monitoring stations. The error estimate was calculates as model prediction minus station measurement. $\mathrm{R}^{2}$ : model predictions against station measurements $(n=16)$

3. Leave-one-our cross-validation: models were constructed based on N-1 measurements and used to predict the excluded measurement. The error estimate was calculated as model prediction minus the excluded measurement. $\mathrm{R}^{2}$ : model predictions against excluded measurements $(\mathrm{n}=116)$ 


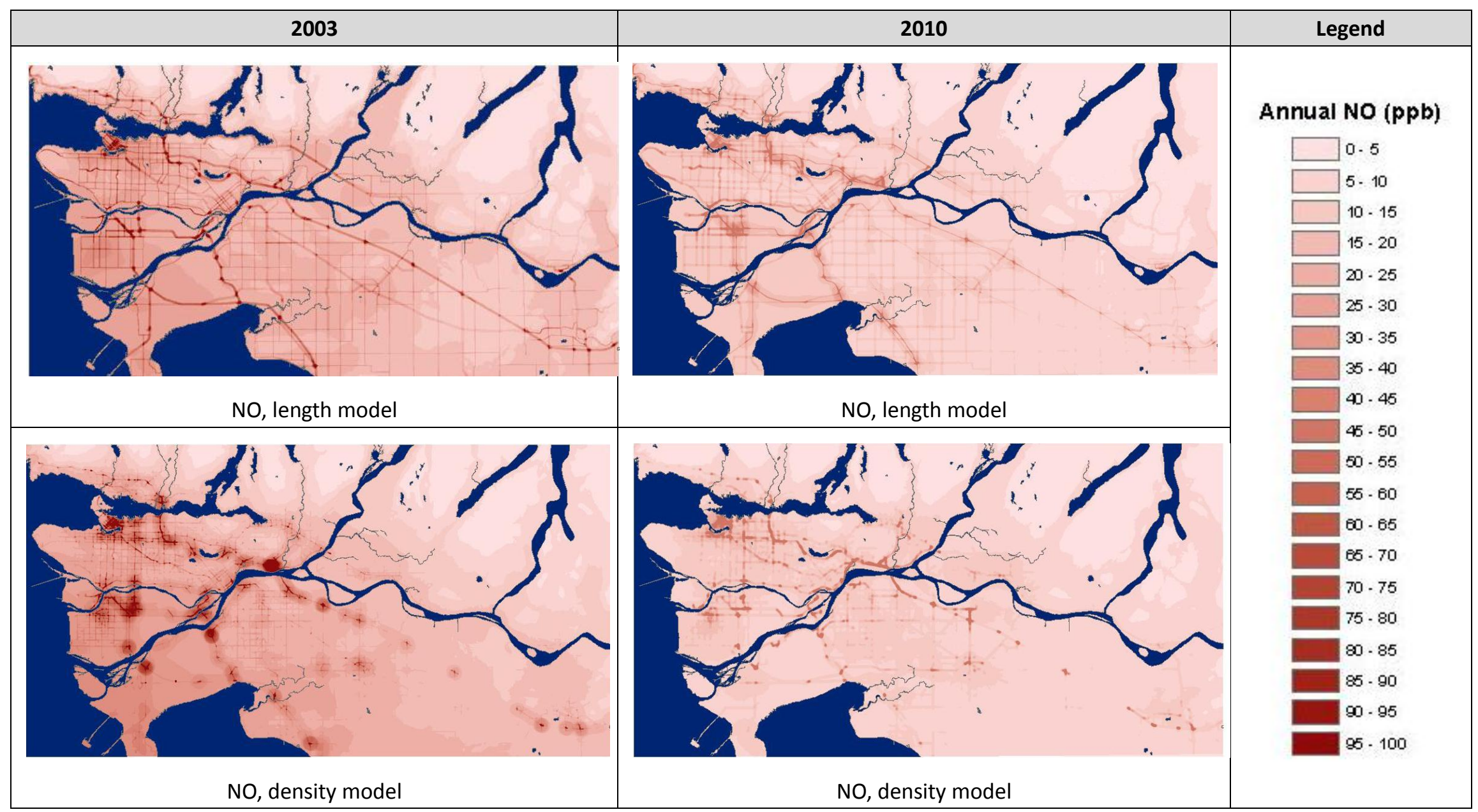

Figure 3.3 Maps of modeled NO concentrations in 2003 (left) and in 2010 (right) 


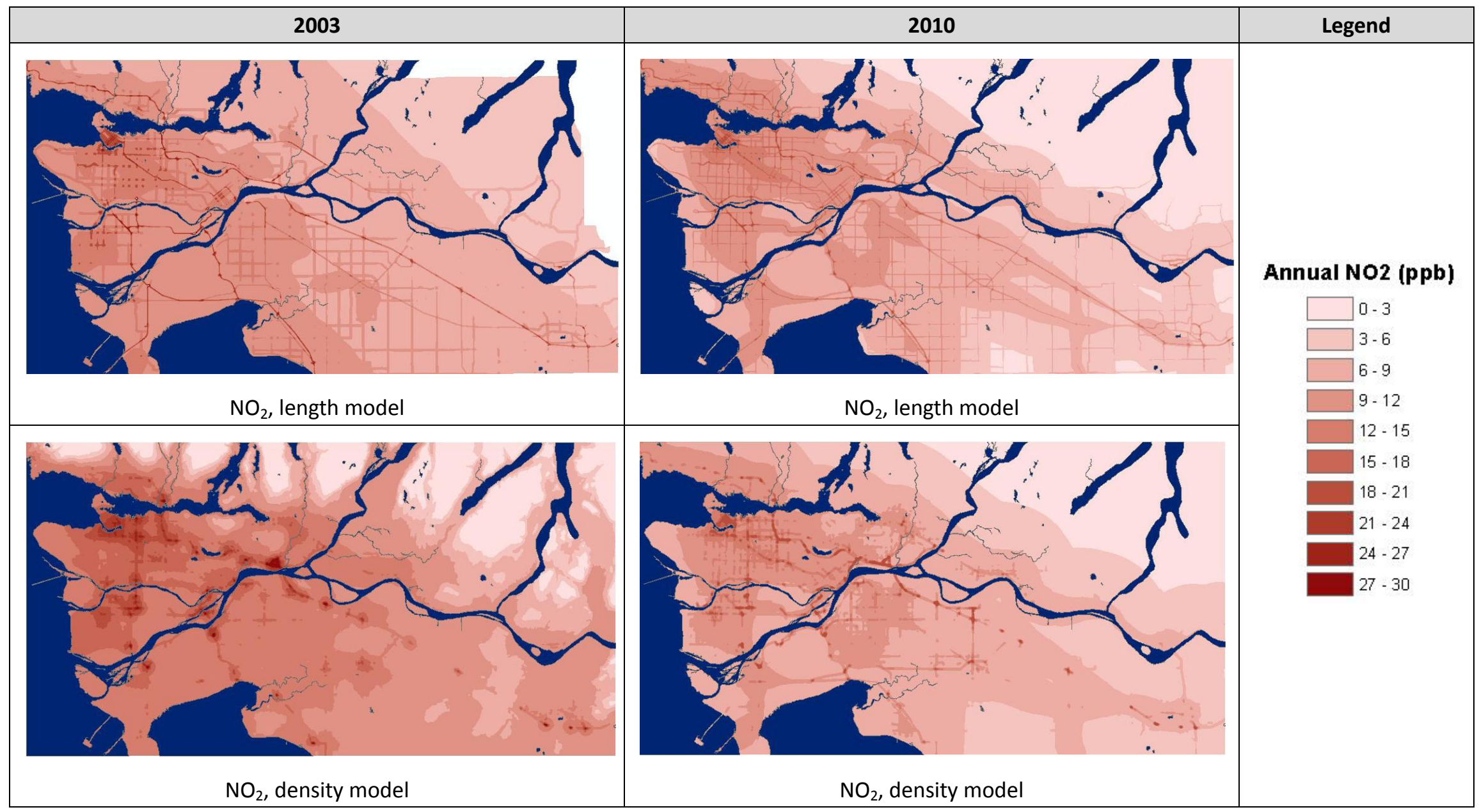

Figure 3.4 Maps of modeled $\mathrm{NO}_{2}$ concentrations in 2003 (left) and in 2010 (right) 
Table 3.3 Summary of 2003 models $^{1}$

\begin{tabular}{|c|c|c|c|c|c|c|}
\hline $\begin{array}{c}\text { Response } \\
\text { (N) }\end{array}$ & $\begin{array}{l}\text { Traffic } \\
\text { metric }\end{array}$ & Equation & $\begin{array}{l}\text { Partial } \\
\text { r2 }\end{array}$ & $\begin{array}{c}\mathbf{R}^{2} \\
\text { Adjusted } \\
\mathbf{R}^{2}\end{array}$ & $\begin{array}{c}\text { Station } \\
\text { error } \\
\text { estimate }^{2} \\
(\mathbf{S D}) \\
\mathbf{R}^{2} \\
\end{array}$ & $\begin{array}{l}\text { LOO error } \\
\text { estimate }^{3} \\
\text { (SD) } \\
\mathbf{R}^{\mathbf{2}}\end{array}$ \\
\hline $\begin{array}{c}\log \mathrm{NO} \\
(114)\end{array}$ & $\begin{array}{l}\text { Road } \\
\text { length }\end{array}$ & $\begin{array}{c}57.581 \\
+0.784 \times \mathbf{R D 1 . 2 0 0} \\
+2.220 \times \mathbf{R D 2 . 1 0 0} \\
+0.007 \times \mathbf{P O P . 2 5 0 0} \\
-0.004 \times \mathbf{E L E V} \\
-0.075 \times \mathbf{X} \\
-0.093 \times \mathbf{Y} \\
\end{array}$ & $\begin{array}{l}0.22 \\
0.36 \\
0.07 \\
0.14 \\
0.06 \\
0.06\end{array}$ & $\begin{array}{l}0.61 \\
0.59\end{array}$ & $\begin{array}{c}3.10 \\
(0.50) \\
0.64\end{array}$ & $\begin{array}{c}0.00 \\
(0.41) \\
0.44\end{array}$ \\
\hline $\begin{array}{c}\log \mathrm{NO} \\
(114)\end{array}$ & $\begin{array}{l}\text { Vehicle } \\
\text { density }\end{array}$ & $\begin{array}{c}116.475 \\
+0.001 \times \text { AD.100 } \\
+0.132 \times \text { TD.1000 } \\
-0.002 \times \mathbf{E L E V} \\
-0.129 \times \mathbf{X} \\
-0.196 \times \mathbf{Y}\end{array}$ & $\begin{array}{l}0.12 \\
0.19 \\
0.07 \\
0.17 \\
0.12\end{array}$ & $\begin{array}{l}0.57 \\
0.55\end{array}$ & $\begin{array}{c}3.24 \\
(0.52) \\
0.62\end{array}$ & $\begin{array}{c}0.00 \\
(0.39) \\
0.51\end{array}$ \\
\hline $\begin{array}{l}\mathrm{NO}_{2} \\
(114)\end{array}$ & $\begin{array}{l}\text { Road } \\
\text { length }\end{array}$ & $\begin{array}{c}519.538 \\
+13.585 \times \mathbf{R D 1 . 1 0 0} \\
+3.661 \times \mathbf{R D 2 . 2 0 0} \\
+0.062 \times \mathbf{P O P . 2 5 0 0} \\
+0.037 \times \mathbf{I N D . 7 5 0} \\
-0.848 \times \mathbf{X} \\
-0.853 \times \mathbf{Y}\end{array}$ & $\begin{array}{l}0.14 \\
0.10 \\
0.08 \\
0.12 \\
0.11 \\
0.14\end{array}$ & $\begin{array}{l}0.54 \\
0.52\end{array}$ & $\begin{array}{c}2.14 \\
(2.46) \\
0.65\end{array}$ & $\begin{array}{c}0.01 \\
(3.00) \\
0.47\end{array}$ \\
\hline $\begin{array}{l}\mathrm{NO}_{2} \\
(114)\end{array}$ & $\begin{array}{l}\text { Vehicle } \\
\text { density }\end{array}$ & $\begin{array}{c}43.792 \\
+0.203 \times \text { TD.200 } \\
+0.072 \times \text { POP.2500 } \\
-0.019 \times \mathbf{E L E V} \\
+0.689 \times \mathbf{T D . 1 0 0 0} \\
-0.612 \times \mathbf{X}\end{array}$ & $\begin{array}{l}0.08 \\
0.10 \\
0.07 \\
0.08 \\
0.07\end{array}$ & $\begin{array}{l}0.57 \\
0.55\end{array}$ & $\begin{array}{c}1.12 \\
(1.92) \\
0.79\end{array}$ & $\begin{array}{c}0.03 \\
(2.90) \\
0.51\end{array}$ \\
\hline
\end{tabular}

1. These 2003 Vancouver models were different from those published in 2007 [24]. This is because, in 2010, we noticed an error in commercial and residential land coverage described by ESRI 2001 land use data that was used in developing previous 2003 models. In a newly downloaded 2001 land use data set, the error was corrected. We then updated the 2003 models (as summarized in the above table) using the later downloaded land use data and used them for later analysis of temporal stability.

2. Models were used to predict concentrations at 16 monitoring stations. The error estimate was calculates as model prediction minus station measurement. $\mathrm{R}^{2}$ : model predictions against station measurements $(\mathrm{n}=16)$ 
3. Leave-one-our cross-validation: models were constructed based on $\mathrm{N}-1$ measurements and used to predict the excluded measurement. The error estimate was calculated as model prediction minus the excluded measurement. $R^{2}$ : model predictions against excluded measurements $(n=114)$ 


\subsection{Change in $\mathrm{NO}$ and $\mathrm{NO}_{2}$ concentrations and in spatial pattern from 2003 to 2010}

\subsubsection{Estimated change by comparing measurements}

Estimated annual averages of $\mathrm{NO}$ and $\mathrm{NO}_{2}$ concentrations were adjusted by their respective ratio of the two 14-day (sampling campaign) sampling period average and annual average measured at 16 monitoring stations (Figure 3.5).

Two 14-day average vs Annual average at 16 stations,

NO

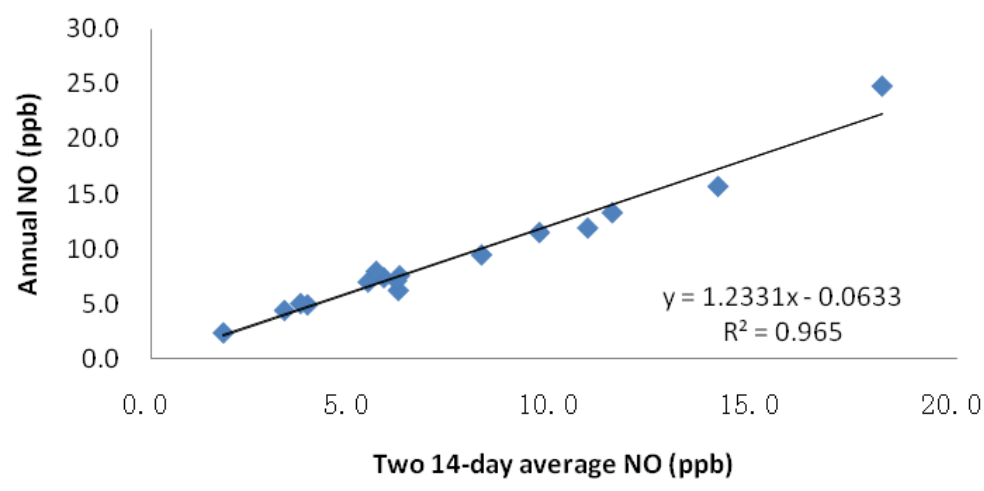

Two 14-day average vs Annual average at 16 stations,

$\mathrm{NO}_{2}$

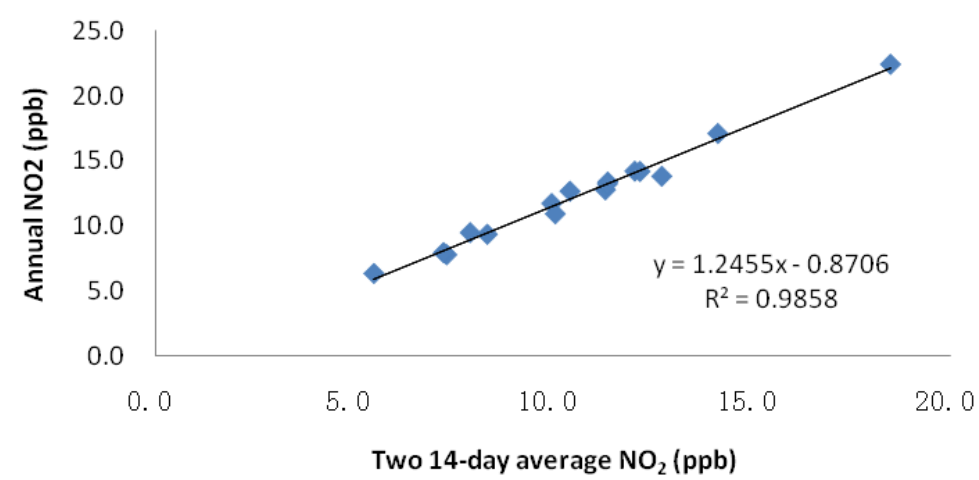

Figure 3.5 Sampling period bias caused by seasonal fluctuation; figures show that the two 14-day sampling periods in 2009/10 underestimated the annual mean for both NO and $\mathrm{NO}_{2}$ 
Out of 116 designated sampling sites in 2003 and 2010, 73 measurements were taken at exactly the same location in both years. This allowed for the estimation of the change in pollutant concentrations from 2003 to 2010, at greater spatial detail than that estimated from monitoring stations. For NO, the correlation between 2003 and 2010 measurements was 0.87 with a mean (sd) decrease of $11.3(9.9)$ ppb. For $\mathrm{NO}_{2}$, the correlation was 0.74 with a mean (sd) decrease of 2.4 (3.2) ppb. The change in concentrations followed a normal distribution (Figure 3.6). A similar downward trend was also observed at Metro Vancouver monitoring stations, where a mean (sd) decrease of 5.5 (3.7) ppb was recorded for $\mathrm{NO}$, and 2.9 (1.0) ppb for $\mathrm{NO}_{2}$. Compared with Metro Vancouver station data, our measurements captured more variability in the change of $\mathrm{NO}$ and $\mathrm{NO}_{2}$ concentrations, attributable to the more widely distributed sampling locations. Greater decreases were observed at locations with higher initial (2003) concentrations.

Despite the general downward trend, increases in pollutant concentrations were observed at a small number of sampling sites, suggesting some localized deviations from the the background trend. Out of six sites where NO concentrations increased, two displayed increases greater than $5 \mathrm{ppb}$ (Figure 3.6). Among the 16 sites where increased $\mathrm{NO}_{2}$ was measured, nine sites recorded increases below $1 \mathrm{ppb}$ and six recorded increases between 1 and $5 \mathrm{ppb}^{6}$. An increase of $11.0 \mathrm{ppb}$ was measured at one location (Site ID 37, located on the west side of Rupert Street, between E 20th avenue and E 21st avenue, 2

\footnotetext{
${ }^{6}$ All increases were based on two two-week averages in both 2003 and 2010, except one site for NO (Site ID 17) and four sites for $\mathrm{NO}_{2}$ (Site ID 17,37,43,76)
} 
meters away from a bus stop). These sites with increased concentrations were geographically scattered, without an observable clustered pattern. This suggests that these increases were likely caused by local events (e.g. a newly introduced bus-stop nearby). Additional sampling would be required to confirm this increase and to investigate potential cause(s).
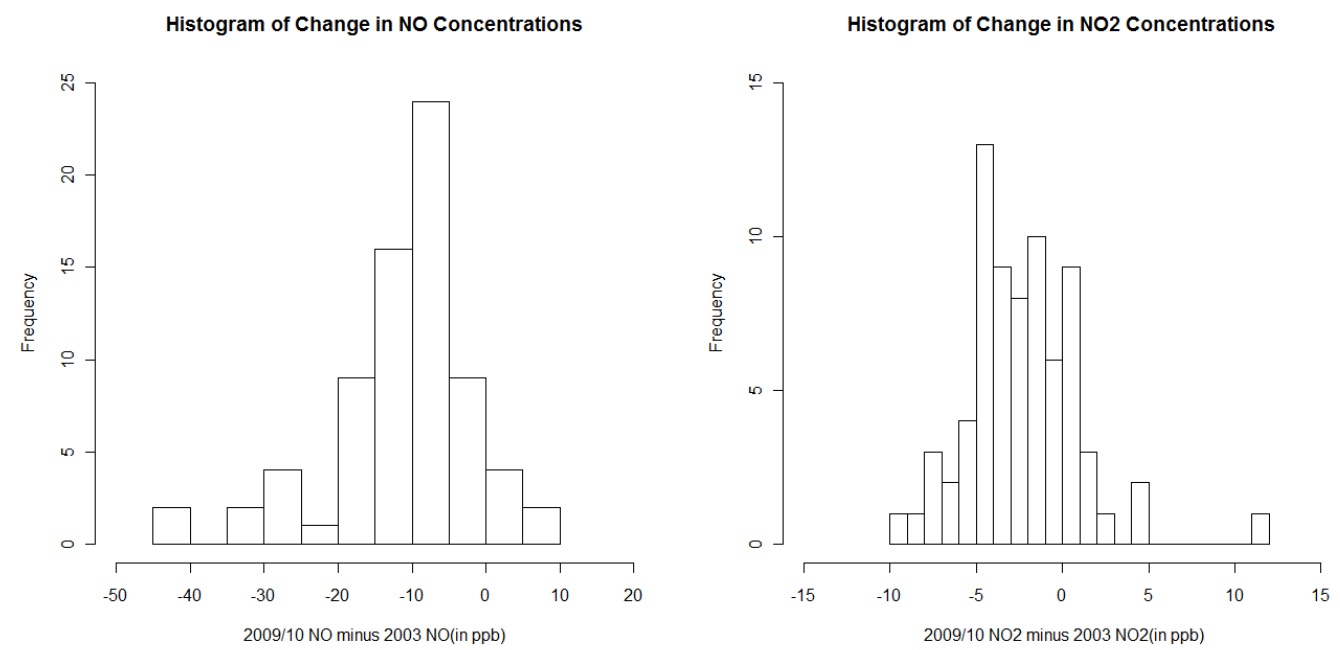

Figure 3.6 Histogram of change in $\mathrm{NO}$ and $\mathrm{NO}_{2}$ concentrations from 2003 to 2010, calculated as 2010 measurements minus 2003 measurements; both $\mathrm{NO}$ (left) and $\mathrm{NO}_{2}$ (right) approximate normal distribution $(n=73)$. The few sites with increased concentrations were geographically scattered across study area.

Other than the observed general downward trend in $\mathrm{NO}$ and $\mathrm{NO}_{2}$ concentrations, we also explored factors contributing to the trend by modeling the change in concentrations using geographic variables (traffic, land use, population density and geographical variables). As shown in Table 3.4, only a very limited fraction of the variation in the change in $\mathrm{NO}$ or $\mathrm{NO}_{2}$ concentrations (adjusted $\mathrm{R}^{2}$ values ranging from 0.06 to 0.24 in the four model equations) was explained. More variability was explained for changes in NO 
than for changes in $\mathrm{NO}_{2}$. The low $\mathrm{R}^{2}$ values for the concentration change models suggests that the observed decreases in pollutant concentrations were associated with factors that were not considered in our LUR modeling, such as general decreases in vehicle emissions (for example, newer vehicles will emit less pollution while older vehicles may emit more pollution) and/or improvements in regional air quality. A summary statistics (Appendix I) shows the distribution of 2003 model predictors at the 73 same-locating sites, and the updated distribution of those same variables in 2010.

Table 3.4 Change $(\Delta)$ in NO and $\mathrm{NO}_{2}$ concentrations modeled by change $(\Delta)$ in LUR variables

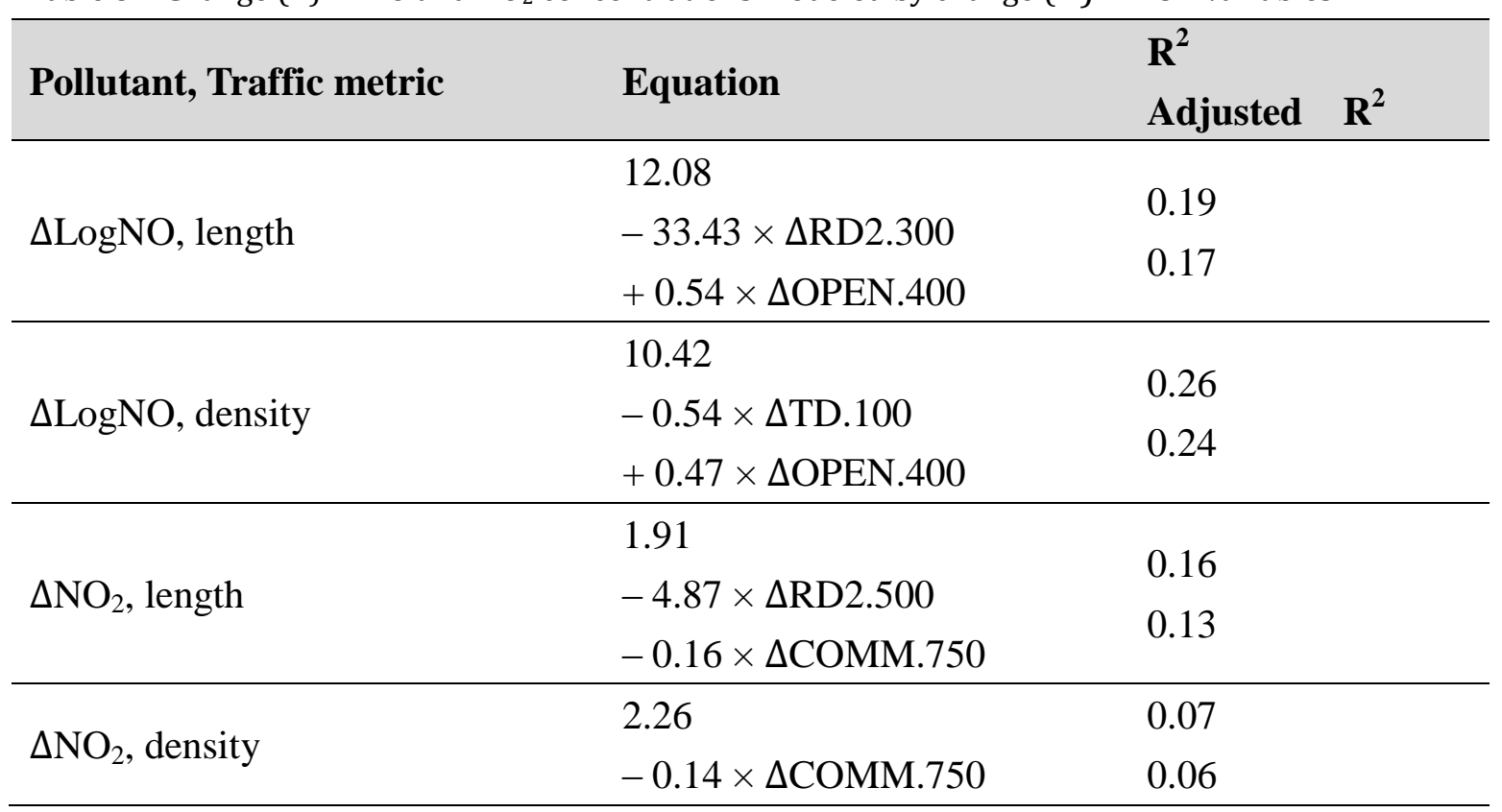




\subsubsection{Estimated change by comparing modeled surfaces}

Another way to estimate the change in pollutant concentrations from 2003 to 2010 was to subtract the modeled surfaces from the two periods. Subtracting the 2003 surface from the 2010 surface resulted in the map of change in estimated $\mathrm{NO}_{2}{ }^{7}$ concentrations (Figure 3.7). From the map of change, we can see that the estimated increases are isolated to essentially un-populated areas and all are located in the northern section of the region. This probably does not reflect real increases, but is an artifact of differences in model parameters between the two periods. Thus in general the change seems to be more regional which supports the use of a temporal trend in extending models over time in this setting.

\footnotetext{
7 Subtracting surfaces was done for the $\mathrm{NO}_{2}$-length model only (the one with highest adjusted $\mathrm{R}^{2}$ value in 2010), because the purpose was to illustrate/explore a method to estimate change between two time periods. One example should suffice.
} 


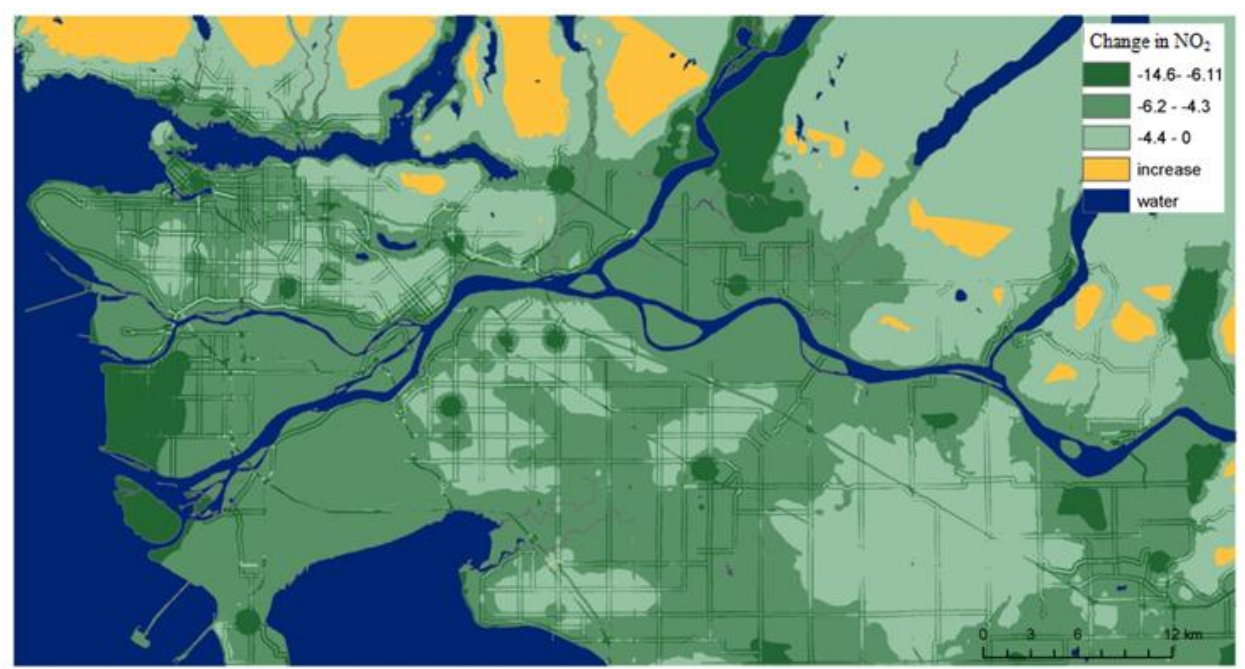

Figure 3.7 Change in NO2 concentrations from 2003 to 2010, estimated by subtracting two modeled surfaces (2010 surface minus 2003 surface)

\subsection{Extending models in time}

As described in section 2.2, we applied the 2010 models to back-cast 2003 concentrations, and 2003 models to forecast 2010 concentrations using each of the four evaluation methods (Table 3.5). 
Table 3.5 Evaluation of extending LUR models over time using four methods: comparing model predictions against actual measurements at 116 sites

\begin{tabular}{|c|c|c|c|c|c|c|c|c|c|c|}
\hline & \multicolumn{5}{|c|}{ Forecast } & \multicolumn{5}{|c|}{ Back-cast } \\
\hline & $\begin{array}{c}2003 \\
\text { Model }\end{array}$ & Method $1^{1}$ & $\begin{array}{c}\text { Method } \\
2^{2}\end{array}$ & $\begin{array}{c}\text { Method } \\
3^{3}\end{array}$ & Method $4^{4}$ & $\begin{array}{c}\text { 2009/10 } \\
\text { Model }\end{array}$ & Method 1 & Method 2 & $\begin{array}{c}\text { Method } \\
3\end{array}$ & $\begin{array}{c}\text { Method } \\
4\end{array}$ \\
\hline \multicolumn{11}{|l|}{ logNO, length } \\
\hline$R^{25}$ & 0.59 & 0.60 & 0.58 & 0.59 & 0.60 & 0.58 & 0.50 & 0.54 & 0.53 & 0.55 \\
\hline Error mean ${ }^{6}$ & 0.00 & 0.30 & 0.65 & 0.32 & 0.00 & 0.00 & -0.22 & -0.67 & -0.24 & -0.00 \\
\hline SD & 0.35 & 0.41 & 0.40 & 0.42 & 0.40 & 0.39 & 0.39 & 0.38 & 0.38 & 0.43 \\
\hline \multicolumn{11}{|l|}{$\log N O$, density } \\
\hline $\mathbf{R}^{2}$ & 0.55 & 0.57 & 0.54 & 0.56 & 0.59 & 0.53 & 0.45 & 0.38 & 0.34 & 0.40 \\
\hline Error mean & 0.00 & 0.31 & 0.98 & 0.73 & 0.00 & 0.00 & -0.23 & -0.77 & -0.32 & -0.00 \\
\hline SD & 0.36 & 0.42 & 0.48 & 0.54 & 0.40 & 0.42 & 0.41 & 0.43 & 0.45 & 0.37 \\
\hline \multicolumn{11}{|l|}{ NO2, length } \\
\hline $\mathbf{R}^{2}$ & 0.52 & 0.54 & 0.52 & 0.52 & 0.61 & 0.63 & 0.44 & 0.46 & 0.46 & 0.49 \\
\hline Error mean & 0.00 & 1.57 & 4.62 & 1.15 & 0.00 & 0.00 & -1.58 & -5.16 & -1.69 & -0.00 \\
\hline SD & 2.79 & 2.35 & 2.34 & 2.34 & 2.08 & 1.99 & 3.08 & 3.05 & 3.05 & 2.96 \\
\hline \multicolumn{11}{|l|}{ NO2, density } \\
\hline $\mathbf{R}^{2}$ & 0.55 & 0.60 & 0.62 & 0.62 & 0.65 & 0.62 & 0.52 & 0.46 & 0.46 & 0.49 \\
\hline Error mean & 0.00 & 1.58 & 7.31 & 3.84 & 0.00 & -0.00 & -1.59 & -5.66 & -2.19 & -0.00 \\
\hline SD & 2.71 & 2.18 & 3.13 & 3.13 & 1.99 & 2.02 & 2.88 & 3.10 & 3.10 & 2.96 \\
\hline
\end{tabular}

1. Method $1=$ Applying a temporal trend (Section 2.2)

2. Method $2=$ Updating values of predictor variables (Section 2.2)

3. Method $3=$ Both applying a temporal trend and updating values of predictor variables (Section 2.2)

4. Method $4=$ Calibrating coefficients using the same predictor variables (Section 2.2)

5. Model predictions against actual measurements; in the columns of 2003 model and 2010 model, adjusted $R^{2}$ values from original models are presented

6. Model prediction minus actual measurement 


\subsubsection{Method 1: applying a temporal trend}

Based on Metro Vancouver sites, the annual average concentration ${ }^{8}$ decreased by 6.8 ppb for NO and $3.5 \mathrm{ppb}$ for $\mathrm{NO}_{2}$ from 2003 to 2010 . Thus when a 2003 model was applied to forecast concentrations in 2010, $6.8 \mathrm{ppb}$ was subtracted from NO predictions and $3.5 \mathrm{ppb}$ was subtracted from $\mathrm{NO}_{2}$ predictions to account for the temporal trend. Similarly, when a 2010 model was used to back-cast concentrations in 2003, $6.8 \mathrm{ppb}$ for $\mathrm{NO}$ and $3.5 \mathrm{ppb}$ for $\mathrm{NO}_{2}$ were added to model predictions.

In forecasting, all the 2003 models explained a slightly larger or similar amount of variability in the 2010 measurements than they did in the 2003 measurements. On the contrary, back-casting the 2010 models explained much less variability in the 2003 measurements than they did in the 2010 measurements (and less variability than the 2003 models explained in the 2003 measurements).

Based on the error means (Table 3.5), the model predictions from forecasting overestimated actual measurements while the model predictions from back-casting under-estimated actual concentrations. This discrepancy between model predictions and actual measurements was expected because the temporal trend (decrease in pollutant concentrations from 2003 to 2010) derived from Metro Vancouver station measurements was likely an underestimate, due to the fact that most Metro Vancouver stations are located at areas with low concentrations and are

8 The annual average was calculated based on 16 monitoring stations where we had placed our Ogawa samplers; data were requested from Metro Vancouver. 
likely to have smaller decrease (from 2003 to 2010) compared to sites with higher initial (2003) concentrations.

Overall, applying a temporal trend proved to be a simple and feasible way to extend LUR models in time. In the case of Metro Vancouver where pollutant concentrations decreased over time, the LUR model's explanatory power was retained in forecasting, but reduced by $8 \sim 19 \%$ (absolute reduction in adjusted $\mathrm{R}^{2}$ values) in back-casting.

\subsubsection{Method 2: updating values of predictor variables}

Results from updating values of predictor variables were similar to those from applying a temporal trend. In forecasting, the 2003 models explained a similar or larger amount of variability in the 2010 measurements than they did in the 2003 measurements. In back-casting, all 2010 models explained 4 16\%less variability in the 2003 measurements than they did in the 2010 measurements (and also less than the 2003 models explained in the 2003 measurements). Compared with method 1, method 2 produced larger mean errors in both forecasting and back-casting, implying that changes in the predictor variables were not the primary cause of changes in pollutant concentrations. Instead, the downward trend in $\mathrm{NO}$ and $\mathrm{NO}_{2}$ concentrations was likely due to regional factors that were not included in the LUR models.

\subsubsection{Method 3: applying a temporal trend and updating values of predictor variables}

Combining the two methods (applying a temporal trend and updating values of predictor 
variables), Method 3 produced $\mathrm{R}^{2}$ values similar to those using the second method. In forecasting, 2003 models explained the same or greater variability in the 2010 measurements as they did in the 2003 measurements. In back-casting, all 2010 models explained less variability in the 2003 measurements than they did in the 2010 measurements (and also less variability than the 2003 models explained for the 2003 measurements). Mean errors from method 3 ranged from 0.24 to $3.24 \mathrm{ppb}$, larger than those from method 1 (from 0.22 to $1.59 \mathrm{ppb}$ ) but smaller than those from method 2 ( from 0.65 to $7.31 \mathrm{ppb}$ ), with the exception of $2003 \mathrm{NO}_{2}$ length model which achieved the least mean error in forecasting 2010 concentrations. In general, this combined method was better than updating predictor variables only (similar $\mathrm{R}^{2}$ values and less mean errors), but no better than applying a temporal trend only (similar $\mathrm{R}^{2}$ values but larger mean errors). Again, this confirmed our previous results that changes in predictor variables had a limited contribution to the change in pollutant concentrations.

\subsubsection{Method 4: calibrating coefficients of previous models using new measurements}

In this method, predictor variables from one year were transferred to fit measurements in the other year. Thus this method tells whether or not the main predictor variables change over time. In forecasting, all 2003 models explained more variability in the 2010 measurements than they did in the 2003 measurements. This suggests that predictor variables from 2003 are still important predictors of the spatial distribution of air pollutants in 2010. In back-casting, however, the 2010 models explained less variability in the 2003 measurements than they did in 
the 2010 measurements. The 2010 models also explained less variability than the 2003 models applied to the 2010 measurements (except $\mathrm{NO}_{2}$ length), indicating that predictor variables included in 2010 models were not able to predict 2003 concentrations as well as the original 2003 models.

\subsection{0 - enhanced models}

By including additional variables that were not tested previously, we built the 2010 -enhanced models, as summarized in Table 3.6. Associated maps are displayed in Figure 3.8. We compared the three sets of LUR models (2003, 2010 and 2010-enhanced) with respect to predictor variables and model adjusted $\mathrm{R}^{2}$ values (Table 3.7). The increase of adjusted $\mathrm{R}^{2}$ values (model's explanatory power) from 2010 to 2010-enhanced was very limited (1-6\% increase). However, in the 2010-enhanced models, the X and Y (longitude/latitude) coordinates were replaced by specific variables, such as bus stop density and intersection density. As the $\mathrm{X}$ and $\mathrm{Y}$ coordinates were likely to have been surrogates for other undefined factors under varying circumstances, we considered this replacement as an improvement. To confirm the replacement, we forced to include $\mathrm{X}$ and $\mathrm{Y}$ into the models and found no increased in $\mathrm{R}^{2}$ values. 
Table 3.6 Summary of 2010-enhanced models: model parameters and validation results

\begin{tabular}{|c|c|c|c|c|c|c|}
\hline $\begin{array}{c}\text { Response } \\
\text { (N) }\end{array}$ & $\begin{array}{l}\text { Traffic } \\
\text { metric }\end{array}$ & Equation & $\begin{array}{c}\text { Partial } \\
\mathbf{r}^{2}\end{array}$ & $\begin{array}{c}\mathbf{R}^{2} ; \\
\text { Adjusted } \\
-\mathbf{R}^{2}\end{array}$ & $\begin{array}{c}\text { GVRD } \\
\text { error } \\
\text { estimate } \\
\text { (SD); } \mathbf{R}^{2}\end{array}$ & $\begin{array}{c}\text { LOO } \\
\text { error } \\
\text { estimate } \\
\text { (SD); } \mathbf{R}^{2}\end{array}$ \\
\hline $\begin{array}{l}\log \mathrm{NO} \\
(112)\end{array}$ & $\begin{array}{l}\text { Road } \\
\text { length }\end{array}$ & $\begin{array}{c}2.196 \\
+0.902 \times \text { RD2.200 } \\
+2.367 \times \text { BSD.750 } \\
+0.002 \times \\
\text { TD.1000/DIST_RD1* } \\
-0.004 \times \text { ELEV } \\
+0.001 \times \text { TD.1000/DIST_RD2 } \\
+16.779 \times \text { IT1.750 }\end{array}$ & $\begin{array}{l}0.30 \\
0.16 \\
0.16 \\
0.14 \\
0.06 \\
0.04\end{array}$ & $\begin{array}{l}0.63 ; \\
0.60\end{array}$ & $\begin{array}{c}-0.40(0.59) \\
0.43\end{array}$ & $\begin{array}{c}0.00(0.40) \\
0.58\end{array}$ \\
\hline $\begin{array}{l}\log \mathrm{NO} \\
(112)\end{array}$ & $\begin{array}{l}\text { Vehicle } \\
\text { density }\end{array}$ & $\begin{array}{c}2.779 \\
-0.005 \times \text { ELEV } \\
+\mathbf{0 . 0 0 2} \times \mathbf{T D . 1 0 0 0 / D I S T R D 1} \\
-0.530 \times \text { DIST_RD2 } \\
+0.009 \times \text { POP.2500 } \\
+0.364 \times \text { BSD.100 } \\
+1.302 \times \mathbf{I T 2 . 2 0 0}\end{array}$ & $\begin{array}{l}0.16 \\
0.16 \\
0.10 \\
0.10 \\
0.07 \\
0.04\end{array}$ & $\begin{array}{l}0.56 \\
0.54\end{array}$ & $\begin{array}{c}-0.59(0.37) \\
0.58\end{array}$ & $\begin{array}{c}0.00(0.44) \\
0.50\end{array}$ \\
\hline $\begin{array}{l}\mathrm{NO}_{2} \\
(112)\end{array}$ & $\begin{array}{l}\text { Road } \\
\text { length }\end{array}$ & $\begin{array}{c}12.088 \\
+10.369 \times \text { RD2.100 } \\
-0.134 \times \text { DIST_SHORE } \\
+0.061 \times \text { POP.2500 } \\
-0.16 \times \text { OPEN.300 } \\
-0.018 \times \text { RES.750 } \\
+7.072 \times \text { RD1.100 } \\
-0.439 \times \text { DIST_RD1 }\end{array}$ & $\begin{array}{l}0.34 \\
0.29 \\
0.21 \\
0.12 \\
0.11 \\
0.09 \\
0.08\end{array}$ & $\begin{array}{c}0.71 \\
0.69\end{array}$ & $\begin{array}{c}0.26(2.12) \\
0.72\end{array}$ & $\begin{array}{c}0.01(1.98) \\
0.65\end{array}$ \\
\hline $\begin{array}{l}\mathrm{NO}_{2} \\
(112)\end{array}$ & $\begin{array}{l}\text { Vehicle } \\
\text { density }\end{array}$ & $\begin{array}{c}10.709 \\
+0.214 \times \text { TD.200 } \\
+0.061 \times \text { POP.2500 } \\
-0.134 \times \text { DIST_SHORE } \\
-0.130 \times \text { OPEN.300 } \\
-0.015 \times \text { RES.750 } \\
+2.678 \times \text { IT2.100 }\end{array}$ & $\begin{array}{l}0.27 \\
0.20 \\
0.17 \\
0.08 \\
0.07 \\
0.07\end{array}$ & $\begin{array}{c}0.68 \\
0.66\end{array}$ & $\begin{array}{c}-0.82(2.42) \\
0.62\end{array}$ & $\begin{array}{c}0.09(2.27) \\
0.57\end{array}$ \\
\hline
\end{tabular}


*Due to variable selection and modeling process for the 2010-enhanced models, "length model" was no longer an appropriate term for an equation including both road length variable and traffic density variable (TD.1000/DIST_RD1 refers to traffic density within a $1000 \mathrm{~m}$ buffer divided by distance to highway). For easy use and consistency with 2010 models, however, this term was still applied. 


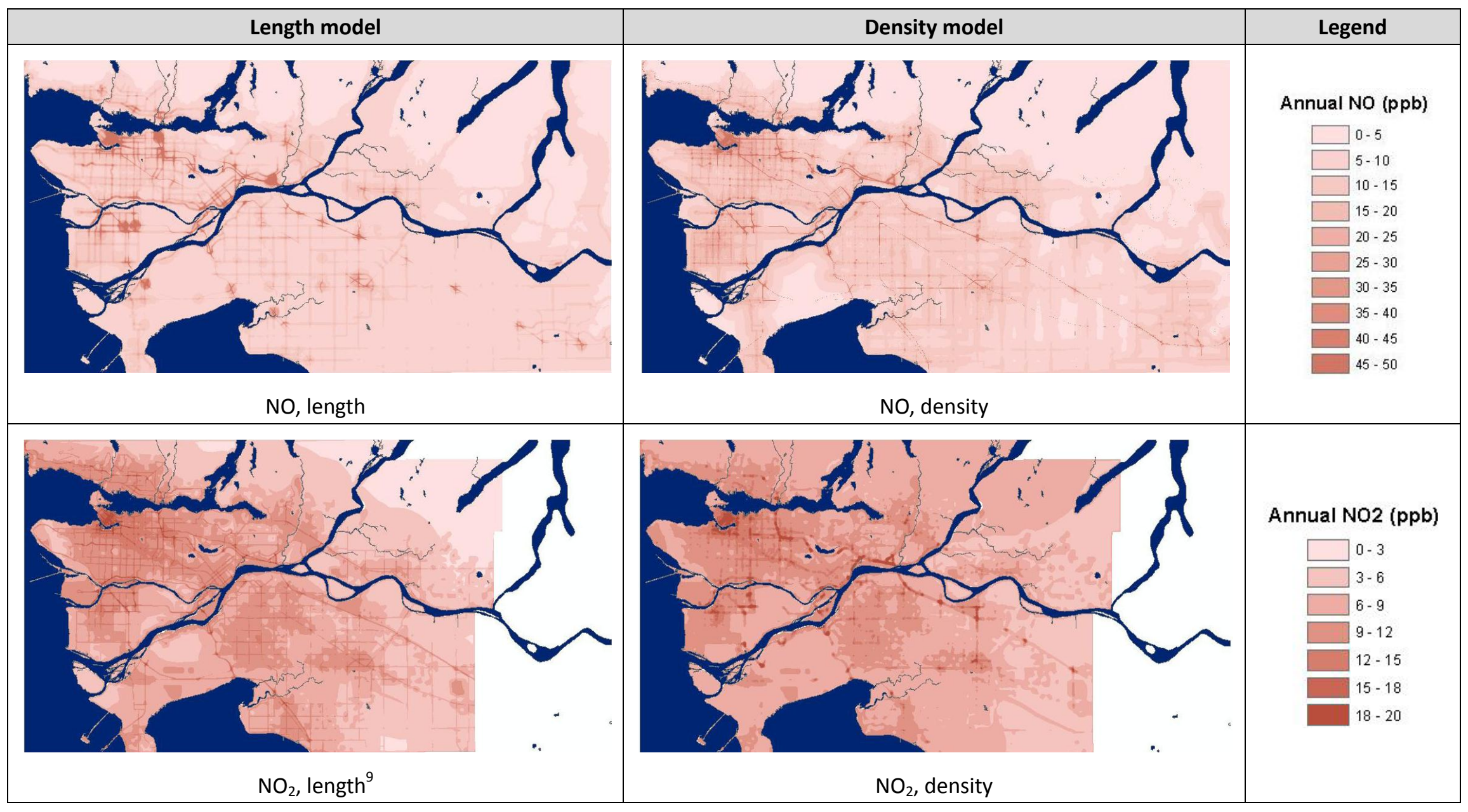

Figure 3.8 Maps of $\mathrm{NO}$ and $\mathrm{NO}_{2}$ concentrations estimated by 2010-enhanced models

\footnotetext{
${ }^{9}$ The 2010-enhanced $\mathrm{NO}_{2}$ models included predictor variables of land use which did not cover the entire study area. As a result, modeled surfaces were not available for parts of the region (as shown in the map. NO maps had full coverage because no land use variables were included in NO models.
} 
Table 3.7 Comparison of LUR models: 2003, 2010 and 2010-enhanced

\begin{tabular}{|c|c|c|c|c|c|c|}
\hline & \multicolumn{3}{|c|}{ Predictor variable (partial $\mathrm{R}^{2}$ ) } & \multicolumn{3}{|c|}{ Model Adjusted $\mathrm{R}^{2}$} \\
\hline & 2003 & 2010 & $\begin{array}{c}2010 \\
\text { - enhanced }\end{array}$ & 2003 & 2010 & $\begin{array}{c}2010 \\
\text { - enhanced }\end{array}$ \\
\hline $\begin{array}{l}\text { LogNO } \\
\text { (length) }\end{array}$ & $\begin{array}{l}\text { RD1.200 (0.22) } \\
\text { RD2.100 (0.36) } \\
\text { POP.2500 (0.07) } \\
\text { ELEV }(0.14) \\
\text { X }(0.06) \\
\text { Y }(0.04)\end{array}$ & $\begin{array}{l}\text { RD2.200 (0.39) } \\
\text { RD1.100 (0.12) } \\
\operatorname{ELEV~(0.08)~} \\
\text { RD1.1000 } \\
(0.05) \\
\text { X (0.12) }\end{array}$ & $\begin{array}{c}\text { RD2.200 }(0.30) \\
\text { BSD.750 }(0.16) \\
\text { TD.1000/Dist_RD1 }(0.16) \\
\text { ELEV }(0.14) \\
\text { TD.1000/Dist_RD2 }(0.06) \\
\text { IT1.750 }(0.04)\end{array}$ & 0.59 & 0.58 & 0.60 \\
\hline $\begin{array}{l}\text { LogNO } \\
\text { (density) }\end{array}$ & $\begin{array}{l}\text { AD.100 (0.12) } \\
\text { TD.1000 (0.19) } \\
\text { ELEV (0.07) } \\
\text { X (0.17) } \\
\text { Y }(0.12)\end{array}$ & $\begin{array}{c}\text { TD.200 (0.36) } \\
\text { POP.2500 (0.11) } \\
\text { ELEV }(0.09)\end{array}$ & $\begin{array}{c}\text { ELEV (0.16) } \\
\text { TD.1000/Dist_RD1 (0.16) } \\
\text { DIST_RD2 (0.10) } \\
\text { POP.2500 (0.10) } \\
\text { BSD.100 (0.07) } \\
\text { IT2.200 (0.04) }\end{array}$ & 0.55 & 0.53 & 0.54 \\
\hline $\begin{array}{c}\text { NO2 } \\
\text { (length) }\end{array}$ & $\begin{array}{l}\text { RD1.100 (0.14) } \\
\text { RD2.200 (0.10) } \\
\text { POP.2500 (0.08) } \\
\text { IND.750 (0.12) } \\
\text { X }(0.11) \\
\text { Y }(0.04)\end{array}$ & $\begin{array}{l}\text { RD2.100 (0.30) } \\
\text { RD1.100 (0.16) } \\
\text { DIST_RD1 } \\
\quad(0.14) \\
\text { POP.2500 }(0.11) \\
\quad \text { X }(0.18)\end{array}$ & $\begin{array}{c}\text { RD2.100 (0.34) } \\
\text { DIST_SHORE (0.29) } \\
\text { POP.2500 (0.21) } \\
\text { OPEN.300 (0.12) } \\
\text { RES.750 (0.11) } \\
\text { RD1.100 (0.09) } \\
\text { DIST_RD1 }(0.08)\end{array}$ & 0.52 & 0.63 & 0.69 \\
\hline $\begin{array}{c}\mathrm{NO} 2 \\
\text { (density) }\end{array}$ & $\begin{array}{c}\text { TD.200 }(0.08) \\
\text { POP.2500 (0.10) } \\
\text { ELEV }(0.07) \\
\text { TD.1000 (0.08) } \\
\text { X }(0.07)\end{array}$ & $\begin{array}{c}\text { TD.200 }(0.35) \\
\text { POP.2500 (0.08) } \\
\text { DIST_RD1 } \\
(0.07) \\
\text { X }(0.12)\end{array}$ & $\begin{array}{c}\text { TD.200 }(0.27) \\
\text { POP.2500 }(0.20) \\
\text { DIST_SHORE }(0.17) \\
\text { OPEN.300 }(0.08) \\
\text { RES.750 }(0.07) \\
\text { IT2.100 }(0.07)\end{array}$ & 0.55 & 0.62 & 0.66 \\
\hline
\end{tabular}




\section{Discussion}

LUR models have been used to estimate individual exposure under the assumption that spatial contrasts of pollutant concentrations are stable over time, so that a model developed in one time period can be retrospectively or prospectively applied at another period. However, this assumption has not been adequately verified. In Metro Vancouver, a set of LUR models were developed in 2003 (2003 models) and have been used both retrospectively and prospectively in a number of studies $[87,88,91]$, without evaluation of the extent to which these models can adequately predict concentrations in other time periods.

To evaluate the temporal stability of LUR models in exposure assessment, we measured $\mathrm{NO}$ and $\mathrm{NO}_{2}$ concentrations at 116 sampling sites in 2010 and used these measurements to develop LUR models (2010 models). A downward trend was observed when NO and $\mathrm{NO}_{2}$ measurements from 2003 were compared with those collected in 2010, consistent with a trend observed at the local monitoring network sites. Measurements taken in 2010 agreed well with those taken in 2003 (correlation $\mathrm{r}=0.87$ for $\mathrm{NO}$ and 0.74 for $\mathrm{NO}_{2}$ ). For $\mathrm{NO}$, a similar amount of variability in the measured concentrations was explained by the 2003 and 2010 models. For $\mathrm{NO}_{2}$, more variability was explained in 2010 than in 2003. The LUR models predicted spatial contrasts 7 years in the past (2010 models) and 7 years in the future (2003 models) well, supporting the validity of applying LUR models 
over time for as long as a 7-year period. Results also demonstrated that for an area where concentrations decreased over time, LUR models were more likely to retain their explanatory power in forecasting compared with in back-casting applications. Further, variables not previously tested in 2003 (e.g. bus stop density and intersection density) were included in the 2010 models producing only limited increases to the explanatory power of the models (1-6\% increase in adjusted $\mathrm{R}^{2}$ values). The following discussion revolves around three themes: downward trend in measured $\mathrm{NO}$ and $\mathrm{NO}_{2}$ concentrations, comparison of LUR models (2003 models, 2010 models, 2010-enhanced models), and temporal stability of LUR models.

\subsection{Downward trend in measured $\mathrm{NO} / \mathrm{NO}_{2}$ concentrations}

\subsubsection{Near-traffic NO concentrations under-represented at monitoring stations}

Compared with Metro Vancouver monitoring stations, our measurements captured a wider range of pollutant concentrations, especially high concentrations of NO. The primary pollutant emitted from vehicles is $\mathrm{NO}$, which is then transformed to $\mathrm{NO}_{2}$ via atmospheric reactions. Thus, NO concentrations decreased with increasing distance from the road while $\mathrm{NO}_{2}$ concentrations were more homogeneous over a larger area. Accordingly, $\mathrm{NO}$ is an indicator of localized traffic impacts while $\mathrm{NO}_{2}$ is an indicator of wider-scale traffic impacts. Given our objective to capture the full range of actual concentrations, our sampling sites were located both inside neighborhoods (away from 
traffic) and on curbside (close to traffic). Metro Vancouver Monitoring stations, in contrast, are mostly located several hundred meters away from major roads. Our results demonstrated that $\mathrm{NO}_{2}$ concentrations were well represented by the Metro Vancouver monitoring network stations while near-traffic NO concentrations were under-represented.

\subsubsection{Overall downward trend in $\mathrm{NO}$ and $\mathrm{NO}_{2}$ concentrations from 2003 to 2010}

A decreasing trend in air pollutant concentrations has been observed from the Metro Vancouver monitoring network stations over recent years [92]. Due to the limited number and spatial distribution of these monitoring stations, however, this trend could only indicate changes in urban background concentrations (at the lower range of concentrations), rather than changes in near-traffic locations. With a wider coverage of 73 measurements taken at exactly the same locations in 2003 and 2010, covering the full range and variability of the entire area, our study confirmed that this trend of decreasing concentrations was consistently observed throughout the airshed.

Both the Metro Vancouver station data and our measurements indicated a downward trend in $\mathrm{NO}$ and $\mathrm{NO}_{2}$ concentrations over the Metro Vancouver area, yet for $\mathrm{NO}$, our measurements showed a larger decrease (mean $(\mathrm{sd})$ decrease $=11.33(9.9) \mathrm{ppb}(\mathrm{n}=73))$ than those from the monitoring stations (mean $(\mathrm{sd})$ decrease $=5.52(3.65) \mathrm{ppb}(\mathrm{n}=20)$ ). This was likely because of differences in the spatial distribution of sampling sites. Thus 
our observations suggest that a significant reduction of NO concentrations occurred in near-traffic locations. For $\mathrm{NO}_{2}$, a secondary pollutant, estimated reductions were similar between the two measurements with a mean (sd) decrease of 2.4 (3.2) ppb based on our measurements and of 2.9 (1.0) ppb based on station measurements. Along those lines, we infer that monitoring stations, mostly located at background sites, are accurate in estimating concentrations and temporal trends for secondary air pollutants, but may under- or over- estimate temporal trends for primary pollutants.

\subsubsection{Locations with increased concentrations}

Despite the general downward trend, increases in NO concentrations were measured at six sites and increases in $\mathrm{NO}_{2}$ concentrations were measured at sixteen sites (out of 73 sites in total). Among the 20 Metro Vancouver monitoring stations, no such increases were observed. While most of the increases were minimal (less than $1 \mathrm{ppb}$, within the precision of Ogawa samplers), a significant increase in $\mathrm{NO}_{2}$ concentration was measured at one location (Site ID 37, measured $\mathrm{NO}_{2}$ was 7.09 ppb in 2003 and $18.11 \mathrm{ppb}$ in 2010). This site was adjacent to a bus stop (within $3 \mathrm{~m}$ distance) in 2010. Thus it is possible that the increase was brought about by a newly built bus stop or a shift in traffic routes. Alternatively, measurement error may also explain this observation. 


\subsection{Comparison of LUR models: 2003, 2010 and 2010-enhanced}

\subsubsection{Increased $\mathrm{R}^{2}$ in $\mathrm{NO}_{2}$ models from 2003 to 2010}

For NO, the 2003 models and 2010 models explained a similar amount of variability in measured concentrations (adjusted $\mathrm{R}^{2}=0.59$ and 0.55 in 2003, 0.58 and 0.53 in 2010, for the length and density model respectively). For $\mathrm{NO}_{2}$ a larger proportion of variability was explained by the 2010 models than by the 2003 model (adjusted $\mathrm{R}^{2}=0.52$ and 0.55 in 2003, 0.66 and 0.63 in 2010). Both the 2003 and 2010 measurements shared the same sampling instruments (Ogawa samplers) and the same technique (Ion Chromatography) to derive concentrations. Models were developed using the same input variables and modeling process. Differences in sampling periods may have affected precision of the estimated annual averages, but should have a limited effect on the precision of the spatial contrast. Thus the increase in $\mathrm{R}^{2}$ values for $\mathrm{NO}_{2}$ models from 2003 to 2010 was likely due to improvements in geographic data quality (quality of input predictive variables) and the lower variability in 2010 concentrations compared with that in 2003 .

\subsubsection{Two traffic metrics: road length versus traffic density}

As in 2003, we constructed LUR models using two types of traffic metrics: road length and traffic density. Road length variables assume an even distribution of traffic along all roads of similar classification, which is not likely to be the case in reality. For example, some roads are busier than others. Traffic density was intended to capture this difference 
and was thus expected to produce better model fit. However, the two metrics produced essentially the same model fit (similar adjusted $\mathrm{R}^{2}$ values and error estimates between road length models and traffic density models) in both 2003 and 2010. This may reflect errors in the EMME/2 traffic flow model, from which we derived traffic density data [24]. The error could be potentially due to saturation of roads during peak traffic periods such that all roads of a similar classification actually do have the same level of traffic during periods of peak traffic and therefore all roads of same classification have similar levels of daily and annual traffic (personal communication with Clark Lim).

Models based on the two traffic metrics produced different validation results (against monitoring stations) in 2003 and in 2010. In 2003, with similar model $\mathrm{R}^{2}$ values, the traffic density models predicted spatial contrasts better at monitoring stations than the road length models did (considerably higher $\mathrm{R}^{2}$ values, with difference $>0.10$ ) [24]. In 2010 , however, the road length models produced higher $\mathrm{R}^{2}$ values than the traffic density model, though the difference was limited $\left(<0.04\right.$ difference in $\mathrm{R}^{2}$ values). In 2003 , the traffic density models seemed better able to predict low concentrations at monitoring stations more distant from traffic but in 2010, this advantage was not seen. Reasons for this change are not clear. The quality of data for the traffic density variables in relation to the model parameters may have contributed to this switch. 


\subsubsection{From 2010 to 2010 -enhanced: limited improvement from inclusion of new variables}

With advances in understanding and data availability, new variables such as wind direction [69] and greenness index [93] have been successfully incorporated into LUR modeling. To evaluate whether incorporation of additional variables could improve LUR models, we added new input variables to develop our 2010-enhanced model. These variables included density estimates (bus stop density, intersection density, building density [26]), distance to pollutant sources (distance to port, distance to seashore [24]), greenness index [93], wind direction in relation to roads [69], as well as some combination/different formulations of variables. In addition, land use data from DMTI Spatial Inc. (used to develop the 2003 and 2010 models) were replaced by data from Metro Vancouver (the regional municipality). The latter was considered more accurate by local knowledge. It also had more detailed land use categories.

The 2010-enhanced LUR models, however, did not prove to explain substantially greater amounts of variability than the 2010 models. The 2010-enhanced models explained only slightly more variability in $\mathrm{NO}$ and $\mathrm{NO}_{2}$ concentrations in 2010 (0.01-0.03 increase in adjusted $\mathrm{R}^{2}$ values) compared to the 2010 models built using the original set of potential input variables. Compared with the 2010 models, the 2010-enhanced models produced less agreement with measurements from Metro Vancouver stations $\left(\mathrm{R}^{2}=0.43-0.72\right.$ for 2010-enhanced models and $0.68-0.88$ for 2010 models). Despite this limited 
improvement, latitude and longitude were excluded from all the 2010-enhanced models. In 2010 models, longitude was included in three (out of four) model equations and it explained a substantial fraction of variability (second most important explanatory variable based on partial $\mathrm{r}^{2}$ value); and in 2003 models, latitude and longitude appeared consistently throughout all models. As the $\mathrm{X}$ and $\mathrm{Y}$ coordinates are likely surrogates for other undefined variables, we considered their replacement with other specific variables, such as bus stop and intersection density, as an improvement.

We attempted to incorporate wind - an important meteorological factor that influences surface distribution of air pollutants [21]- into our LUR modeling, but the attempt was not successful. In other studies, inclusion of wind has led to marginal improvements in model predictive power . Arain et al (2006) developed a methodology to include wind effects in LUR models using interpolated wind direction based on a network of 38 weather stations in the Toronto-Hamilton urban airshed [21]. The incorporation of wind fields raised $\mathrm{R}^{2}$ values from 0.65 to 0.69 for the Toronto $\mathrm{NO}_{2}$ surface, and from 0.75 to 0.76 for the Hamilton $\mathrm{NO}_{2}$ surface. Higher pollutant concentrations were observed downwind of major expressways on modeled $\mathrm{NO}_{2}$ surfaces, in both Toronto and Hamilton, as expected based on source-receptor relations [21]. Su et al (2008) developed an innovative source area LUR (SA-LUR) model which integrated wind speed, wind direction and cloud cover/insulation. The SA-LUR model produced better estimates of hourly $\mathrm{NO}$ and $\mathrm{NO}_{2}$ concentrations than regular LUR models at routine sites $\left(\mathrm{R}^{2}\right.$ 
increased from $61 \%$ to $86 \%$ for $\mathrm{NO}$, and from $78 \%$ to $92 \%$ for $\mathrm{NO}_{2}$ ) [65]. In another LUR study in Portland, Oregon, inclusion of wind direction increased model predictive power by $15 \%$ [28]. In our study, without field measurements, we manually coded the wind variable as downwind or upwind in relation to roads, assuming a general westward wind direction for the entire study area based on annual average wind direction at 16 locations in the Metro Vancouver region ${ }^{10}$. Better data (such as field measurements) may help explain more variability in our models.

\subsection{Temporal stability of LUR models - exposure assessment for epidemiological studies}

The primary motivation of this study was to evaluate the temporal stability of LUR models to retrospectively or prospectively estimate chronic exposure to traffic-related air pollution in ongoing epidemiologic studies. Our study fulfilled this goal by comparing model predictions and actual measurements in Metro Vancouver over a 7-year period. Four methods of extending a model over time were explored. Overall our results support the validity of extending a LUR model in time for exposure assessment in this setting.

Applying a temporal trend proved to be a simple and acceptable means to temporally extend LUR models in Vancouver. This method adjusts absolute concentrations rather than spatial contrasts between two time periods. Both the 2003 models and 2010 models

\footnotetext{
10 Tim Oke and John Hay. The Climate of Vancouver. 2nd edition. B.C Geographical series, number 50. 1994. Page 50.
} 
explained a moderate fraction of variability in measured $\mathrm{NO}$ and $\mathrm{NO}_{2}$ concentrations (adjusted $\mathrm{R}^{2}=0.52-0.66$ ). When extended in time (Table 3.5), the 2003 LUR models explained 54-60\% variability in 2010 measurements, more than they did in 2003 measurements (52-59\%). The 2010 models, on the other hand, explained $44-52 \%$ variability in 2003 measurements, less than they did in 2010 measurements (53-63\%). These results suggest that the 2003 LUR models were able to prospectively predict spatial contrasts over a 7-year periods, and that the 2010 models were able to retrospectively identify spatial contrasts over the same time frame, in spite of reduced explanatory power.

The decreased explanatory power in the back-casting scenario is consistent with the observed downward trend in $\mathrm{NO} / \mathrm{NO}_{2}$ concentrations and data characteristics of our measurements. The measured concentrations in 2003 were more variable than those in 2010, with more values at the extremes. As a result, models fitted to such data will tend to have lower $\mathrm{R}^{2}$ values and to more accurately estimate values in the middle of the distribution than those at the extremes. Thus the 2003 models were expected to predict 2010 concentrations well since the distribution was limited to the range in which we expected 2003 models to be most applicable (as observed in our forecasting scenario). On the contrary, the 2010 measurements were less variable and consequently, models fitted to such data tended to have higher $\mathrm{R}^{2}$ values, but would not be able to precisely predict 2003 extreme values. Thus, for locations/airsheds where concentrations are 
decreasing over time, a model is more likely to retain its explanatory power in forecast than in back-cast applications.

Hence, while LUR models can be extended forward in time with confidence for an area where pollutant concentrations are decreasing over time (e.g. Metro Vancouver), caution needs to be exercised in retrospective application, especially for subjects living near traffic. Exposure levels for these subjects tends to be high and potentially beyond the concentrations range on which the models were built, which can contribute to exposure misclassification. Verification with other types of measurements, such as personal monitoring [94], may help reduce the uncertainty in exposure estimates by LUR models.

A similar study was conducted recently in the Netherlands, testing the extent that LUR models can adequately predict concentrations in earlier or later time periods [95]. Their analysis reported that measured spatial contrasts in outdoor $\mathrm{NO}_{2}$ in 1999-2000 and 2007 agreed well with each other, and that LUR models could accurately predict spatial contrasts 8 years in the past and 8 years in the future. LUR models from 1999-2000 and 2007 explained $85 \%$ and $86 \%$ of observed spatial variability, respectively. The 2007 LUR model explained $77 \%$ of spatial variability in the $1999-2000$ measurements and the 1999-2000 model explained $81 \%$ of variability in the 2007 measurements. These results support the use of the LUR model to predict concentrations at an earlier or later time. Despite similar study goals, differences between the study conducted in The Netherlands and our study for Metro Vancouver included: 1) The Netherlands study had a much 
larger study area $\left(41,848 \mathrm{~km}^{2}\right.$, national-wide) than ours $\left(2,877 \mathrm{~km}^{2}\right.$, an urban setting);

2) They used an indicator variable for different spatial scales while we did not use ; 3)

We had a greater spatial contrast in $\mathrm{NO}_{2}$ concentrations over time; 4) the Netherlands LUR models explained more variability in $\mathrm{NO}_{2}$ concentrations. In spite of all the differences, both studies found good agreement between $\mathrm{NO}_{2}$ concentrations measured at two time periods, both support the use of LUR models in epidemiologic studies based on the findings that LUR models predicted spatial contrast well in forecasting and back-casting, and both studies observed a decrease in the models' explanatory power in back-casting scenarios, which is likely to be attributed to the observed downward trend in pollutant concentrations.

Another study conducted in Rome (Italy) [96] (only an abstract available by the time this thesis was written), compared two LUR models from 1995/96 and 2007, over a decade apart. With similar mean $\mathrm{NO}_{2}$ concentrations and similar model $\mathrm{R}^{2}$ values in the two time periods, the authors concluded that the two models were comparable despite the inclusion of different variables in the models, and that the LUR approach was useful for a large cohort over a long period of time.

Updating predictor variables, the second method in extending models in time, achieved similar success as the first method in predicting spatial contrast (measured by $\mathrm{R}^{2}$ of model predictions against actual measurements), but with reduced accuracy (measured by error means). This supported our conclusion that the downward trend in $\mathrm{NO}$ and $\mathrm{NO}_{2}$ 
concentrations was a regional trend.

Although we found that updating predictor variables was equivalent in predicting spatial contrasts to the application of a temporal trend, the results may vary under different situations, depending on the association between predictor variables included in a specific model and the change in pollutant concentrations. As Molter (2010) noted, temporal changes in predictor variables do not necessarily lead to changes in pollutant concentrations [86]. For example, concentrations may remain the same with increased traffic volume and decreased vehicle emission rates because one factor counteracts the other. Because predictor variables were selected based on their relationship with concurrent concentrations, rather than based on their relationship with change in concentrations over time, it is possible that one LUR model may be better at capturing changes in spatial contrast than the other, if it includes predictor variables that are associated with changes in pollutant concentrations while the other model does not. For example, in our back-casting scenarios for NO, updating predictor variables produced a higher $\mathrm{R}^{2}$ value $\left(\mathrm{R}^{2}=0.54\right)$ than applying a temporal trend $\left(\mathrm{R}^{2}=0.50\right)$ using the road length model. However, the results switched for the traffic density model, when the $\mathrm{R}^{2}$ value from updating predictor variables $\left(\mathrm{R}^{2}=0.38\right)$ was less than that from applying a temporal trend $\left(\mathrm{R}^{2}=0.45\right)$. This warrants caution in using this method when factors contributing to change in pollutant concentrations are unknown and not reflected in the predictor variables. 
In the third method, we combined the previous two methods by applying a temporal trend and updating the values of predictor variables. Compared with updating predictor variable values only, the joint method produced the same $\mathrm{R}^{2}$ values but reduced the mean errors. This was expected because adding a temporal trend does not improve prediction of spatial contrasts, but it does account for a change in background concentrations in the entire study area. Compared with applying a temporal trend only, results from the joint method varied (both $\mathrm{R}^{2}$ values and error means), depending on pollutant $\left(\mathrm{NO} / \mathrm{NO}_{2}\right)$, model type (road length/traffic density) and temporal direction (forecasting/back-casting). Overall, the joint method was better than updating predictor variable values only, but may or may not be better than applying a temporal trend only, depending on the specific case.

The final method was to calibrate an existing model using concurrent measurements. Compared with the previous three methods (applying a temporal trend, updating predictor variables, and joint methods), the calibration method produced the best estimates (highest $\mathrm{R}^{2}$ values and lowest error mean) in our forecasting scenarios (using calibrated 2003 models to predict concentrations in 2010). This is consistent with the fact that the 2003 predictor variables are as good as 2010 predictor variables in estimating spatial contrasts in $\mathrm{NO}$ and $\mathrm{NO}_{2}$ concentrations. On the other hand, in back-casting (using calibrated 2010 models to predict concentrations in 2003), this calibration method did not provide better predictions than other methods. 
Only two studies were found to have explored temporally transferring LUR models using calibration methods. For the first LUR model, Briggs et al (1997) have tested its temporal transferability using the calibration method [17]. With the initial LUR model developed from 80 measurements in Huddersfield UK, they calibrated the model for the following year using measurements taken at 10 randomly selected sites. The initial model explained $60 \%$ variability in $\mathrm{NO}_{2}$ concentrations and the calibrated model explained $51 \%$ variability in the following year. Model performance was further evaluated by comparing model predictions and actual measurements at another 10 sites, with an $\mathrm{R}^{2}$ value of 0.76 . It was concluded that the model might thus be used as a means of mapping long-term air pollution concentrations. Due to its short temporal window (less than one year), the study cannot speak to the long-term stability of LUR models. Molter et al (2010) recently applied this temporal calibration method to Manchester [86]. Instead of obtaining actual measurements for calibration, they used data from an air dispersion model to produce individual LUR models for $\mathrm{NO}_{2}$ and $\mathrm{PM}_{10}$ concentrations for each year from 1996 to 2008, based on an original LUR model developed in 2005. Those calibrated $\mathrm{NO}_{2}$ models showed consistently high $\mathrm{R}^{2}$ values when predictions were compared with measured concentrations at monitoring stations. Their study provided a novel approach of using a dispersion model to transfer LUR models in time.

In summary, the results of transferring Metro Vancouver LUR models over a 7-year period suggest: 
1) The background reduction in $\mathrm{NO}$ and $\mathrm{NO}_{2}$ concentrations was largely associated with factors that were not included as predictor variables in our LUR modeling; emission reduction is a likely cause.

2) Because of the decreasing trend, the 2003 models are more "stable" in forecasting than are the 2010 models in back-casting. The 2003 models explained more variability in 2010 concentrations than the 2010 models did in 2003 concentrations.

3) The spatial contrast of pollutant concentrations have largely remained the same in Metro Vancouver, over the period between 2003 and 2010, although this conclusion is limited by the original strength of the models to explain variability in pollutant concentrations. With a substantial fraction of variability unexplained, our LUR model may have failed to detect a shift in spatial contrasts.

4) None of the methods for temporal transfer were found to be consistently better than others. In the case of Metro Vancouver, applying a temporal trend might be a most favored cost-effective approach. For other areas, choosing an appropriate method depends on model specifics, local conditions and data availability. 


\section{Conclusion}

This study fulfilled its original objectives. The Metro Vancouver 2003 LUR models for $\mathrm{NO}$ and $\mathrm{NO}_{2}$ were updated to 2010, providing an up-to-date exposure assessment tool to facilitate epidemiological studies, as well as evaluation of air quality management programs. The changes in $\mathrm{NO}$ and $\mathrm{NO}_{2}$ concentrations were assessed by comparing measured concentrations in 2003 and 2010. An overall reduction was confirmed, likely caused by emission reduction throughout the entire study area. In addition, the temporal stability of the LUR models was evaluated by comparing model prediction with actual measurements. The observed agreements verified the assumption that LUR models developed from a particular time point could be applied to other time points. Thus it strengthened the validity of applying LUR models to cohort studies where recruitment and follow-up occurs over 5-10 years. Finally, the 2010 models were enhanced by a moderate increase in explained variability of $\mathrm{NO}$ and $\mathrm{NO}_{2}$ concentrations when new predictor variables were introduced.

One of the major strengths of this study is that we applied four methods to extend LUR models in time. The results not only demonstrated the temporal stability of the models in every situation, but also pointed out that selecting an appropriate method fit to local condition would help improve the accuracy of exposure estimates. Another strength was our large sample size, 116 measurements designated to cover the full range and 
variability of $\mathrm{NO}$ and $\mathrm{NO}_{2}$ concentrations throughout the study area. Among the 116 measurements, 73 were taken at exactly the same location in 2003 and 2010, which enabled us to assess the trend in pollutant concentrations between the two periods with higher spatial accuracy than that from monitoring stations. This study also has several limitations. First, our two two-week sampling periods resulted in under-estimated measurements of annual means in 2010. This underestimation is likely to explain why, in extending models in time, forecasting produced overestimation and back-casting produced underestimation. However, it is not likely to affect our conclusions regarding LUR models' temporal stability which emphasizes relative (spatial contrast) rather than absolute concentrations. Another limitation is that a certain amount of variability in NO and $\mathrm{NO}_{2}$ concentrations remain unexplained by the LUR models.

In conclusion, this study demonstrated the temporal stability of LUR model in Metro Vancouver over a period of 7 years, supporting their application in epidemiological studies to estimate subjects' long-term exposure to traffic-related air pollutants. 


\section{References}

1. Gilliland F, Avol E, Kinney P, Jerrett M, Dvonch T, Lurmann F, Buckley T, Breysse $\mathrm{P}$, Keeler $\mathrm{G}$, de Villiers $\mathrm{T}$ et al: Air pollution exposure assessment for epidemiologic studies of pregnant women and children: lessons learned from the Centers for Children's Environmental Health and Disease Prevention Research. Environ Health Perspect 2005, 113(10):1447-1454.

2. Glinianaia SV, Rankin J, Bell R, Pless-Mulloli T, Howel D: Particulate air pollution and fetal health a systematic review of the epidemiologic evidence. Epidemiology 2004, 15(1):36-45.

3. Jerrett M, Arain A, Kanaroglou P, Beckerman B, Potoglou D, Sahsuvaroglu T, Morrison J, Giovis C: A review and evaluation of intraurban air pollution exposure models. Journal of Exposure Analysis and Environmental Epidemiology 2005, 15(2):185-204.

4. Monn C: Exposure assessment of air pollutants: A review on spatial heterogeneity and indoor/outdoor/personal exposure to suspended particulate matter, nitrogen dioxide and ozone. Atmospheric Environment 2001, 35(1):1-32.

5. Brunekreef $B$, Janssen $\mathrm{NAH}$, deHartog J, Harssema $\mathrm{H}$, Knape $\mathrm{M}$, vanVliet $\mathrm{P}$ : Air pollution from truck traffic and lung function in children living near motorways. Epidemiology 1997, 8(3):298-303.

6. Janssen $\mathrm{NAH}$, Brunekreef $\mathrm{B}$, van Vliet $\mathrm{P}$, Aarts F, Meliefste $\mathrm{K}$, Harssema H, Fischer $P$ : The relationship between air pollution from heavy traffic and allergic sensitization, bronchial hyperresponsiveness, and respiratory symptoms in Dutch schoolchildren. Environmental Health Perspectives 2003, 111(12):1512-1518.

7. Janssen NAH, van Vliet PHN, Aarts F, Harssema H, Brunekreef B: Assessment of exposure to traffic related air pollution of children attending schools near motorways. Atmospheric Environment 2001, 35(22):3875-3884.

8. Kim JJ, Smorodinsky S, Lipsett M, Singer BC, Hodgson AT, Ostro B: Traffic-related air pollution near busy roads - The East Bay children's respiratory health study. American Journal of Respiratory and Critical Care Medicine 2004, 170(5):520-526.

9. van Vliet P, Knape M, de Hartog J, Janssen N, Harssema H, Brunekreef B: Motor vehicle exhaust and chronic respiratory symptoms in children living near freeways. Environ Res 1997, 74(2):122-132.

10. Aguilera I, Sunyer J, Fernandez-Patier R, Hoek G, -Alfaro AA, Meliefste K, Bomboi-Mingarro MT, Nieuwenhuijsen MJ, Herce-Garraleta D, Brunekreef B: Estimation of outdoor NOx, NO2, and BTEX exposure in a cohort of 
pregnant women using land use regression modeling. Environmental Science \& Technology 2008, 42(3):815-821.

11. Bell ML: The use of ambient air quality modeling to estimate individual and population exposure for human health research: A case study of ozone in the Northern Georgia Region of the United States. Environment International 2006, 32(5):586-593.

12. Liao DP, Peuquet DJ, Duan YK, Whitsel EA, Dou JW, Smith RL, Lin HM, Chen JC, Heiss G: GIS approaches for the estimation of residential-level ambient PM concentrations. Environmental Health Perspectives 2006, 114(9):1374-1380.

13. Briggs $D$ : The role of GIS: Coping with space (and time) in air pollution exposure assessment. Journal of Toxicology and Environmental Health - Part $A$ 2005, 68(13-14):1243-1261.

14. Aguilera I, Sunyer J, Fernandez-Patier RJ, Esteban RG, Bomboi T: Using land-use regression modeling to estimate exposure to VOCs in a cohort of pregnant women. Epidemiology 2007, 18(5):S42-S43.

15. Brauer M, Ainslie B, Buzzelli M, Henderson S, Larson T, Marshall J, Nethery E, Steyn D, Su J: Models of Exposure for Use in Epidemiological Studies of Air Pollution Health Impacts. In: Nato Sci Peace Secur. 2008: 589-604.

16. Briggs DJ, Collins S, Elliott P, Fischer P, Kingham S, Lebret E, Pryl K, VAnReeuwijk $\mathrm{H}$, Smallbone $\mathrm{K}$, VanderVeen A: Mapping urban air pollution using GIS: a regression-based approach. International Journal of Geographical Information Science 1997, 11(7):699-718.

17. Briggs DJ, de Hoogh C, Guiliver J, Wills J, Elliott P, Kingham S, Smallbone K: A regression-based method for mapping traffic-related air pollution: application and testing in four contrasting urban environments. Science of the Total Environment 2000, 253(1-3):151-167.

18. Brauer M, Hoek G, van Vliet P, Meliefste K, Fischer P, Gehring U, Heinrich J, Cyrys J, Bellander $T$, Lewne $M$ et al: Estimating long-term average particulate air pollution concentrations: Application of traffic indicators and geographic information systems. Epidemiology 2003, 14(2):228-239.

19. Briggs et al. D.J. Briggs AA, C. Dore, G. Hoek, M. Petrakis and G. Shaddick: Air pollution modelling for support to policy on health and environmental risks in Europe, Final Report Section 6. Imperial College, London 2005, EVK2-2002-00176.

20. Cyrys J, Hochadel M, Gehring U, Hoek G, Diegmann V, Brunekreef B, Heinrich J: GIS-based estimation of exposure to particulate matter and NO2 in an urban area: Stochastic versus dispersion modeling. Environmental Health Perspectives 2005, 113(8):987-992.

21. Arain MA, Blair R, Finkelstein N, Brook JR, Sahsuvaroglu T, Beckerman B, Zhang $L$, Jerrett $M$ : The use of wind fields in a land use regression model to predict air pollution concentrations for health exposure studies. 
Atmospheric Environment 2006, 41(16):3453-3464.

22. Hochadel M, Heinrich J, Gehring U, Morgenstern V, Kuhlbusch T, Link E, Wichmann HE, Kramer U: Predicting long-term average concentrations of traffic-related air pollutants using GIS-based information. Atmospheric Environment 2006, 40(3):542-553.

23. Mukerjee S, Smith L, Liao X, Neas L, Stallings C, Johnson M: Spatial analysis of air pollution and development of a land-use regression (LUR) model in an urban airshed. Epidemiology 2006, 17(6):S481-S481.

24. Henderson SB, Beckerman B, Jerrett M, Brauer M: Application of land use regression to estimate long-term concentrations of traffic-related nitrogen oxides and fine particulate matter. Environmental Science \& Technology 2007, 41(7):2422-2428.

25. Morgenstern V, Zutavern A, Cyrys J, Brockow I, Gehring U, Koletzko S, Bauer CP, Reinhardt D, Wichmann HE, Heinrich J: Respiratory health and individual estimated exposure to traffic-related air pollutants in a cohort of young children. Occup Environ Med 2007, 64(1):8-16.

26. Atari DO, Luginaah I, Xu XH, Fung K: Spatial Variability of Ambient Nitrogen Dioxide and Sulfur Dioxide in Sarnia, Chemical Valley, Ontario, Canada. Journal of Toxicology and Environmental Health-Part a-Current Issues 2008, 71(24):1572-1581.

27. Clougherty JE, Wright RJ, Baxter LK, Levy JI: Land use regression modeling of intra-urban residential variability in multiple traffic-related air pollutants. Environmental Health 2008, 7:-.

28. Mavko ME, Tang B, George LA: A sub-neighborhood scale land use regression model for predicting NO2. Science of the Total Environment 2008, 398(1-3):68-75.

29. Mukerjec S, Smith L, Chung K, Johnson M, Stallings C, Neas L: Comparison of Land Use Regression Models for NO2 and VOC Exposure Studies in Three Cities. Epidemiology 2008, 19(6):S131-S131.

30. Rosenlund M, Forastiere F, Stafoggia M, Porta D, Perucci M, Ranzi A, Nussio F, Perucci CA: Comparison of regression models with land-use and emissions data to predict the spatial distribution of traffic-related air pollution in Rome. Journal of Exposure Science and Environmental Epidemiology 2008, 18(2):192-199.

31. Ryan PH, LeMasters GK, Levin L, Burkle J, Biswas P, Hu SH, Grinshpun S, Reponen T: A land-use regression model for estimating microenvironmental diesel exposure given multiple addresses from birth through childhood. Science of the Total Environment 2008, 404(1):139-147.

32. Yanosky JD, Paciorek CJ, Schwartz J, Laden F, Puett R, Suh HH: Spatio-temporal modeling of chronic PM10 exposure for the Nurses' Health Study. Atmos Environ 2008, 42(18):4047-4062. 
33. Yanosky JD, Schwartz J, Suh HH: Associations Between Measures of Socioeconomic Position and Chronic Nitrogen Dioxide Exposure in Worcester, Massachusetts. Journal of Toxicology and Environmental Health-Part a-Current Issues 2008, 71(24):1593-1602.

34. Atari DO, Luginaah $I N$ : Assessing the distribution of volatile organic compounds using land use regression in Sarnia, "Chemical Valley", Ontario, Canada. Environmental Health 2009, 8:-.

35. Beelen R, Hoek G, Pebesma E, Vienneau D, de Hoogh K, Briggs DJ: Mapping of background air pollution at a fine spatial scale across the European Union. Science of the Total Environment 2009, 407(6):1852-1867.

36. Eeftens M, Beelen R, Brunekreef B, Meliefste K, Hoek G: Extrapolation of Land-Use Regression Models in Time. Epidemiology 2009, 20(6):S69-S69.

37. Kashima S, Yorifuji T, Tsuda T, Doi H: Application of land use regression to regulatory air quality data in Japan. Science of the Total Environment 2009, 407(8):3055-3062.

38. Larson T, Henderson SB, Brauer M: Mobile Monitoring of Particle Light Absorption Coefficient in an Urban Area as a Basis for Land Use Regression. Environmental Science \& Technology 2009, 43(13):4672-4678.

39. Liu Y, Paciorek CJ, Koutrakis P: Estimating Regional Spatial and Temporal Variability of PM2.5 Concentrations Using Satellite Data, Meteorology, and Land Use Information. Environmental Health Perspectives 2009, 117(6):886-892.

40. Mukerjee S, Smith LA, Johnson MM, Neas LM, Stallings CA: Spatial analysis and land use regression of VOCs and NO2 from school-based urban air monitoring in Detroit/Dearborn, USA. Science of the Total Environment 2009, 407(16):4642-4651.

41. Poplawski K, Gould T, Setton E, Allen R, Su J, Larson T, Henderson S, Brauer M, Hystad $\mathrm{P}$, Lightowlers $\mathrm{C}$ et al: Intercity transferability of land use regression models for estimating ambient concentrations of nitrogen dioxide. Journal of Exposure Science and Environmental Epidemiology 2009, 19(1):107-117.

42. Porta D, Cesaroni G, Badaloni C, Stafoggia M, Meliefste K, Forastiere F, Perucci CA: Nitrogen Dioxide Spatial Variability in Rome (Italy): An Application of the LUR Model Over a Decade. Epidemiology 2009, 20(6):S121-S121.

43. Su JG, Jerrett M, Beckerman B, Wilhelm M, Ghosh JK, Ritz B: Predicting traffic-related air pollution in Los Angeles using a distance decay regression selection strategy. Environmental Research 2009, 109(6):657-670.

44. Vienneau D, de Hoogh K, Briggs D: A GIS-based method for modelling air pollution exposures across Europe. Science of the Total Environment 2009, 408(2):255-266.

45. Yanosky JD, Paciorek CJ, Suh HH: Predicting chronic fine and coarse particulate exposures using spatiotemporal models for the Northeastern 
and Midwestern United States. Environ Health Perspect 2009, 117(4):522-529.

46. Wilton D, Szpiro A, Gould T, Larson T: Improving spatial concentration estimates for nitrogen oxides using a hybrid meteorological dispersion/land use regression model in Los Angeles, CA and Seattle, WA. Science of the Total Environment 2010, 408(5):1120-1130.

47. Clark NA, Demers PA, Karr CJ, Koehoorn M, Lencar C, Tamburic L, Brauer M: Effect of early life exposure to air pollution on development of childhood asthma. Environ Health Perspect, 118(2):284-290.

48. Brauer M, Hoek G, Van Vliet P, Meliefste K, Fischer PH, Wijga A, Koopman LP, Neijens HJ, Gerritsen J, Kerkhof $M$ et al: Air pollution from traffic and the development of respiratory infections and asthmatic and allergic symptoms in children. American Journal of Respiratory and Critical Care Medicine 2002, 166(8):1092-1098.

49. Gehring U, Cyrys J, Sedlmeir G, Brunekreef B, Bellander T, Fischer P, Bauer CP, Reinhardt D, Wichmann HE, Heinrich J: Traffic-related air pollution and respiratory health during the first 2 yrs of life. European Respiratory Journal 2002, 19(4):690-698.

50. Brauer M, Gehring U, Brunekreef B, de Jongste J, Gerritsen J, Rovers M, Wichmann HE, Wijga A, Heinrich J: Traffic-related air pollution and otitis media. Environmental Health Perspectives 2006, 114(9):1414-1418.

51. LeMasters GK, Wilson K, Levin L, Biagini J, Ryan P, Lockey JE, Stanforth S, Maier S, Yang J, Burkle J et al: High prevalence of aeroallergen sensitization among infants of atopic parents. Journal of Pediatrics 2006, 149(4):505-511.

52. Brauer M, Hoek G, Smit HA, de Jongste JC, Gerritsen J, Postma DS, Kerkhof M, Brunekreef $B$ : Air pollution and development of asthma, allergy and infections in a birth cohort. European Respiratory Journal 2007, 29(5):879-888.

53. Cesaroni G, Badaloni C, Porta D, Forastiere F, Perucci CA: Traffic-related air pollution based on self-report; GIS, and land-use regression and respiratory health in adults. Epidemiology 2007, 18(5):S128-S128.

54. Slama R, Morgenstern V, Cyrys J, Zutavern A, Herbarth O, Wichmann HE, Heinrich J, Group LS: Traffic-related atmospheric pollutants levels during pregnancy and offspring's term birth weight: a study relying on a land-use regression exposure model. Environmental Health Perspectives 2007, 115(9):1283-1292.

55. Brauer M: A cohort study of traffic related air-pollution impacts on birth outcomes (vol 116, pg 680, 2008). Environmental Health Perspectives 2008, 116(12):A519-A519.

56. Morgenstern V, Zutavern A, Cyrys J, Brockow I, Koletzko S, Kramer U, Behrendt $\mathrm{H}$, Herbarth $\mathrm{O}$, von Berg $\mathrm{A}$, Bauer $\mathrm{CP}$ et al: Atopic diseases, allergic sensitization, and exposure to traffic-related air pollution in children. 
American Journal of Respiratory and Critical Care Medicine 2008, 177(12):1331-1337.

57. Karr CJ, Demers PA, Koehoorn MW, Lencar CC, Tamburic L, Brauer M: Influence of Ambient Air Pollutant Sources on Clinical Encounters for Infant Bronchiolitis. American Journal of Respiratory and Critical Care Medicine 2009, 180(10):995-1001.

58. Karr CJ, Rudra CB, Miller KA, Gould TR, Larson T, Sathyanarayana S, Koenig $J Q$ : Infant exposure to fine particulate matter and traffic and risk of hospitalization for RSV bronchiolitis in a region with lower ambient air pollution. Environmental Research 2009, 109(3):321-327.

59. Sahsuvaroglu T, Arain A, Kanaroglou P, Finkelstein N, Newbold B, Jerrett M, Beckerman B, Brook J, Finkelstein M: A land use regression model for predicting ambient concentrations of nitrogen dioxide in Hamilton, Ontario, Canada (vol 56, pg 1059, 2006). Journal of the Air \& Waste Management Association 2006, 56(10):1366-1366.

60. Larson T, Su J, Baribeau AM, Buzzelli M, Setton E, Brauer M: A spatial model of urban winter woodsmoke concentrations. Environmental Science \& Technology 2007, 41(7):2429-2436.

61. Team RDC: R: A Language and Environment for Statistical Computing. $R$ Foundation for Statistical Computing 2011.

62. Smith L, Mukerjee S, Gonzales M, Stallings C, Neas L, Norris G, Ozkaynak H: Use of GIS and ancillary variables compound and nitrogen dioxide to predict volatile organic levels at unmonitored locations. Atmospheric Environment 2006, 40(20):3773-3787.

63. Wheeler AJ, Smith-Doiron M, Xu X, Gilbert NL, Brook JR: Intra-urban variability of air pollution in Windsor, Ontario - Measurement and modeling for human exposure assessment. Environmental Research 2008, 106(1):7-16.

64. Hoek G, Beelen R, de Hoogh K, Vienneau D, Gulliver J, Fischer P, Briggs D: A review of land-use regression models to assess spatial variation of outdoor air pollution. Atmospheric Environment 2008, 42(33):7561-7578.

65. Su JG, Brauer M, Ainslie B, Steyn D, Larson T, Buzzelli M: An innovative land use regression model incorporating meteorology for exposure analysis. Science of the Total Environment 2008, 390(2-3):520-529.

66. Su JG, Jerrett M, Beckerman B: A distance-decay variable selection strategy for land use regression modeling of ambient air pollution exposures. Science of the Total Environment 2009, 407(12):3890-3898.

67. Allen R, Amram O, Henderson S, Brauer M: Transferability of Traffic Pollution Land-Use Regression Models Between Canadian Cities. Epidemiology 2008, 19(6):S150-S151.

68. Vienneau D, de Hoogh K, Beelen R, Fischer P, Hoek G, Briggs D: Comparison of land-use regression models between Great Britain and the Netherlands. 
Atmospheric Environment 2010, 44(5):688-696.

69. Arain MA, Blair R, Finkelstein N, Brook JR, Sahsuvaroglu T, Beckerman B, Zhang $L$, Jerrett $M$ : The use of wind fields in a land use regression model to predict air pollution concentrations for health exposure studies. Atmospheric Environment 2007, 41(16):3453-3464.

70. Gilbert NL, Goldberg MS, Beckerman B, Brook JR, Jerrett M: Assessing spatial variability of ambient nitrogen dioxide in Montreal, Canada, with a land-use regression model. Journal of the Air \& Waste Management Association 2005, 55(8):1059-1063.

71. Gilbert NL, Goldberg MS, Beckerman B, Jerrett M, Brook JR: Predicting spatial variability of ambient nitrogen dioxide in Montreal, Canada, with a land use regression model. Epidemiology 2004, 15(4):S200-S200.

72. Ross Z, English PB, Scalf R, Gunier R, Smorodinsky S, Wall S, Jerrett M: Nitrogen dioxide prediction in Southern California using land use regression modeling: potential for environmental health analyses. Journal of Exposure Science and Environmental Epidemiology 2006, 16(2):106-114.

73. Sahsuvaroglu T, Arain A, Kanaroglou P, Finkelstein N, Newbold B, Jerrett M, Beckerman B, Brook J, Finkelstein M, Gilbert NL: A land use regression model for predicting ambient concentrations of nitrogen dioxide in Hamilton, Ontario, Canada. Journal of the Air \& Waste Management Association 2006, 56(8):1059-1069.

74. Moore DK, Jerrett M, Mack WJ, Kunzli N: A land use regression model for predicting ambient fine particulate matter across Los Angeles, CA. Journal of Environmental Monitoring 2007, 9(3):246-252.

75. Ross Z, Jerrett M, Ito K, Tempalski B, Thurston GD: A land use regression for predicting fine particulate matter concentrations in the New York City region. Atmospheric Environment 2007, 41(11):2255-2269.

76. Sangrador JLT, Nunez MCE, Villarreal AB, Cadena LH, Jerrett M, Romieu I: A Land Use Regression Model for Predicting PM2.5 in Mexico City. Epidemiology 2008, 19(6):S259-S259.

77. Su J, Jerrett M, Beckerman B: Modeling Intra-Urban Spatial Variability of Volatile Organic Compounds Using a Land Use Regression Method. Epidemiology 2008, 19(6):S312-S313.

78. Wilton D, Larson T, Gould T, Szpiro A: Including Caline3 Dispersion Model Predictions into a Land Use Regression Model for NOx in Los Angeles, California and Seattle, Washington. Epidemiology 2008, 19(6):S273-S273.

79. Jerrett M, Su JG, Beckerman B, Verma D, Arain MA, Kanaroglou P, Stieb D, Finkelstein $\mathrm{M}$, Brook $\mathrm{J}$ : A land use regression model for predicting ambient volatile organic compound concentrations in Toronto, Canada. Atmospheric Environment 2010, 44(29):3529-3537.

80. Allen RW GE, Barkhasragchaa B, Byambaa T, Lkhasuren O, Amram O, Takaro 
TK, and Janes CR. : An Assessment of Air Pollution and its Attributable Mortality in Ulaanbaatar, Mongolia. Air Quality, Atmosphere \& Health 2011, in press.

81. Kanaroglou PS, Jerrett M, Morrison J, Beckerman B, Arain MA, Gilbert NL, Brook JR: Establishing an air pollution monitoring network for intra-urban population exposure assessment: A location-allocation approach. Atmospheric Environment 2005, 39(13):2399-2409.

82. Jerrett $\mathrm{M}$ : On the Use and Interpretation of Land Use Regression Estimates in Chronic Air Pollution Epidemiology. Epidemiology 2008, 19(6):S38-S38.

83. Ryan PH, LeMasters GK, Biswas P, Hu S, Bernstein DI, Lockey J, Villareal M, Khurana Hershey GK, Grinshpun S: Characterization of diesel exposure and wheezing in infants: the Cincinnati Childhood Allergy and Air Pollution Study (CCAAPS). Journal of Allergy and Clinical Immunology 2007, 119(1):S236-S236.

84. Madsen C, Nafstad P, Eikvar L, Schwarze PE, Ronningen KS, Haaheim LL: Association between tobacco smoke exposure and levels of C-reactive protein in the Oslo II Study. European Journal of Epidemiology 2007, 22(5):311-317.

85. Jerrett M, Arain MA, Kanaroglou P, Beckerman B, Crouse D, Gilbert NL, Brook $\mathrm{JR}$, Finkelstein N, Finkelstein MM: Modeling the intraurban variability of ambient traffic pollution in Toronto, Canada. Journal of Toxicology and Environmental Health-Part a-Current Issues 2007, 70(3-4):200-212.

86. Molter A, Lindley S, de Vocht F, Simpson A, Agius R: Modelling air pollution for epidemiologic research--part II: predicting temporal variation through land use regression. Sci Total Environ 2010, 409(1):211-217.

87. Clark NA, Demers PA, Karr CJ, Koehoorn M, Lencar C, Tamburic L, Brauer M: Effect of early life exposure to air pollution on development of childhood asthma. Environ Health Perspect 2010, 118(2):284-290.

88. Brauer M, Lencar C, Tamburic L, Koehoorn M, Demers P, Karr C: A cohort study of traffic-related air pollution impacts on birth outcomes. Environmental Health Perspectives 2008, 116(5):680-686.

89. Henderson SB, Michael: Measurement and modeling of traffic-related air pollution in the British Columbia Lower Mainland for use in health risk assessment and epidemiological analysis. CHER Research Papers 2005

90. Su JG, Brauer M, Buzzelli $M$ : Estimating urban morphometry at the neighborhood scale for improvement in modeling long-term average air pollution concentrations. Atmospheric Environment 2008, 42(34):7884-7893.

91. Karr CJ, Demers PA, Koehoorn MW, Lencar CC, Tamburic L, Brauer M: Influence of ambient air pollutant sources on clinical encounters for infant bronchiolitis. Am J Respir Crit Care Med 2009, 180(10):995-1001.

92. Metro V: $\mathbf{2 0 0 9}$ Lower Fraser Valley Air Quality Report December 2010 Page 
11.

93. Su JG, Jerrett M, Beckerman B, Verma D, Arain MA, Kanaroglou P, Stieb D, Finkelstein $\mathrm{M}$, Brook $\mathrm{J}$ : A land use regression model for predicting ambient volatile organic compound concentrations in Toronto, Canada. Atmospheric Environment 2010, 44(29):3529-3537.

94. Nethery E, Leckie SE, Teschke K, Brauer M: From measures to models: an evaluation of air pollution exposure assessment for epidemiological studies of pregnant women. Occup Environ Med 2008, 65(9):579-586.

95. Eeftens M, Beelen R, Fischer P, Brunekreef B, Meliefste K, Hoek G: Stability of measured and modelled spatial contrasts in NO2 over time. Occup Environ Med 2011.

96. Porta D, Cesaroni G, Badaloni C, Stafoggia M, Meliefste K, Forastiere F, Perucci CA: Nitrogen Dioxide Spatial Variability in Rome (Italy): An Application of the LUR Model Over a Decade. Epidemiology 2009, 20(6):S121 110.1097/1001.ede.0000362420.0000336474.0000362459. 


\section{Appendices}




\section{Appendix A: List of 16 Metro Vancouver monitoring stations}

\begin{tabular}{|c|c|c|c|c|}
\hline \multirow{2}{*}{ Station ID } & \multirow{2}{*}{ Station Name } & \multirow{2}{*}{ Station Location } & \multicolumn{2}{|c|}{ Coordinates (in UTM ) } \\
\hline & & & Longitude (X) & Latitude(Y) \\
\hline $\mathrm{T} 1$ & $\begin{array}{l}\text { Downtown } \\
\text { Vancouver }\end{array}$ & $\begin{array}{c}\text { Robson \& Hornby } \\
\text { Streets }\end{array}$ & 491231.9667 & 5458898.8572 \\
\hline $\mathrm{T} 2$ & Kitsilano & $\begin{array}{l}\text { Kitsilano High School, } \\
2550 \text { West 10th Ave }\end{array}$ & 488108.3349 & 5456556.7952 \\
\hline $\mathrm{T} 4$ & Burnaby & $\begin{array}{c}6400 \text { East Hastings } \\
\text { Street }\end{array}$ & 502127.4316 & 5458503.1796 \\
\hline T6 & Second Narrows & $\begin{array}{c}\text { GVRD Beach Works } \\
\text { Yard, } 75 \text { Riverside Drive }\end{array}$ & 498505.2887 & 5460977.6350 \\
\hline T9 & Port Moody & $\begin{array}{l}\text { Moody Street \& } \\
\text { Esplanade }\end{array}$ & 510948.1089 & 5458685.9827 \\
\hline $\mathrm{T} 13$ & North Delta & 8554 - 116th St & 507163.4336 & 5445071.4699 \\
\hline $\mathrm{T} 15$ & Surrey East & $\begin{array}{c}\text { GVRD Clayton } \\
\text { Reservoir, } \\
\text { 72nd Ave. and 192nd St. }\end{array}$ & 522299.3428 & 5442282.5818 \\
\hline T17 & Richmond South & $\begin{array}{c}\text { Williams Road and } \\
\text { Aragon Road }\end{array}$ & 492108.4098 & 5443182.6005 \\
\hline $\mathrm{T} 18$ & Burnaby South & $\begin{array}{c}\text { McPherson School, } 5455 \\
\text { Rumble }\end{array}$ & 501274.4613 & 5451419.1603 \\
\hline $\mathrm{T} 20$ & Pitt Meadows & $\begin{array}{c}\text { Meadowlands } \\
\text { Elementary School, } \\
18477 \text { Dewdney Trun }\end{array}$ & 521185.5719 & 5454763.7421 \\
\hline $\mathrm{T} 26$ & MAHON PARK & $\begin{array}{c}\text { 16th Street And Jones } \\
\text { Avenue }\end{array}$ & 493922.8647 & 5463476.5912 \\
\hline $\mathrm{T} 27$ & Langley & $\begin{array}{l}\text { D.W. Poppy School, } \\
\text { 23752 52nd Avenue }\end{array}$ & 531612.1961 & 5438174.6679 \\
\hline $\mathrm{T} 30$ & Maple Ridge & $\begin{array}{l}\text { Golden Ears Elementary } \\
\text { School, } 23124 \text { 118th Ave }\end{array}$ & 530438.8168 & 5451439.7093 \\
\hline $\mathrm{T} 31$ & $\begin{array}{c}\text { Metro } \\
\text { Vancouver } \\
\text { International } \\
\text { Airport } \\
\end{array}$ & 3153 Templeton Street & 489034.6127 & 5448171.5435 \\
\hline $\mathrm{T} 32$ & Coquitlam & $\begin{array}{c}\text { Douglas College, } 1250 \\
\text { Pinetree Way }\end{array}$ & 515159.1965 & 5459487.5217 \\
\hline T33 & Abbotsford & 32995 Bevan Avenue & 550435.3276 & 5432423.0597 \\
\hline
\end{tabular}




\section{Appendix B: SOEH Lab SOP - High Pressure Ion Chromatography (IC) Conductivity and UV/VIS Analysis for Anions - Nitrite, Nitrate and Phosphate}

\section{UBC School of Occupational and Environmental Hygiene (SOEH)}

High Pressure Ion Chromatography (IC) Conductivity and UV/VIS Analysis for Anions - Nitrite, Nitrate and Phosphate

Creation Date: 07/21/05 Method Version: SOEH-SOP\# A.00.18

Revised by: Cris Barzan

Approved by:

Date: May 21, 2010

Date:

S:ISharedISOEH LabISOEH Laboratory SOP's\Analytical Methods - SOEH SOP's\HP-IC for Nitrite, Nitrate and

Phosphate_REVISED_052110.doc

\section{Introduction}

The method of analysis for anions of nitrite, nitrate and o-phosphate $\left(\mathrm{NO}_{2}{ }^{-}, \mathrm{NO}_{3}{ }^{-}\right.$and $\mathrm{PO}_{4}{ }^{-}$) in various types of aqueous samples such as biological matrices and Ogawa air sampler devices (Figure 1).

Figure 1 - HP-IC Analysis of 7 Anions including ions of $\mathrm{NO}_{2}{ }^{-}, \mathrm{NO}_{3}{ }^{-}$and $\mathrm{PO}_{4}{ }^{-}$

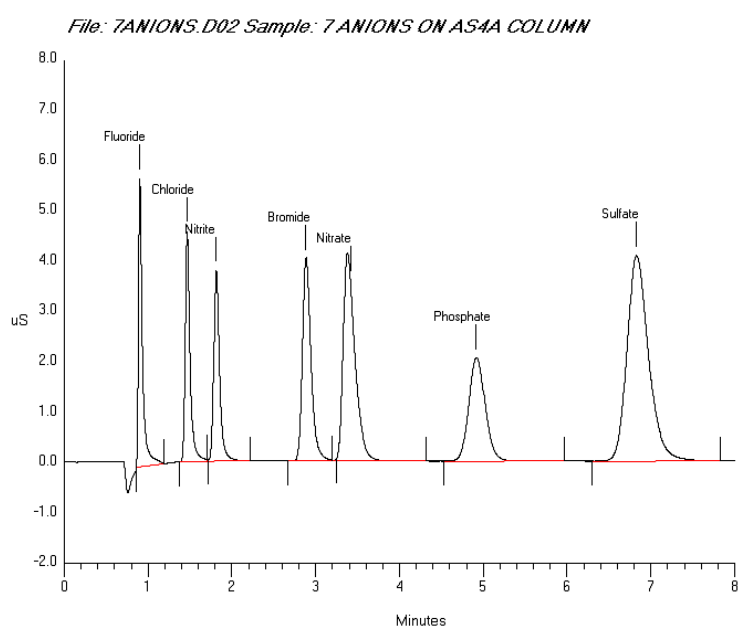




\section{Apparatus and Dionex Instrument Plumbing Configuration}

Dionex High Pressure Ion Chromatograph with Conductivity detector

Column: IonPac AS4A-SC - 4 mm analytical column (P/N 43174)

Guard column: IonPac AG4A-SC (4 mm 10-32 - P/N 43175)

Anion Self-Regenerating Suppressor ASRS-1 (4mm, P/N 043189)

\section{PLUMBING FOR THE AUTOSUPPRESSION RECYCLE MODE OPERATION}

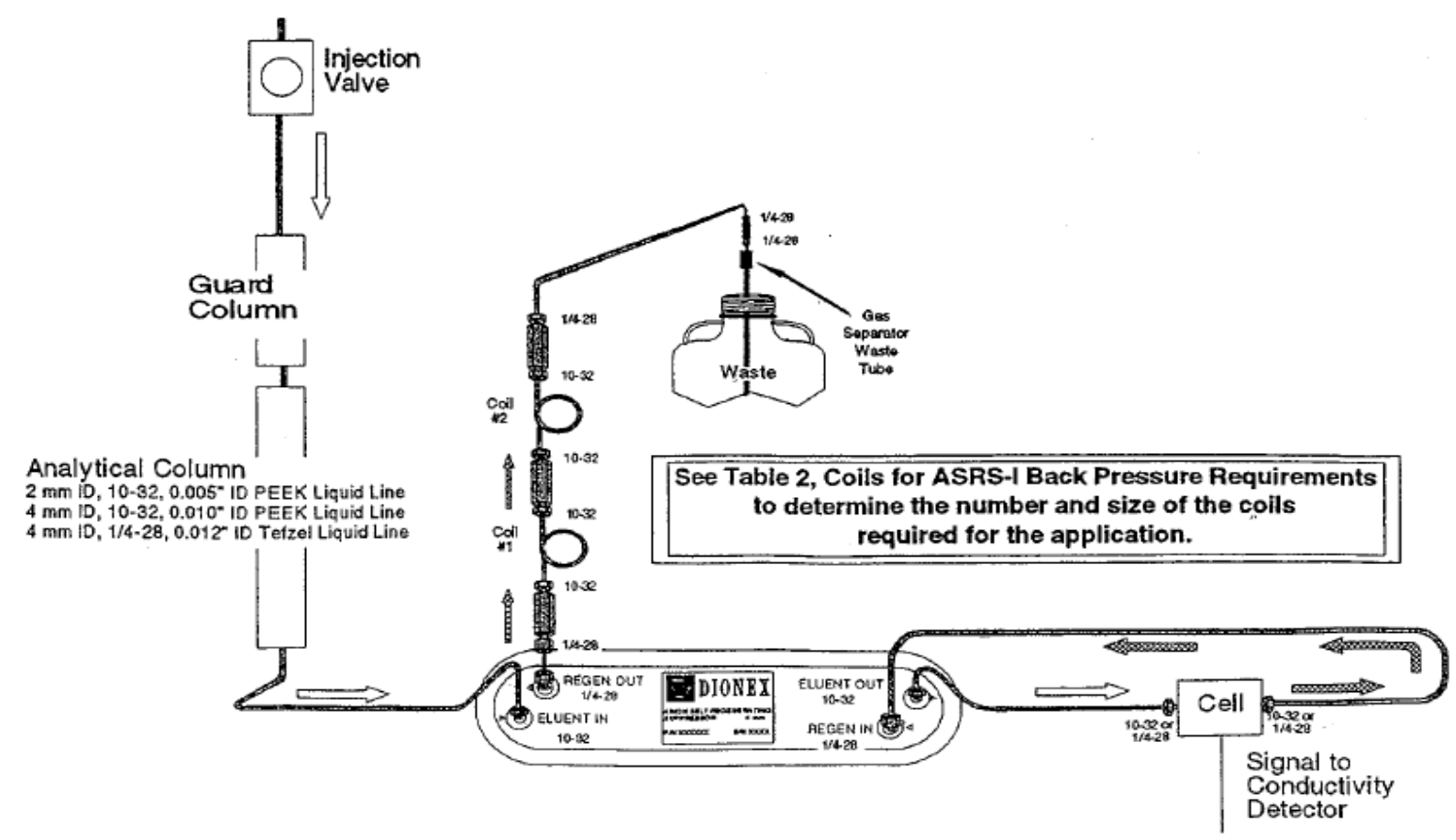

\section{Operating Parameters}

Eluent: $3.5 \mathrm{mM} \mathrm{Na}_{2} \mathrm{CO}_{3}$ and $1 \mathrm{mM} \mathrm{NaHCO}$

Flow Rate: $1.5 \mathrm{~mL} / \mathrm{min}$

Regenerant: Autosuppression Recycle Mode (see Page 11 of Dionex Document \#034650 for installation) 
Detection: Suppressed conductivity ASRS-I

\section{Reagents and Standards}

Deionized water, 17.8 resistance or better and 0.2 um filtered

Sodium Bicarbonate - Certified A.C.S. Fsiher Chemicals \# S233B-500

Sodium Carbonate - Certified A.C.S. Fisher Chemicals \# S263-500

Potassium Phosphate Monobasic - NF/FCC Fisher Chemicals \# P380-500

Sodium Nitrite - 99\% Riedel-de-Haen P/N 31443

Potassium Nitrate - Certified A.C.S. Fisher Chemicals \# P/N 263-500

\section{Preparation of Reagents and Standards}

Eluent Stock Solution $-0.35 \mathrm{M} \mathrm{Na}_{2} \mathrm{CO}_{3}$ and $0.1 \mathrm{M} \mathrm{NaHCO}_{3}$

Weigh out $38.1 \mathrm{~g}$ of $\mathrm{Na}_{2} \mathrm{CO}_{3}$ and 8.41 grams of $\mathrm{NaHCO}_{3}$. Carefully add to a 1 liter volumetric flask containing about $500 \mathrm{~mL}$ of deionized water. Dilute to the mark and mix thoroughly. Store the eluent stock at $4{ }^{\circ} \mathrm{C}$ in a plastic container.

\section{Eluent Solution - Anion Solution of $1.8 \mathrm{mM} \mathrm{Na}_{2} \mathrm{CO}_{3}$ and $1.7 \mathrm{mM} \mathrm{NaH} \mathrm{CO}$}

Pipet $20 \mathrm{mLs}$ of eluent concentrate into the Dionex $2 \mathrm{~L}$ eluent container with deionized water with a specific resistance of 17.8 megaohm-cm or greater

\section{Sodium Nitrite $\left(\mathrm{NaNO}_{2}\right)$ - Stock Solution (ppm)}

Weigh out and record accurately an amount of sodium nitrite ( 0.5 to 1 gram) and transfer into a $1000 \mathrm{~mL}$ volumetric flask. Dilute with approximately $500 \mathrm{~mL}$ of deionized water and thoroughly mix. Top up to the mark and store in a plastic container at $4{ }^{\circ} \mathrm{C}$. Stock solution is stable for at least 3 months (Dionex Application note 135 - page 2).

The concentration of the nitrite stock ( $\mathrm{ppm}$ ) diluted into $1000 \mathrm{mLs}$ of nanopure water:

$\left[\mathrm{NO}_{2}{ }^{-}\right]_{\mathrm{ppm}}=1000 \mathrm{X} \quad\left(\right.$ Weighed $\mathrm{NaNO}_{2} / \mathrm{M} . \mathrm{W}$ of $\mathrm{NaNO}_{2}$ ) X $\quad$ M.W. of $\mathrm{NO}_{2}$

M.W. of $\mathrm{NaNO}_{2}=69$

M.W. of $\quad \mathrm{NO}_{2}=46$

\section{Potassium Nitrate $\left(\mathrm{KNO}_{3}\right)$ - Stock Solution (ppm)}


Weigh out and record accurately an amount of potassium nitrate ( 0.5 to 1 gram) and transfer into a $1000 \mathrm{~mL}$ volumetric flask. Dilute with approximately $500 \mathrm{~mL}$ of deionized water and thoroughly mix. Top up to the mark and store in a plastic container at $4{ }^{\circ} \mathrm{C}$. Stock solution is stable for at least 3 months (Dionex Application note 135 - page 2).

The concentration of the nitrate stock (ppm) diluted into $1000 \mathrm{mLs}$ of nanopure water:

$\left[\mathrm{NO}_{3}{ }^{-}\right]_{\mathrm{ppm}}=1000 \mathrm{X} \quad\left(\right.$ Weighed $\mathrm{KNO}_{3} / \mathrm{M} . \mathrm{W}$ of $\left.\mathrm{KNO}_{3}\right) \quad \mathrm{X} \quad \mathrm{M} . \mathrm{W}$. of $\mathrm{NO}_{3}$

M.W. of $\mathrm{KNO}_{3}=101.11$

M.W. of $\mathrm{NO}_{3}=62$

\section{Potassium Phosphate $\left(\mathrm{KH}_{2} \mathrm{PO}_{4}\right)$ - Stock Solution (ppm)}

Weigh out and record accurately an amount of potassium phosphate ( 0.5 to $1 \mathrm{gram})$ and transfer into a $1000 \mathrm{~mL}$ volumetric flask. Dilute with approximately $500 \mathrm{~mL}$ of deionized water and thoroughly mix. Top up to the mark and store in a plastic container at $4{ }^{\circ} \mathrm{C}$. Stock solution is stable for at least 3 months (Dionex Application note 135 - page 2).

The concentration of the phosphate stock (ppm) diluted into $1000 \mathrm{mLs}$ of nanopure water:

$\left[\mathrm{PO}_{4}{ }^{-}\right] \mathrm{ppm}=1000 \mathrm{X} \quad\left(\right.$ Weighed $\mathrm{KH}_{2} \mathrm{PO}_{4} / \mathrm{M} . \mathrm{W}$ of $\left.\mathrm{KH}_{2} \mathrm{PO}_{4}\right) . \mathrm{x} \quad$ M.W. of $\mathrm{PO}_{4}$

M.W. of $\mathrm{KH}_{2} \mathrm{PO}_{4}=136.09$

M.W. of $\mathrm{PO}_{4}=79$

\section{$\underline{\text { Calibration Standards }}$}

Working standards at lower analyte concentrations are prepared from the $1000 \mathrm{mg} / \mathrm{L}$ stocks. Dilute the stocks to a set of calibration working standards that encompase the range of concentrations found in the samples. Using 100 volumetric flasks, calculate the transfer volumes $(\mathrm{uL})$ needed to dilute a set of 5 or 6 calibration points in a range close to the lowest level of detection (LOD) and in the expected upper range of the samples. 
Run one set of calibration standards at the beginning of each batch analysis and one identical set after all samples are run. This acts as the back calibration check. To ensure that the analysis is valid, the low levels of the back calibration check should be within $\pm 20 \%$ and all other levels within $\pm 10-15 \%$ of those at the beginning.

If, after everything is analyzed, any samples are out of the calibration range, dilute them by a known factor and re-run them so that they are contained by the calibration standards.

\section{Conditioning the lonPac AS4A-SC - $4 \mathrm{~mm}$ analytical column}

Prepare a $500 \mathrm{~mL}$ solution of $0.5 \mathrm{M} \mathrm{NaOH}$

Disconnect the analytical column from the injector valve, anion suppressor and guard column.

Use $0.5 \mathrm{M} \mathrm{NaOH}$ to clean the column for $30-60$ minutes at $1.0 \mathrm{~mL} / \mathrm{minute}$ flow rate.

Re-condition with eluent (desired concentration of eluent) stabilize the column with a flow rate of $1 \mathrm{~mL} / \mathrm{minute}$ and run for 15 minutes.

\section{Hydrating the Anion Ion Suppression Unit (ASRS-I)}

Prepare the ASRA-1 for use by hydrating the eluent chamber with the mobile phase (eluent). Let sit for at least 20 minutes prior to use.

\section{Sample Preparation}

\section{1) General Aqueous Samples}

Filter all samples through a 0.2 um Gelman Ion Chromatography Acrodisc IC syringe filter and discard the first 3 drops (approx $300 \mathrm{uL}$ ). Transfer the sample directly into a clean HP-IC autosampler vial.

\section{2) Ogawa Samplers - Air Analysis for Nitrous Oxide and $\mathrm{NO}_{\mathrm{x}}$}

These samplers are a passive type monitor that are impregnated with a preporiety reagent on the surface of a MCE collection pad. The two types of pads are the $\mathrm{NO}_{2}$ and the $\mathrm{NO}_{\mathrm{x}}$ and the samplers are assembled with both pads installed on each end of an Ogawa sampler and delivered to the field for static samples. Usually the Ogawa is setup in the 
field for a duration of 1-3 weeks and upon reception back in the lab, the sampler is disassembled and the each pad is transferred to a Nalgene narrow mouth $15 \mathrm{~mL}$ bottle and extracted with $6 \mathrm{mLs}$ of nanopure water (> $17.8 \mathrm{ohms}$ resistivity measured). Each sample is then agitated for about 30 minutes on a rotary shaker.

The $\mathrm{NO}_{\mathrm{x}}$ pad is coloured purple as a distinquishing marker for this analyte but in some cases if the sampler has been exposed for short durations of time at high temperatures (or improperly refrigerated) the colouration will not be present. As an additional aid, each sampler can be marked to distinguish the end that has the $\mathrm{NO}_{\mathrm{x}}$ pad installed.

After removal of the collection pads and extraction, the holding time is 3 months (90 days) as recommended by the manufacturer.

\section{3) Phosphoric Acid in Air}

Air samples are collected onto $\mathrm{ORBO}^{\mathrm{tm}} 53$ tubes at a flow rate of $150 \mathrm{mLs} / \mathrm{min}$. The tubes are extracted by removing the front and back portions into $8 \mathrm{~mL}$ test tubes and extracting each with $4 \mathrm{mLs}$ of the HP-IC mobile phase. The samples are placed in a bath of boiling water for 10 minutes and then allowed to cool before a filtered $(0.2 \mathrm{um}$ pre-filter) aliquote is transferred to HP-IC vials. Phosphoric acid is determined by measurement of the phosphate ion by conductivity detection and the calculation of the acid is converted by from the micrograms amount of phosphate to an equvilent concentration of phosphoric acid (NIOSH Method 7903).

\section{Quality Control Procedures}

Prepare quality control (QC) samples using a number of the mid-level calibration standards. Position one QC sample in the batch sequence per every 10 samples. Also make a duplicate of every $10^{\text {th }}$ sample.

\section{Reference Methods}

NIOSH 7903 Method Reference-InorganicAcids (HF, $\mathrm{HCl}, \mathrm{H}_{3} \mathrm{PO}_{4}, \mathrm{HBr}, \mathrm{HNO}_{3}$ and $\mathrm{H}_{2} \mathrm{SO}_{4}$

Ogawa Document Version $3.98-\mathrm{NO}, \mathrm{NO}_{2}, \mathrm{NO}_{\mathrm{x}}$ and $\mathrm{SO}_{2}$ Sampling Protocol Using the Ogawa Sampler

\section{Method Revisions}




$\begin{array}{lcrlr}\text { Revision Number } & \text { Author/Reviser } & \text { Date } & \text { Description } \\ \text { SOEH-SOP \# A.00.16 } & \text { Timothy Ma } & 07 / 24 / 05 & 1^{\text {st }} \text { Version } \\ \text { SOEH-SOP \# A.00.17 } & \text { Timothy Ma } & 10 / 29 / 07 & \text { Revised calibration } \\ \text { SOEH-SOP \# A.00.18 } & \text { Niki Chum } & 11 / 09 / 07 & \text { Added QC procedures } \\ \text { SOEH-SOP \# A.00.19 } & \text { Cris Barzan } & 05 / 21 / 10 & \text { Updated Procedures }\end{array}$




\section{Appendix C: Calculation of ambient concentrations of NO and NO2}

Each Ogawa sampler was loaded with two filters for NOx and NO2 respectisvely. Filters were dissolved in $6 \mathrm{ml}$ de-ionized (DI) water and extracted for Ion Chromatography (IC) analysis, which determined the concentration of nitrite ion $\left(\mathrm{NO}^{2-}\right)$ in the dissolved DI water.

NO concentration $(\mathrm{ppb})$
$=\frac{(\text { Mass of nitrite from NOx filter }- \text { Mass of nitrite from NO2 filter })(\mathrm{ng}) \times \alpha \mathrm{NO}}{\text { Duration }(\mathrm{min})}$

$\mathrm{NO} 2$ concentration (ppb)

$=\frac{\text { Mass of nitrite from NO2 filter }(\mathrm{ng}) \times \alpha \mathrm{NO} 2}{\text { Duration }(\mathrm{min})}$

Where:

Mass of nitrite from NOx/NO2 filter (in ng) = Nitrite $(\mathrm{ppm}) \times 6 \mathrm{ml}$ x 1000

$a{ }^{1} \mathrm{NO}=10000 /[(-0.78 \times \mathrm{P} \times \mathrm{RH})+220], \mathrm{P}$ is Ogawa constant ${ }^{2}, \mathrm{~T}$ and $\mathrm{RH}$ are average temperature and humidity

$\alpha \mathrm{NO} 2=10000 /[(0.677 \times \mathrm{P} \times \mathrm{RH})+(2.009 \times \mathrm{T})+89.8]$

1. Ogawa Alpha coefficient, i.e. sampling rate

2. Dimensionless vapor pressure coefficient - varies with temperature - take value from Table 5 in Ogawa protocol and adjacent worksheet (see NO, NO2, NOx and SO2 Sampling Protocal Using the Ogawa Sampler http://www.ogawausa.com/pdfs/prono-noxno2so206.pdf). P=1 at 20C. Assign value based upon average temperature. 


\title{
Appendix D: R codes for LUR modeling (By Sarah Henderson)
}

\author{
setwd ("C:I\RII") \# set working directory \\ ourdata = read.table ("datafile.csv", header=T, sep=",") \\ attach (ourdata)
}

source ("lur_functions.r") \# functions attached below

source ("check_r2..r") \# check_r2 function attached below

ranks = get_ranks_table ("NO2", "density")

stepwiselist $=$ include_in_stepwise (ranks)

variablelist $=\mathrm{c}($ "NO2", stepwiselist $)$

newdata $=$ ourdata[, variablelist $]$

basemodel $=\operatorname{lm}($ newdata, na.action=na.omit $)$

stepmodel $=\operatorname{step}($ basemodel, trace $=$ FALSE $)$

stepmodel = get_stepwise_model("NO2", "density")

summary (stepmodel)

stepmodel $=$ update $($ stepmodel, . . - AD.100) $\# *$ variable to remove

summary (stepmodel)

stepmodel $=$ step $($ stepmodel, trace=FALSE)

summary (stepmodel)

NO2_length = stepmodel

check_r2 (NO2_length)

-lur_functions.r

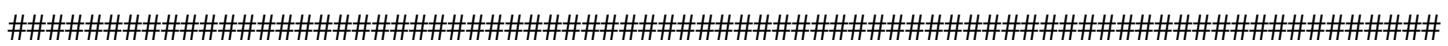

\# Function to return a table of rankings between input $\mathrm{Y}$ and the potentially

\# predictive covariates.

\# Function variable group should be of form "RD1."

\# Function output is a list of character class, names of variables 


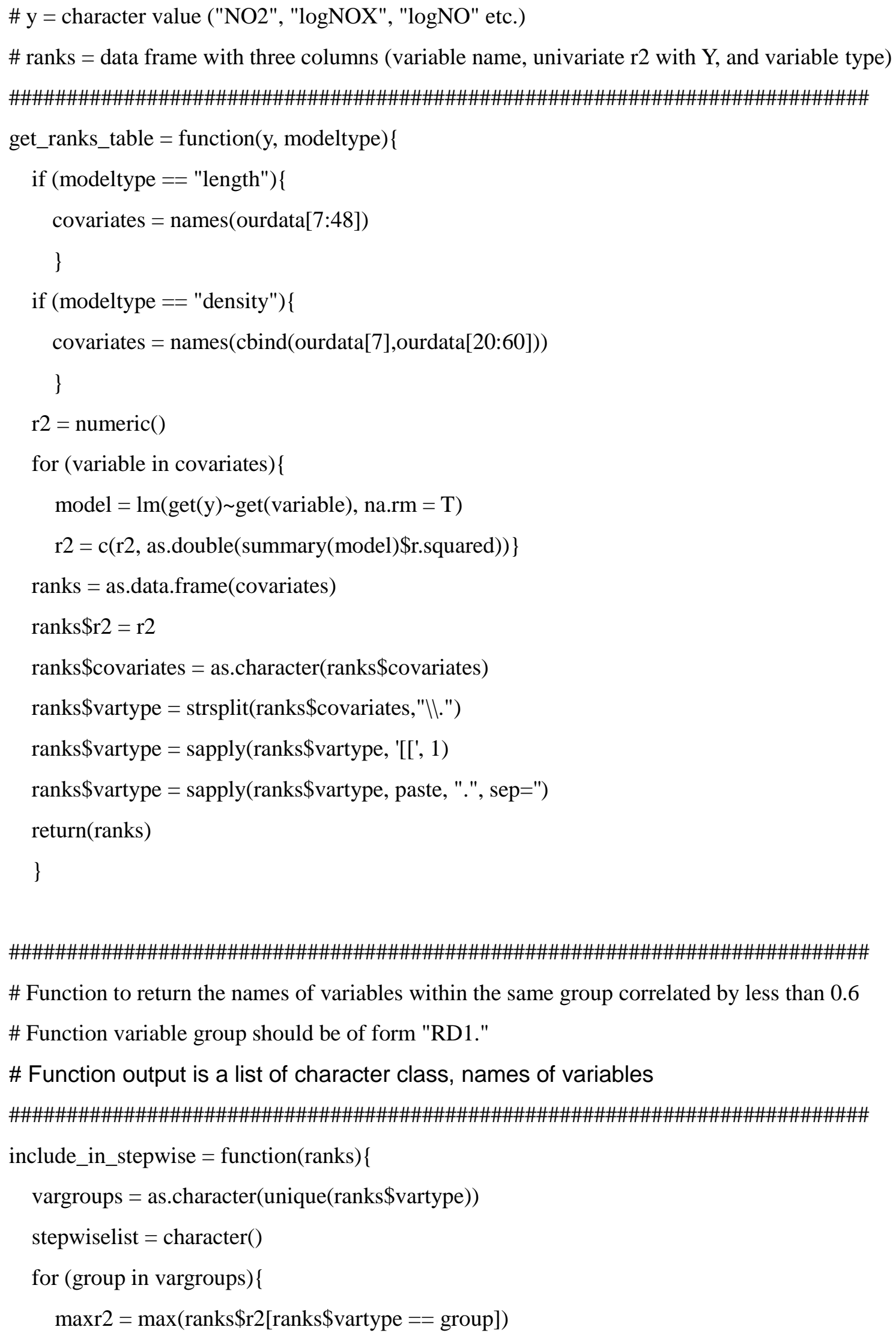




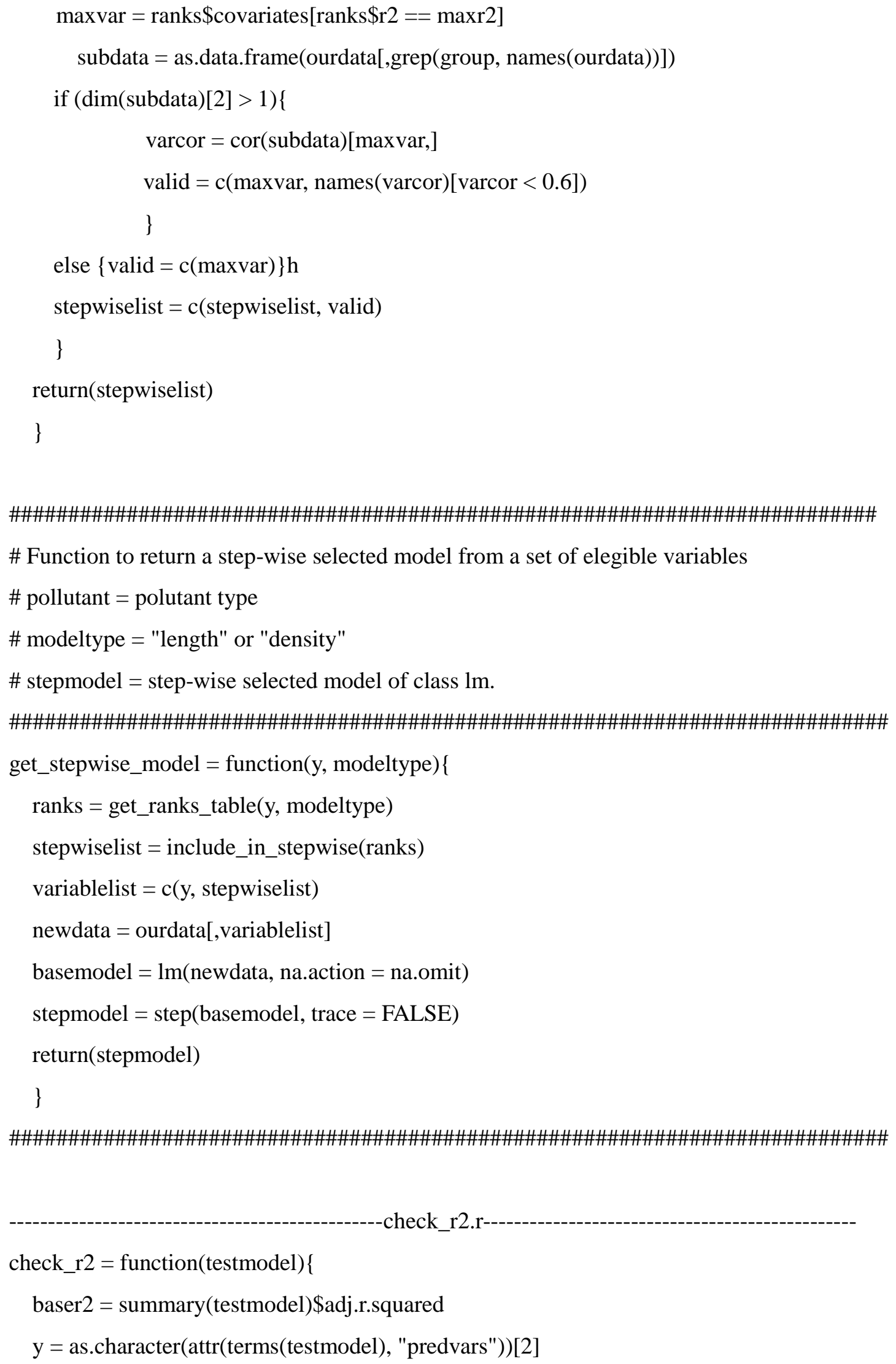




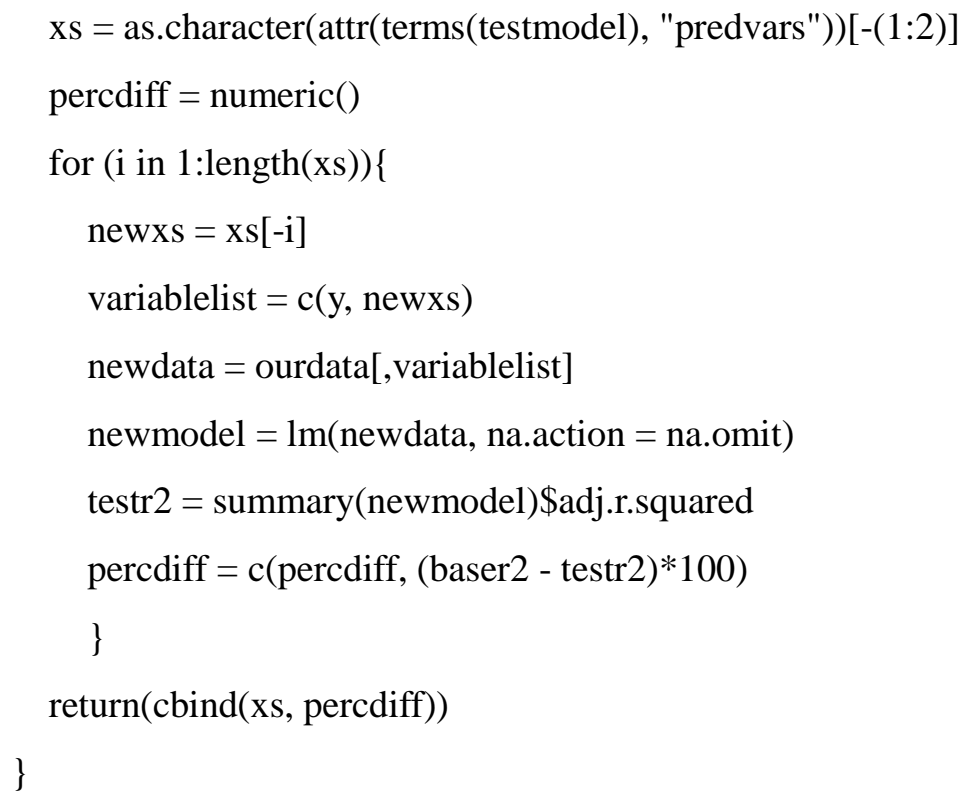




\section{Appendix E: Location measurements for 116 sampling sites in 2010 (in UTM)}

\begin{tabular}{|c|c|c|c|c|c|c|c|c|}
\hline \multirow{2}{*}{$\begin{array}{c}\text { Location } \\
\text { ID }\end{array}$} & \multicolumn{2}{|c|}{2009 Fall } & \multicolumn{2}{|c|}{2010 Spring } & \multicolumn{2}{|c|}{ Average } & \multicolumn{2}{|c|}{ Difference } \\
\hline & $\mathbf{x}$ & $\mathbf{Y}$ & $\mathbf{x}$ & $\mathbf{Y}$ & $x$ & $\mathbf{Y}$ & $x$ & $\mathbf{Y}$ \\
\hline 1 & 493479 & 5466022 & 493480 & 5466032 & 493480 & 5466027 & -1 & -10 \\
\hline 2 & 490451 & 5463953 & 490455 & 5463953 & 490453 & 5463953 & -5 & 0 \\
\hline 3 & 494068 & 5463937 & 494067 & 5463944 & 494067 & 5463940.5 & 1 & -7 \\
\hline 4 & 496652 & 5463945.5 & 496652 & 5463950 & 496652 & 5463947.75 & -1 & -4.5 \\
\hline 5 & 491969 & 5462983 & 491973 & 5462985 & 491971 & 5462984 & -5 & -2 \\
\hline 6 & 494496 & 5462470.5 & 494480 & 5462441 & 494488 & 5462455.75 & 16 & 29.5 \\
\hline 7 & 496482 & 5461853.5 & 496483 & 5461859 & 496483 & 5461856.25 & -1 & -5.5 \\
\hline 8 & 512884 & 5460438.5 & 512886 & 5460434 & 512885 & 5460436.25 & -2 & 4.5 \\
\hline 9 & 490442 & 5459921 & 490454 & 5459940 & 490448 & 5459930.5 & -12 & -19 \\
\hline 10 & 495605 & 5459430 & 495594 & 5459431.5 & 495600 & 5459430.75 & 11 & -1.5 \\
\hline 11 & 498963 & 5459410.5 & 498973 & 5459430 & 498968 & 5459420.25 & -10 & -19.5 \\
\hline 12 & 514926 & 5459388 & 514930 & 5459380.5 & 514928 & 5459384.25 & -4 & 7.5 \\
\hline 13 & 490000 & 5458926 & 490009 & 5458932 & 490005 & 5458929 & -9 & -6 \\
\hline 14 & 492934 & 5458427 & 492930 & 5458403 & 492932 & 5458415 & 4 & 24 \\
\hline 15 & 496972 & 5458441 & 496979 & 5458457.5 & 496976 & 5458449.25 & -7 & -16.5 \\
\hline 16 & 502048 & 5458475.5 & 502055 & 5458473 & 502052 & 5458474.25 & -7 & 2.5 \\
\hline 17 & 510935 & 5458451 & 510930 & 5458460.5 & 510933 & 5458455.75 & 5 & -9.5 \\
\hline 18 & 518547 & 5458429 & 518567 & 5458412 & 518557 & 5458420.5 & -20 & 17 \\
\hline 19 & 491003 & 5457898 & 490989 & 5457926 & 490996 & 5457912 & 14 & -28 \\
\hline 20 & 485004 & 5457376 & 485012 & 5457379 & 485008 & 5457377.5 & -8 & -3 \\
\hline 21 & 487516 & 5457404 & 487521 & 5457427 & 487518 & 5457415.5 & -6 & -23 \\
\hline 22 & 489496 & 5457461.5 & 489485 & 5457438 & 489491 & 5457449.75 & 11 & 23.5 \\
\hline 23 & 495007 & 5457434 & 495019 & 5457433 & 495013 & 5457433.5 & -12 & 1 \\
\hline 24 & 500402 & 5457272 & 500403 & 5457276 & 500403 & 5457274 & -1 & -4 \\
\hline 25 & 503484 & 5457516.5 & 503490 & 5457517.5 & 503487 & 5457517 & -6 & -1 \\
\hline 26 & 508516 & 5457386.5 & 508518 & 5457384 & 508517 & 5457385.25 & -3 & 2.5 \\
\hline 27 & 514006 & 5457514 & 514008 & 5457509 & 514007 & 5457511.5 & -2 & 5 \\
\hline 28 & 516575 & 5457419.5 & 516575 & 5457397 & 516575 & 5457408.25 & 0 & 22.5 \\
\hline 29 & 498023 & 5457003 & 498037 & 5457016.5 & 498030 & 5457009.75 & -14 & -13.5 \\
\hline 30 & 488000 & 5456362 & 488002 & 5456370 & 488001 & 5456366 & -2 & -8 \\
\hline 31 & 491987 & 5456397 & 491977 & 5456400 & 491982 & 5456398.5 & 10 & -3 \\
\hline 32 & 493502 & 5456488 & 493498 & 5456499 & 493500 & 5456493.5 & 4 & -11 \\
\hline 33 & 485911 & 5455966 & 485916 & 5455959 & 485913 & 5455962.5 & -6 & 7 \\
\hline 34 & 490079 & 5455915.5 & 490136 & 5455824 & 490108 & 5455869.75 & -57 & 91.5 \\
\hline 35 & 495870 & 5456042 & 495873 & 5456057.5 & 495872 & 5456049.75 & -3 & -15.5 \\
\hline
\end{tabular}




\begin{tabular}{|c|c|c|c|c|c|c|c|c|}
\hline \multirow{2}{*}{$\begin{array}{c}\text { Location } \\
\text { ID }\end{array}$} & \multicolumn{2}{|c|}{2009 Fall } & \multicolumn{2}{|c|}{2010 Spring } & \multicolumn{2}{|c|}{ Average } & \multicolumn{2}{|c|}{ Difference } \\
\hline & $x$ & $\mathbf{Y}$ & $x$ & $Y$ & $x$ & $Y$ & $x$ & $Y$ \\
\hline 36 & 493936 & 5455478 & 493940 & 5455441.5 & 493938 & 5455459.75 & -4 & 36.5 \\
\hline 37 & 497530 & 5455466 & 497527 & 5455465.5 & 497529 & 5455465.75 & 3 & 0.5 \\
\hline 38 & 506954 & 5455416 & 506956 & 5455414 & 506955 & 5455415 & -2 & 2 \\
\hline 39 & 509539 & 5455537 & 509615 & 5455449 & 509577 & 5455493 & -76 & 88 \\
\hline 40 & 491942 & 5454907 & 491938 & 5454911.5 & 491940 & 5454909.25 & 4 & -4.5 \\
\hline 41 & 520987 & 5454686.5 & 520991 & 5454692 & 520989 & 5454689.25 & -4 & -5.5 \\
\hline 42 & 486499 & 5454452 & 486501 & 5454436 & 486500 & 5454444 & -2 & 16 \\
\hline 43 & 495942 & 5454455.5 & 495945 & 5454462 & 495944 & 5454458.75 & -3 & -6.5 \\
\hline 44 & 499549 & 5454456.5 & 499549 & 5454463 & 499549 & 5454459.75 & -1 & -6.5 \\
\hline 45 & 512504 & 5454433 & 512508 & 5454431 & 512506 & 5454432 & -5 & 2 \\
\hline 46 & 515998 & 5454424.5 & 516000 & 5454422 & 515999 & 5454423.25 & -3 & 2.5 \\
\hline 47 & 488534 & 5453958 & 488536 & 5453961 & 488535 & 5453959.5 & -2 & -3 \\
\hline 48 & 494417 & 5453923.5 & 494424 & 5453912 & 494421 & 5453917.75 & -7 & 11.5 \\
\hline 49 & 497415 & 5453989 & 497410 & 5453985.5 & 497413 & 5453987.25 & 5 & 3.5 \\
\hline 50 & 490450 & 5453475.5 & 490437 & 5453477.5 & 490444 & 5453476.5 & 13 & -2 \\
\hline 51 & 492929 & 5453470.5 & 492931 & 5453476.5 & 492930 & 5453473.5 & -3 & -6 \\
\hline 52 & 508585 & 5453748.5 & 508585 & 5453747 & 508585 & 5453747.75 & 0 & 1.5 \\
\hline 53 & 495878 & 5452957 & 495880 & 5452941.5 & 495879 & 5452949.25 & -2 & 15.5 \\
\hline 54 & 499071 & 5452864 & 499096 & 5452873 & 499084 & 5452868.5 & -25 & -9 \\
\hline 55 & 494474 & 5452407.5 & 494474 & 5452409 & 494474 & 5452408.25 & -1 & -1.5 \\
\hline 56 & 500424 & 5452442 & 500432 & 5452477 & 500428 & 5452459.5 & -8 & -35 \\
\hline 57 & 505022 & 5452478.5 & 505034 & 5452476 & 505028 & 5452477.25 & -12 & 2.5 \\
\hline 58 & 528472 & 5452439 & 528477 & 5452449 & 528475 & 5452444 & -5 & -10 \\
\hline 59 & 503058 & 5451926 & 503068 & 5451938 & 503063 & 5451932 & -10 & -12 \\
\hline 60 & 491592 & 5451415.5 & 491594 & 5451428 & 491593 & 5451421.75 & -3 & -12.5 \\
\hline 61 & 498059 & 5451478 & 498087 & 5451475 & 498073 & 5451476.5 & -29 & 3 \\
\hline 62 & 530431 & 5451494.5 & 530429 & 5451487 & 530430 & 5451490.75 & 2 & 7.5 \\
\hline 63 & 493479 & 5450936 & 493486 & 5450934 & 493482 & 5450935 & -8 & 2 \\
\hline 64 & 495442 & 5450952.5 & 495470 & 5450949 & 495456 & 5450950.75 & -28 & 3.5 \\
\hline 65 & 506457 & 5450958.5 & 506493 & 5450913 & 506475 & 5450935.75 & -36 & 45.5 \\
\hline 66 & 489990 & 5450458 & 489983 & 5450489 & 489987 & 5450473.5 & 7 & -31 \\
\hline 67 & 504394 & 5450397.5 & 504398 & 5450394 & 504396 & 5450395.75 & -4 & 3.5 \\
\hline 68 & 512554 & 5450385.5 & 512552 & 5450378 & 512553 & 5450381.75 & 2 & 7.5 \\
\hline 69 & 514581 & 5449450.5 & 514588 & 5449462 & 514584 & 5449456.25 & -8 & -11.5 \\
\hline 70 & 509842 & 5448938.5 & 509843 & 5448937 & 509843 & 5448937.75 & -1 & 1.5 \\
\hline 71 & 511993 & 5447961.5 & 511986 & 5447958 & 511990 & 5447959.75 & 7 & 3.5 \\
\hline 72 & 507529 & 5447365 & 507526 & 5447383 & 507528 & 5447374 & 3 & -18 \\
\hline 73 & 513959 & 5446923 & 513958 & 5446923 & 513958 & 5446923 & 1 & 0 \\
\hline
\end{tabular}




\begin{tabular}{|c|c|c|c|c|c|c|c|c|}
\hline \multirow{2}{*}{$\begin{array}{l}\text { Location } \\
\text { ID }\end{array}$} & \multicolumn{2}{|c|}{2009 Fall } & \multicolumn{2}{|c|}{2010 Spring } & \multicolumn{2}{|c|}{ Average } & \multicolumn{2}{|c|}{ Difference } \\
\hline & $x$ & $\mathbf{Y}$ & $x$ & $Y$ & $x$ & $Y$ & $\mathbf{x}$ & $Y$ \\
\hline 74 & 490434 & 5446368 & 490425 & 5446394 & 490430 & 5446381 & 9 & -26 \\
\hline 75 & 509544 & 5446456 & 509567 & 5446449 & 509556 & 5446452.5 & -23 & 7 \\
\hline 76 & 516527 & 5445961.5 & 516543 & 5446004 & 516535 & 5445982.75 & -16 & -42.5 \\
\hline 77 & 486525 & 5445450 & 486525 & 5445450 & 486525 & 5445450 & 0 & 0 \\
\hline 78 & 488523 & 5445461 & 488536 & 5445454.5 & 488530 & 5445457.75 & -13 & 6.5 \\
\hline 79 & 490041 & 5445459 & 490048 & 5445465 & 490045 & 5445462 & -7 & -6 \\
\hline 80 & 512045 & 5445338.5 & 512044 & 5445505 & 512045 & 5445421.75 & 1 & -166.5 \\
\hline 81 & 507010 & 5444949 & 507007 & 5444950 & 507008 & 5444949.5 & 3 & -1 \\
\hline 82 & 508560 & 5444391 & 508559 & 5444389 & 508560 & 5444390 & 1 & 2 \\
\hline 83 & 486895 & 5443954 & 486899 & 5443955.5 & 486897 & 5443954.75 & -4 & -1.5 \\
\hline 84 & 489223 & 5442883 & 489221 & 5442901.5 & 489222 & 5442892.25 & 2 & -18.5 \\
\hline 85 & 490372 & 5442931 & 490376 & 5442933 & 490374 & 5442932 & -4 & -2 \\
\hline 86 & 491996 & 5442958 & 491996 & 5442967.5 & 491996 & 5442962.75 & 0 & -9.5 \\
\hline 87 & 506982 & 5442438.5 & 506990 & 5442438 & 506986 & 5442438.25 & -9 & 0.5 \\
\hline 88 & 522554 & 5442351.5 & 522550 & 5442376 & 522552 & 5442363.75 & 4 & -24.5 \\
\hline 89 & 486457 & 5441939 & 486489 & 5441906 & 486473 & 5441922.5 & -32 & 33 \\
\hline 90 & 509419 & 5441896.5 & 509422 & 5441889 & 509421 & 5441892.75 & -3 & 7.5 \\
\hline 91 & 511893 & 5441927.5 & 511906 & 5441910 & 511900 & 5441918.75 & -13 & 17.5 \\
\hline 92 & 524479 & 5439420.5 & 524493 & 5439403 & 524486 & 5439411.75 & -15 & 17.5 \\
\hline 93 & 531370 & 5437883 & 531366 & 5437882 & 531368 & 5437882.5 & 4 & 1 \\
\hline 94 & 494474 & 5437456 & 494481 & 5437475 & 494477 & 5437465.5 & -8 & -19 \\
\hline 95 & 524986 & 5437021.5 & 524989 & 5437030 & 524987 & 5437025.75 & -4 & -8.5 \\
\hline 96 & 514964 & 5431432 & 514965 & 5431438 & 514964 & 5431435 & -2 & -6 \\
\hline 97 & 510067 & 5430948 & 510056 & 5430942.5 & 510062 & 5430945.25 & 11 & 5.5 \\
\hline 98 & 512407 & 5430952 & 512423 & 5430947 & 512415 & 5430949.5 & -17 & 5 \\
\hline 99 & 514967 & 5429918 & 514972 & 5429924 & 514970 & 5429921 & -5 & -6 \\
\hline 100 & 494162 & 5428937 & 494175 & 5428960 & 494169 & 5428948.5 & -13 & -23 \\
\hline 101 & 519676 & 5439870 & 519673 & 5439874 & 519675 & 5439872 & 3 & -4 \\
\hline 102 & 489745 & 5450703 & 489751 & 5450670 & 489748 & 5450686.5 & -6 & 33 \\
\hline 103 & 489926 & 5456777 & 489914 & 5456784 & 489920 & 5456780.5 & 12 & -7 \\
\hline 104 & 491444 & 5450855 & 491436 & 5450852 & 491440 & 5450853.5 & 8 & 3 \\
\hline 105 & 491557 & 5453535 & 491544 & 5453542.5 & 491550 & 5453538.75 & 13 & -7.5 \\
\hline 106 & 494409 & 5451606 & 494407 & 5451608 & 494408 & 5451607 & 2 & -2 \\
\hline 107 & 494410 & 5458936 & 494419 & 5458949.5 & 494415 & 5458942.75 & -9 & -13.5 \\
\hline 108 & 516788 & 5450609 & 516809 & 5450580 & 516799 & 5450594.5 & -21 & 29 \\
\hline 109 & 511743 & 5451347.5 & 511736 & 5451344 & 511740 & 5451345.75 & 7 & 3.5 \\
\hline 110 & 507503 & 5449489 & 507503 & 5449482.5 & 507503 & 5449485.75 & 0 & 6.5 \\
\hline 111 & 545196 & 5433779 & 545197 & 5433773 & 545197 & 5433776 & -1 & 6 \\
\hline
\end{tabular}




\begin{tabular}{|c|c|c|c|c|c|c|c|c|}
\hline \multirow{2}{*}{$\begin{array}{c}\text { Location } \\
\text { ID }\end{array}$} & \multicolumn{2}{|c|}{ 2009 Fall } & \multicolumn{2}{c|}{ 2010 Spring } & \multicolumn{2}{c|}{ Average } & \multicolumn{2}{c|}{ Difference } \\
\cline { 2 - 8 } & $\mathbf{X}$ & $\mathbf{Y}$ & $\mathbf{X}$ & $\mathbf{Y}$ & $\mathbf{X}$ & $\mathbf{Y}$ & $\mathbf{X}$ & $\mathbf{Y}$ \\
\hline 112 & 549972 & 5435150.5 & 549971 & 5435141 & 549971 & 5435145.75 & 1 & 9.5 \\
\hline 113 & 547954 & 5434225 & 547939 & 5434214 & 547946 & 5434219.5 & 15 & 11 \\
\hline 114 & 552091 & 5435382 & 552096 & 5435370 & 552093 & 5435376 & -6 & 12 \\
\hline 115 & 554293 & 5433536.5 & 554291 & 5433523 & 554292 & 5433529.75 & 2 & 13.5 \\
\hline 116 & 509658 & 5458222.5 & 509646 & 5458322.5 & 509652 & 5458272.5 & 12 & -100 \\
\hline
\end{tabular}




\section{Appendix F: 2010 sampling results (in ppb)}

\begin{tabular}{|c|c|c|c|c|c|c|}
\hline \multirow{2}{*}{$\begin{array}{c}\text { Location } \\
\text { ID } \\
\end{array}$} & \multicolumn{2}{|c|}{2009 Fall } & \multicolumn{2}{|c|}{2010 Spring } & \multicolumn{2}{|c|}{ 2009-10 Average } \\
\hline & $\mathrm{NO2}$ & NO & $\mathrm{NO2}$ & NO & NO2 & NO \\
\hline 1 & 5.99 & 4.86 & 3.36 & 4.08 & 4.68 & 4.47 \\
\hline 2 & 8.99 & 9.78 & 6.58 & 6.10 & 7.78 & 7.94 \\
\hline 3 & 10.81 & 13.81 & 5.08 & 5.85 & 7.95 & 9.83 \\
\hline 4 & 9.39 & 11.03 & 4.65 & 5.28 & 7.02 & 8.16 \\
\hline 5 & 10.79 & 13.50 & 7.33 & 7.52 & 9.06 & 10.51 \\
\hline 6 & 18.18 & 23.30 & 9.07 & 12.75 & 13.62 & 18.02 \\
\hline 7 & 12.48 & 12.20 & 6.89 & 9.22 & 9.69 & 10.71 \\
\hline 8 & 9.59 & 3.60 & 4.46 & 5.36 & 7.02 & 4.48 \\
\hline 9 & 14.92 & 17.23 & 11.04 & 10.13 & 12.98 & 13.68 \\
\hline 10 & 14.65 & 23.44 & 8.38 & 14.61 & 11.52 & 19.03 \\
\hline 11 & 16.71 & 6.95 & 9.23 & 7.91 & 12.97 & 7.43 \\
\hline 12 & 10.14 & 12.03 & 8.01 & 5.53 & 9.08 & 8.78 \\
\hline 13 & 16.47 & 24.68 & 10.25 & 9.97 & 13.36 & 17.33 \\
\hline 14 & 20.91 & 47.88 & 10.41 & 21.32 & 15.66 & 34.60 \\
\hline 15 & 13.69 & 26.07 & 10.70 & 7.60 & 12.19 & 16.84 \\
\hline 16 & 9.68 & 8.22 & 7.07 & 4.90 & 8.37 & 6.56 \\
\hline 17 & 15.12 & 25.41 & 13.00 & 18.65 & 14.06 & 22.03 \\
\hline 18 & 5.10 & 2.88 & 4.62 & 2.59 & 4.86 & 2.74 \\
\hline 19 & 19.04 & 31.39 & 11.36 & 10.39 & 15.20 & 20.89 \\
\hline 20 & 18.93 & 37.69 & 8.84 & 22.11 & 13.89 & 29.90 \\
\hline 21 & 16.90 & 29.65 & 10.09 & 7.29 & 13.49 & 18.47 \\
\hline 22 & 21.21 & 30.09 & 9.70 & 14.62 & 15.46 & 22.36 \\
\hline 23 & 20.23 & 49.73 & 13.85 & 33.08 & 17.04 & 41.41 \\
\hline 24 & 12.23 & 15.54 & 9.36 & 4.44 & 10.80 & 9.99 \\
\hline 25 & 9.98 & 13.40 & 8.65 & 3.20 & 9.31 & 8.30 \\
\hline 26 & 10.61 & 11.31 & 6.40 & 4.10 & 8.50 & 7.71 \\
\hline 27 & 11.12 & 8.02 & 5.38 & 8.83 & 8.25 & 8.43 \\
\hline 28 & 9.79 & 11.36 & 6.87 & 8.88 & 8.33 & 10.12 \\
\hline 29 & 18.41 & 39.21 & 14.49 & 12.65 & 16.45 & 25.93 \\
\hline 30 & 16.10 & 21.08 & 7.56 & 9.24 & 11.83 & 15.16 \\
\hline 31 & 17.17 & 36.17 & 13.09 & 13.04 & 15.13 & 24.60 \\
\hline 32 & 18.99 & 49.81 & 12.31 & 24.58 & 15.65 & 37.20 \\
\hline 33 & 14.36 & 16.22 & 7.48 & 6.39 & 10.92 & 11.30 \\
\hline 34 & 15.07 & 15.30 & 6.56 & 7.75 & 10.81 & 11.52 \\
\hline 35 & 17.27 & 64.74 & 14.15 & 16.76 & 15.71 & 40.75 \\
\hline 36 & 16.81 & 25.15 & 6.96 & 10.66 & 11.88 & 17.90 \\
\hline
\end{tabular}




\begin{tabular}{|c|c|c|c|c|c|c|}
\hline \multirow{2}{*}{$\begin{array}{c}\text { Location } \\
\text { ID }\end{array}$} & \multicolumn{2}{|c|}{2009 Fall } & \multicolumn{2}{|c|}{2010 Spring } & \multicolumn{2}{|c|}{ 2009-10 Average } \\
\hline & $\mathrm{NO2}$ & NO & NO2 & NO & NO2 & NO \\
\hline 37 & 17.50 & 41.78 & 12.98 & 17.10 & 15.24 & 29.44 \\
\hline 38 & 13.93 & 38.34 & 10.28 & 20.64 & 12.10 & 29.49 \\
\hline 39 & 11.92 & 19.28 & 8.96 & 14.93 & 10.44 & 17.11 \\
\hline 40 & 14.56 & 16.64 & 7.31 & 8.35 & 10.94 & 12.50 \\
\hline 41 & 7.83 & 11.48 & 5.40 & 9.15 & 6.61 & 10.31 \\
\hline 42 & 16.41 & 19.58 & 6.06 & 11.84 & 11.24 & 15.71 \\
\hline 43 & 17.26 & 14.08 & \multicolumn{2}{|c|}{ Sampler missing } & 17.26 & 14.08 \\
\hline 44 & 14.88 & 23.74 & 11.96 & 7.62 & 13.42 & 15.68 \\
\hline 45 & 9.72 & 8.91 & 5.67 & 7.60 & 7.70 & 8.25 \\
\hline 46 & 11.30 & 4.80 & 6.26 & 8.25 & 8.78 & 6.53 \\
\hline 47 & 13.24 & 15.92 & 6.14 & 10.03 & 9.69 & 12.98 \\
\hline 48 & 17.26 & 32.10 & 13.61 & 16.14 & 15.43 & 24.12 \\
\hline 49 & 15.44 & 14.83 & 8.41 & 6.93 & 11.93 & 10.88 \\
\hline 50 & 17.61 & 26.23 & 8.36 & 14.20 & 12.99 & 20.21 \\
\hline 51 & 14.94 & 16.53 & 6.69 & 8.20 & 10.81 & 12.37 \\
\hline 52 & 17.83 & 55.10 & 16.62 & 33.27 & 17.22 & 44.18 \\
\hline 53 & 12.64 & 26.02 & 7.35 & 8.98 & 9.99 & 17.50 \\
\hline 54 & 13.67 & 6.65 & 8.04 & 9.50 & 10.86 & 8.08 \\
\hline 55 & 16.12 & 19.35 & 8.64 & 12.48 & 12.38 & 15.92 \\
\hline 56 & 18.62 & 20.29 & 5.86 & 23.75 & 12.24 & 22.02 \\
\hline 57 & 16.61 & 20.92 & 8.77 & 13.26 & 12.69 & 17.09 \\
\hline 58 & 9.72 & 9.42 & 5.78 & 7.32 & 7.75 & 8.37 \\
\hline 59 & 15.56 & 15.82 & 10.04 & 8.05 & 12.80 & 11.94 \\
\hline 60 & 14.23 & 15.45 & 6.10 & 11.08 & 10.16 & 13.27 \\
\hline 61 & 12.03 & 12.42 & 7.72 & 5.04 & 9.87 & 8.73 \\
\hline 62 & 8.90 & 6.12 & 4.16 & 6.21 & 6.53 & 6.17 \\
\hline 63 & 20.95 & 49.18 & 14.10 & 37.94 & 17.53 & 43.56 \\
\hline 64 & 14.07 & 13.24 & 9.67 & 9.61 & 11.87 & 11.42 \\
\hline 65 & 14.33 & 16.53 & 8.05 & 12.46 & 11.19 & 14.49 \\
\hline 66 & 16.69 & 21.83 & 7.47 & 12.19 & 12.08 & 17.01 \\
\hline 67 & 15.89 & 16.26 & 8.60 & 8.78 & 12.24 & 12.52 \\
\hline 68 & 11.38 & 5.47 & 5.97 & 7.51 & 8.68 & 6.49 \\
\hline 69 & 17.70 & 45.17 & 13.84 & 24.79 & 15.77 & 34.98 \\
\hline 70 & 11.66 & 8.84 & 7.60 & 7.40 & 9.63 & 8.12 \\
\hline 71 & \multicolumn{2}{|c|}{ No filter } & 7.79 & 14.75 & 7.79 & 14.75 \\
\hline 72 & 14.05 & 9.92 & 7.17 & 6.67 & 10.61 & 8.30 \\
\hline 73 & 11.25 & 7.63 & 5.84 & 7.44 & 8.55 & 7.54 \\
\hline 74 & 20.22 & 46.94 & 12.06 & 18.49 & 16.14 & 32.71 \\
\hline 75 & 12.86 & 9.63 & 7.02 & 7.12 & 9.94 & 8.38 \\
\hline 76 & 11.61 & 11.52 & \multicolumn{2}{|c|}{ Sampler missing } & 11.61 & 11.52 \\
\hline
\end{tabular}




\begin{tabular}{|c|c|c|c|c|c|c|}
\hline \multirow{2}{*}{$\begin{array}{c}\text { Location } \\
\text { ID }\end{array}$} & \multicolumn{2}{|c|}{2009 Fall } & \multicolumn{2}{|c|}{2010 Spring } & \multicolumn{2}{|c|}{ 2009-10 Average } \\
\hline & NO2 & NO & NO2 & NO & NO2 & NO \\
\hline 77 & 12.85 & 17.60 & 4.51 & 6.34 & 8.68 & 11.97 \\
\hline 78 & 14.26 & 23.43 & 3.65 & 8.12 & 8.95 & 15.78 \\
\hline 79 & 17.05 & 38.89 & 8.42 & 11.57 & 12.73 & 25.23 \\
\hline 80 & 13.38 & 30.54 & 13.06 & 25.98 & 13.22 & 28.26 \\
\hline 81 & 12.24 & 7.06 & 7.23 & 6.54 & 9.74 & 6.80 \\
\hline 82 & 14.66 & 12.12 & 6.62 & 11.69 & 10.64 & 11.90 \\
\hline 83 & 13.88 & 23.82 & 2.90 & 11.51 & 8.39 & 17.67 \\
\hline 84 & 12.58 & 21.83 & 5.63 & 9.01 & 9.11 & 15.42 \\
\hline 85 & 11.20 & 19.53 & 4.26 & 5.74 & 7.73 & 12.63 \\
\hline 86 & 12.07 & 22.58 & 3.92 & 7.24 & 7.99 & 14.91 \\
\hline 87 & 13.67 & 11.04 & 4.24 & 8.08 & 8.95 & 9.56 \\
\hline 88 & 13.57 & 24.63 & 8.46 & 20.86 & 11.01 & 22.74 \\
\hline 89 & 13.75 & 13.80 & 4.09 & 7.81 & 8.92 & 10.81 \\
\hline 90 & 14.21 & 9.20 & 5.25 & 7.44 & 9.73 & 8.32 \\
\hline 91 & 12.51 & 14.45 & 6.97 & 8.89 & 9.74 & 11.67 \\
\hline 92 & 16.23 & 31.48 & 8.46 & 20.40 & 12.35 & 25.94 \\
\hline 93 & \multicolumn{2}{|c|}{ Sampler missing } & 3.12 & 4.17 & 3.12 & 4.17 \\
\hline 94 & 14.85 & 30.96 & 6.21 & 17.37 & 10.53 & 24.17 \\
\hline 95 & 8.92 & 6.19 & 3.54 & 5.21 & 6.23 & 5.70 \\
\hline 96 & 9.46 & 5.72 & 4.24 & 4.70 & 6.85 & 5.21 \\
\hline 97 & 8.55 & 7.18 & 4.59 & 6.94 & 6.57 & 7.06 \\
\hline 98 & 8.88 & 9.62 & 4.32 & 9.26 & 6.60 & 9.44 \\
\hline 99 & 7.42 & 3.88 & 2.35 & 5.28 & 4.89 & 4.58 \\
\hline 100 & 8.49 & 6.85 & 4.26 & 4.30 & 6.38 & 5.57 \\
\hline 101 & 15.64 & 32.53 & 7.58 & 18.69 & 11.61 & 25.61 \\
\hline 102 & 18.56 & 40.01 & 8.86 & 15.23 & 13.71 & 27.62 \\
\hline 103 & 23.73 & 52.68 & 10.31 & 31.82 & 17.02 & 42.25 \\
\hline 104 & 19.33 & 39.29 & 13.06 & 31.37 & 16.19 & 35.33 \\
\hline 105 & 16.44 & 30.58 & 7.25 & 22.89 & 11.84 & 26.74 \\
\hline 106 & 16.95 & 31.52 & 11.03 & 37.47 & 13.99 & 34.49 \\
\hline 107 & 20.32 & 61.25 & 14.84 & 38.33 & 17.58 & 49.79 \\
\hline 108 & 10.01 & 6.35 & 5.16 & 5.35 & 7.59 & 5.85 \\
\hline 109 & 12.48 & 9.60 & 10.06 & 7.50 & 11.27 & 8.55 \\
\hline 110 & 18.40 & 33.17 & 9.99 & 17.80 & 14.20 & 25.49 \\
\hline 111 & 15.95 & 44.82 & 7.40 & 21.92 & 11.67 & 33.37 \\
\hline 112 & 10.64 & 15.27 & 6.10 & 15.21 & 8.37 & 15.24 \\
\hline 113 & \multicolumn{2}{|c|}{ Mistake } & 5.12 & 6.31 & 5.12 & 6.31 \\
\hline 114 & 8.34 & 10.11 & 5.15 & 8.59 & 6.75 & 9.35 \\
\hline 115 & 7.39 & 4.38 & 4.65 & 4.43 & 6.02 & 4.40 \\
\hline 116 & 14.80 & 38.69 & 9.89 & 8.41 & 12.35 & 23.55 \\
\hline
\end{tabular}




\begin{tabular}{|c|c|c|c|c|c|c|}
\hline \multirow{2}{*}{ Location } & \multicolumn{2}{|c|}{ 2009 Fall } & \multicolumn{2}{c|}{ 2010 Spring } & \multicolumn{2}{c|}{ 2009-10 Average } \\
\hline ID & NO2 & NO & NO2 & NO & NO2 & NO \\
\hline Count & 113 & & & & 114 & 116 \\
\hline Mean & 14.02 & 21.32 & 7.92 & 12.09 & 10.91 & 16.55 \\
\hline Stdev & 3.70 & 14.08 & 3.07 & 7.94 & 3.26 & 10.44 \\
\hline Min & 5.10 & 2.88 & 2.35 & 2.59 & 3.12 & 2.74 \\
\hline Max & 23.73 & 64.74 & 16.62 & 38.33 & 17.58 & 49.79 \\
\hline $\mathbf{2 5 \% i l e ~}$ & 11.25 & 10.11 & 5.70 & 7.15 & 8.48 & 8.38 \\
\hline 75\%ile & 16.71 & 30.54 & 9.84 & 14.89 & 12.98 & 22.45 \\
\hline Median & 14.21 & 16.53 & 7.44 & 9.00 & 10.84 & 13.12 \\
\hline
\end{tabular}


Appendix G: Quality control for 2010 measurements 
Co-located samplers

\begin{tabular}{|c|c|c|c|c|c|c|}
\hline Location & \multicolumn{3}{|c}{ NO, Fall } & \multicolumn{3}{c|}{ NO , Fall } \\
\hline ID & GVRD & Ogawa & Error & GVRD & Ogawa & Error \\
\hline T1 & 26.22 & 24.61 & 1.61 & 20.10 & 15.78 & 4.32 \\
\hline T2 & 22.72 & 24.04 & -1.32 & 18.00 & 14.41 & 3.59 \\
\hline T4 & 9.38 & 10.46 & -1.08 & 11.10 & 10.22 & 0.88 \\
\hline T6 & 12.17 & 14.79 & -2.62 & 12.30 & 12.09 & 0.21 \\
\hline T9 & 12.11 & 14.57 & -2.46 & 12.10 & 10.77 & 1.33 \\
\hline T13 & 9.55 & 9.55 & 0.00 & 13.50 & 14.13 & -0.63 \\
\hline T15 & 5.19 & 9.16 & -3.97 & 8.70 & 7.85 & 0.85 \\
\hline T17 & 16.50 & 15.40 & 1.10 & 14.40 & 13.22 & 1.18 \\
\hline T18 & 8.19 & 20.25 & -12.06 & 14.90 & 16.10 & -1.20 \\
\hline T20 & 7.40 & 8.49 & -1.09 & 7.10 & 6.28 & 0.82 \\
\hline T27 & 2.39 & 4.33 & -1.94 & 7.00 & 6.13 & 0.87 \\
\hline T30 & 5.26 & 6.19 & -0.93 & 8.30 & 8.18 & 0.12 \\
\hline T32 & 11.00 & 13.55 & -2.55 & 11.40 & 10.32 & 1.08 \\
\hline T33 & 6.11 & 11.91 & -5.80 & 9.40 & 9.31 & 0.09 \\
\hline Mean & 11.01 & 13.38 & -2.37 & 12.02 & 11.06 & 0.97 \\
\hline SD & 6.75 & 6.17 & 3.38 & 3.92 & 3.33 & 1.46 \\
\hline
\end{tabular}

\begin{tabular}{|c|c|c|c|c|c|c|}
\hline Location & \multicolumn{3}{|c|}{ NO, Spring } & \multicolumn{3}{c|}{ NO $_{2}$ Spring } \\
\hline ID & GVRD & Ogawa & Error & GVRD & Ogawa & Error \\
\hline T1 & 7.43 & 16.65 & -9.22 & 16.49 & 15.59 & 0.90 \\
\hline T4 & 2.97 & 14.26 & -11.29 & 9.06 & 4.09 & 4.97 \\
\hline T6 & 8.05 & 19.40 & -11.35 & 12.78 & 8.83 & 3.95 \\
\hline T9 & 2.46 & 7.37 & -4.91 & 10.08 & 8.55 & 1.53 \\
\hline T13 & 2.13 & 8.07 & -5.94 & 8.47 & 6.65 & 1.82 \\
\hline T15 & 0.83 & 6.50 & -5.67 & 6.28 & 4.44 & 1.84 \\
\hline T17 & 2.53 & 9.25 & -6.72 & 7.49 & 6.49 & 1.00 \\
\hline T18 & 1.67 & 7.19 & -5.52 & 8.66 & 6.21 & 2.45 \\
\hline T20 & 2.05 & 6.70 & -4.65 & 6.15 & 4.05 & 2.10 \\
\hline T26 & 2.06 & 7.83 & -5.77 & 8.31 & 5.65 & 2.66 \\
\hline T27 & 0.41 & 6.90 & -6.49 & 3.45 & 2.49 & 0.96 \\
\hline T30 & 1.12 & 5.27 & -4.15 & 5.42 & 4.17 & 1.25 \\
\hline T31 & 2.21 & 11.73 & -9.52 & 7.86 & 6.25 & 1.61 \\
\hline T32 & 1.89 & 3.33 & -1.44 & 7.84 & 8.17 & -0.33 \\
\hline T33 & 1.29 & 6.66 & -5.37 & 6.88 & 4.10 & 2.78 \\
\hline Mean & 2.61 & 9.14 & -6.53 & 8.35 & 6.38 & 1.97 \\
\hline SD & 2.19 & 4.45 & 2.72 & 3.10 & 3.15 & 1.30 \\
\hline
\end{tabular}




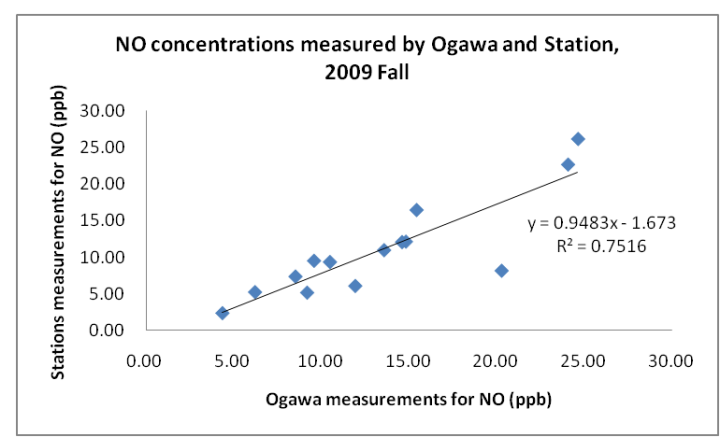

Correlation: 0.87

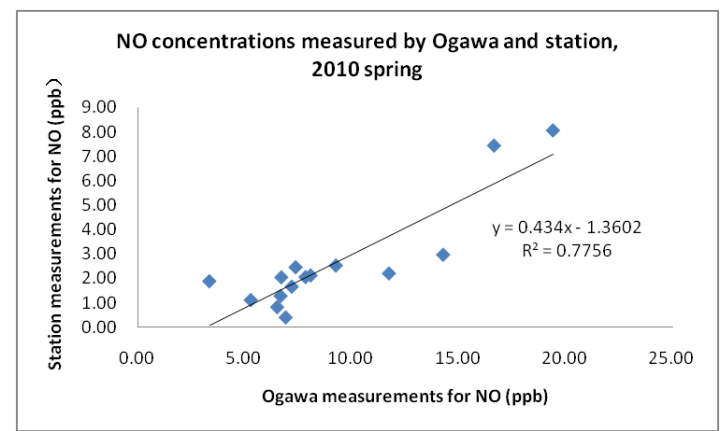

Correlation: 0.88

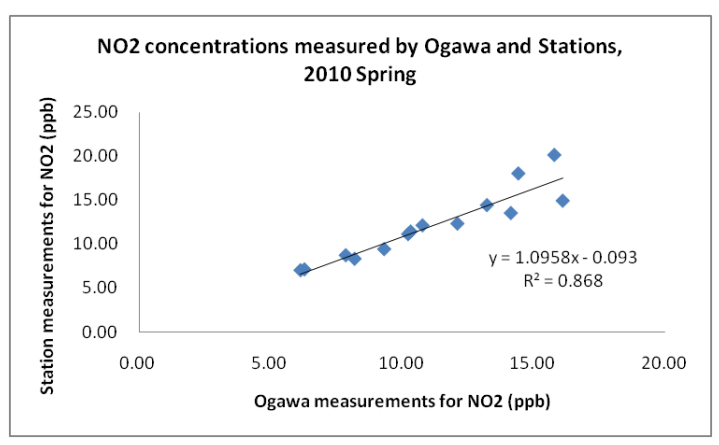

Correlation: 0.93

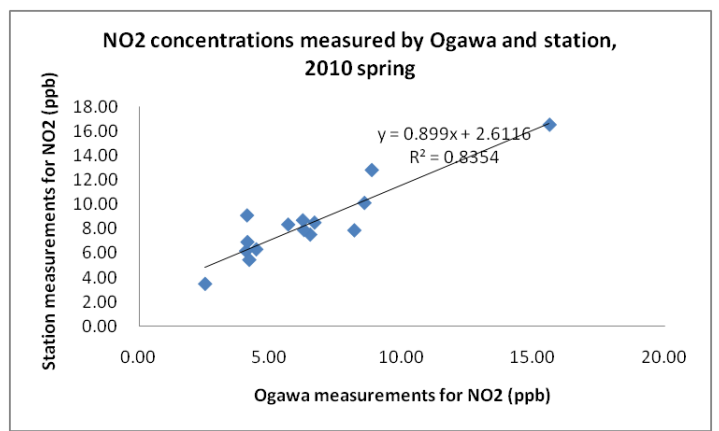

Correlation: 0.91 


\section{Duplicates}

2009 fall (17 in total)

\begin{tabular}{|c|c|c|c|c|}
\hline Location ID & NO $(\mathbf{p p b})$ & Duplicate $\mathbf{N O}(\mathbf{p p b})$ & NO2 $\mathbf{( p p b )}$ & Duplicate NO2 (ppb) \\
\hline 3 & 12.10 & 13.10 & 10.50 & 10.90 \\
\hline 9 & 15.50 & 16.90 & 14.60 & 18.50 \\
\hline 17 & 23.70 & 24.50 & 14.80 & 14.50 \\
\hline 18 & 1.10 & 1.80 & 4.80 & 4.20 \\
\hline 29 & 37.50 & 37.50 & 18.10 & 18.80 \\
\hline 30 & 19.30 & 21.90 & 15.80 & 15.50 \\
\hline 44 & 22.00 & 22.70 & 14.60 & 14.10 \\
\hline 51 & 14.80 & 18.80 & 14.60 & 12.50 \\
\hline 52 & 53.40 & 55.50 & 17.50 & 19.30 \\
\hline 55 & 17.60 & 20.00 & 15.80 & 14.50 \\
\hline 62 & 4.40 & 4.40 & 8.60 & 8.50 \\
\hline 69 & 43.40 & 43.50 & 17.40 & 17.90 \\
\hline 73 & 5.90 & 6.70 & 10.90 & 11.10 \\
\hline 79 & 37.10 & 43.40 & 16.70 & 16.50 \\
\hline 82 & 10.40 & 12.00 & 14.30 & 13.30 \\
\hline 95 & 4.50 & 4.70 & 8.60 & 8.00 \\
\hline 98 & 7.90 & 8.90 & 8.60 & 8.60 \\
\hline Correlation & & 0.99 & & 0.95 \\
\hline Mean difference (sd) & & $1.51(1.63)$ & & $0.03(1.32)$ \\
\hline & & & & \\
\hline & & & & \\
\hline
\end{tabular}

2010 spring (17 in total)

\begin{tabular}{|c|c|c|c|c|}
\hline Location ID & NO (ppb) & Duplicate $\mathbf{N O}(\mathbf{p p b})$ & $\mathbf{N O}_{\mathbf{2}} \mathbf{( p p b )}$ & Duplicate $\mathbf{N O}_{\mathbf{2}} \mathbf{( p p b )}$ \\
\hline 1 & 4.92 & 2.88 & 3.99 & 4.90 \\
\hline 2 & 6.79 & 4.34 & 8.14 & 9.15 \\
\hline 3 & 4.63 & 6.48 & 7.42 & 6.03 \\
\hline 10 & 16.96 & 12.34 & 8.72 & 13.59 \\
\hline 13 & 9.03 & 9.47 & 13.95 & 13.25 \\
\hline 14 & 20.03 & 23.05 & 16.65 & 10.88 \\
\hline 16 & 3.53 & 5.43 & 7.04 & 6.66 \\
\hline 32 & 24.03 & 20.98 & 14.05 & 9.88 \\
\hline 38 & 19.10 & 18.47 & 9.48 & 10.38 \\
\hline 61 & 4.29 & 4.92 & 7.38 & 7.59 \\
\hline 73 & 6.86 & 6.68 & 5.79 & 5.50 \\
\hline 74 & 16.78 & 17.07 & 12.32 & 11.12 \\
\hline 75 & 5.99 & 7.09 & 7.27 & 6.42 \\
\hline 77 & 5.41 & 6.08 & 4.89 & 3.79 \\
\hline 95 & 4.50 & 4.95 & 3.73 & 3.10 \\
\hline
\end{tabular}




\begin{tabular}{|c|c|c|c|c|}
\hline Location ID & NO (ppb) & Duplicate NO (ppb) & NO $_{\mathbf{2}}$ (ppb) & Duplicate $\mathbf{N O}_{\mathbf{2}}$ (ppb) \\
\hline 98 & 7.48 & 9.28 & 4.62 & 3.68 \\
\hline 102 & 14.20 & 13.68 & 8.43 & 8.79 \\
\hline Correlation & \multicolumn{2}{|c|}{0.95} & & 0.81 \\
\hline Mean difference (sd) & \multicolumn{2}{|c|}{$0.08(1.99)$} & & $0.54(2.23)$ \\
\hline
\end{tabular}

Field blanks

\begin{tabular}{|c|c|c|c|c|c|}
\hline \multicolumn{3}{|c|}{2009 Fall } & \multicolumn{3}{|c|}{2010 Spring } \\
\hline $\begin{array}{l}\text { Field blank } \\
\text { ID }\end{array}$ & $\begin{array}{c}\text { NOx Nitrite } \\
\text { (ug/ml) }\end{array}$ & $\begin{array}{c}\mathrm{NO}_{2} \text { Nitrite } \\
\text { (ug/ml) }\end{array}$ & $\begin{array}{c}\text { Field blank } \\
\text { ID }\end{array}$ & $\begin{array}{c}\text { NOx Nitrite } \\
\text { (ug/ml) }\end{array}$ & $\begin{array}{c}\mathrm{NO}_{2} \text { Nitrite } \\
\text { (ug/ml) }\end{array}$ \\
\hline $\mathrm{F} 2$ & 0.028 & 0.012 & $\mathrm{~F} 2$ & n.a. & n.a. \\
\hline F3 & 0.016 & 0.011 & F4 & n.a. & n.a. \\
\hline F5 & 0.034 & 0.006 & F6 & n.a. & n.a. \\
\hline F9 & 0.045 & 0.036 & F8 & n.a. & n.a. \\
\hline F11 & 0.023 & 0.018 & F10 & n.a. & n.a. \\
\hline F12 & 0.014 & 0.020 & F12 & n.a. & n.a. \\
\hline F17 & 0.025 & 0.008 & F14 & n.a. & n.a. \\
\hline F18 & 0.023 & 0.020 & F16 & n.a. & n.a. \\
\hline F19 & 0.052 & 0.025 & F17 & n.a. & n.a. \\
\hline F23 & 0.023 & 0.049 & F18 & 0.037 & n.a. \\
\hline $\mathrm{F} 25$ & 0.017 & 0.028 & F19 & n.a. & n.a. \\
\hline F31 & 0.029 & 0.040 & F21 & n.a. & n.a. \\
\hline F34 & 0.024 & 0.007 & $\mathrm{~F} 22$ & n.a. & n.a. \\
\hline F35 & 0.015 & 0.021 & F23 & n.a. & n.a. \\
\hline F36 & 0.027 & 0.026 & F24 & n.a. & n.a. \\
\hline F37 & 0.018 & 0.007 & $\mathrm{~F} 25$ & n.a. & n.a. \\
\hline \multirow[t]{9}{*}{ F39 } & 0.019 & 0.051 & F26 & n.a. & n.a. \\
\hline & & & F28 & 0.096 & n.a. \\
\hline & & & F34 & 0.061 & n.a. \\
\hline & & & F35 & 0.028 & 0.026 \\
\hline & & & F36 & n.a. & n.a. \\
\hline & & & F37 & n.a. & n.a. \\
\hline & & & F38 & n.a. & n.a. \\
\hline & & & F39 & 0.047 & n.a. \\
\hline & & & $\mathrm{F} 40$ & n.a. & n.a. \\
\hline Avg & 0.025 & 0.023 & & & \\
\hline SD & 0.010 & 0.014 & & & \\
\hline Count & 17 & 17 & Count & 5 & 1 \\
\hline $\operatorname{LOD}^{1}$ & 0.056 & 0.066 & $\mathrm{LOD}^{2}$ & 0.031 & 0.033 \\
\hline
\end{tabular}

1. $\mathrm{LOD}=\mathrm{Avg}+3 \mathrm{SD}$

2. $\mathrm{LOD}=$ half of lowest lab standard 


\section{Appendix H: Ogawa sampling at UBC to check shelter effect}

Background: In 2010 spring sampling campaign, 14 measurements were taken using brown shelters, instead of original Ogawa shelters, due to lack of Ogawa shelters at the last day of sampling. Disagreement was later found in duplicates where both samplers using Ogawa shelter or brown shelter were placed at the same location.

Objective: The objective of this supplementary sampling was to test if samplers using brown shelter produced systematic difference from those using Ogawa samplers.

Methods: 12 pairs of samplers, one using Ogawa white shelter, the other using brown shelter, were deployed across UBC campus during July26 to July 30 (Mon. - Fri.) in 2010. Each pair of samplers was placed at the same location, at the same height above ground. Samplers were taken off two weeks after and analyzed in lab.

Results: Brown shelters were found to produce systematically higher measurements than Ogawa shelters. For NOx, concentration (brown) $=1.19 \times$ concentration (Ogawa), R2 = 0.52; for NO2, concentration (brown) $=1.37 \times$ concentration (Ogawa), R2 $=0.48$. The intercepts were forced to zero because the range of concentrations from our field sampling fell out of the range of concentrations from UBC sampling. As a result, measurements at 14 sites were adjusted accordingly. 
Appendix I: Summary statistics of predictor variables at the 73 same-locating sites, in 2003 and in 2010

\begin{tabular}{|c|c|c|c|c|c|c|c|c|c|c|c|c|c|c|}
\hline \multicolumn{8}{|c|}{ Distribution of variables in 2003} & \multicolumn{7}{|c|}{ Distribution of variables in 2010} \\
\hline $\begin{array}{c}\text { Variable } \\
\text { description }\end{array}$ & Mean & SD & Min & $25 \%$ ile & Med & $75 \%$ ile & $\operatorname{Max}$ & Mean & SD & Min & $25 \%$ ile & Med & $75 \%$ ile & Max \\
\hline $\begin{array}{c}\text { Distance to } \\
\text { highway }\end{array}$ & 1.4 & 1.4 & 0.0 & 0.4 & 1.0 & 1.8 & 7.0 & 1.3 & 1.4 & 0.0 & 0.4 & 1.0 & 1.8 & 7.0 \\
\hline RD1. 100 & 0.0 & 0.1 & 0.0 & 0.0 & 0.0 & 0.0 & 0.5 & 0.0 & 0.1 & 0.0 & 0.0 & 0.0 & 0.0 & 0.5 \\
\hline RD1. 200 & 0.1 & 0.2 & 0.0 & 0.0 & 0.0 & 0.0 & 1.3 & 0.1 & 0.2 & 0.0 & 0.0 & 0.0 & 0.0 & 1.4 \\
\hline RD1. 300 & 0.2 & 0.5 & 0.0 & 0.0 & 0.0 & 0.0 & 1.3 & 0.2 & 0.5 & 0.0 & 0.0 & 0.0 & 0.0 & 2.5 \\
\hline RD1. 500 & 0.6 & 1.1 & 0.0 & 0.0 & 0.0 & 0.9 & 5.4 & 0.6 & 1.1 & 0.0 & 0.0 & 0.0 & 0.9 & 5.3 \\
\hline RD1. 750 & 1.1 & 1.9 & 0.0 & 0.0 & 0.0 & 1.7 & 8.6 & 1.2 & 1.9 & 0.0 & 0.0 & 0.0 & 1.6 & 9.0 \\
\hline RD1.1000 & 1.9 & 2.6 & 0.0 & 0.0 & 0.0 & 3.0 & 10.9 & 2.0 & 2.7 & 0.0 & 0.0 & 0.0 & 3.5 & 11.6 \\
\hline RD2.100 & 0.1 & 0.1 & 0.0 & 0.0 & 0.0 & 0.1 & 0.4 & 0.1 & 0.1 & 0.0 & 0.0 & 0.0 & 0.1 & 0.4 \\
\hline RD2. 200 & 0.2 & 0.3 & 0.0 & 0.0 & 0.0 & 0.4 & 0.9 & 0.2 & 0.3 & 0.0 & 0.0 & 0.0 & 0.4 & 1.0 \\
\hline RD2. 300 & 0.5 & 0.5 & 0.0 & 0.0 & 0.5 & 0.8 & 1.9 & 0.5 & 0.5 & 0.0 & 0.0 & 0.5 & 0.8 & 2.0 \\
\hline RD2. 500 & 1.2 & 0.9 & 0.0 & 0.6 & 1.2 & 1.8 & 4.6 & 1.3 & 1.0 & 0.0 & 0.6 & 1.2 & 1.9 & 4.7 \\
\hline RD2. 750 & 2.5 & 1.6 & 0.0 & 1.5 & 2.5 & 3.4 & 8.1 & 2.7 & 1.8 & 0.0 & 1.5 & 2.5 & 3.6 & 9.8 \\
\hline RD2. 1000 & 4.5 & 2.5 & 0.0 & 3.0 & 4.5 & 5.6 & 14.0 & 4.8 & 2.7 & 0.0 & 3.1 & 4.6 & 6.1 & 15.7 \\
\hline ELEV & 50.2 & 42.1 & 0.0 & 9.0 & 44.0 & 82.0 & 197.0 & 50.3 & 42.2 & 0.0 & 9.0 & 44.0 & 82.0 & 197.0 \\
\hline
\end{tabular}




\begin{tabular}{|c|c|c|c|c|c|c|c|c|c|c|c|c|c|c|}
\hline \multicolumn{8}{|c|}{ Distribution of variables in 2003} & \multicolumn{7}{|c|}{ Distribution of variables in 2010} \\
\hline $\begin{array}{c}\text { Variable } \\
\text { description }\end{array}$ & Mean & SD & Min & $25 \%$ ile & Med & $75 \%$ ile & Max & Mean & SD & Min & $25 \%$ ile & Med & $75 \%$ ile & Max \\
\hline$X / 10000$ & 50.2 & 1.5 & 48.5 & 49.1 & 49.6 & 51.0 & 55.4 & 50.2 & 1.5 & 48.5 & 49.1 & 49.6 & 51.0 & 55.4 \\
\hline$X / 10000$ & 545.2 & 0.8 & 543.0 & 544.6 & 545.4 & 545.7 & 546.6 & 545.2 & 0.8 & 543.0 & 544.6 & 545.4 & 545.7 & 546.6 \\
\hline POP. 750 & 47.3 & 31.6 & 0.0 & 29.0 & 39.0 & 63.0 & 191.0 & 48.8 & 31.4 & 0.0 & 27.3 & 38.0 & 62.4 & 204.5 \\
\hline POP.1000 & 45.0 & 27.6 & 0.0 & 30.0 & 38.0 & 58.0 & 170.0 & 46.5 & 31.3 & 1.7 & 26.5 & 38.7 & 60.2 & 178.6 \\
\hline POP.1250 & 42.5 & 24.8 & 2.0 & 28.0 & 36.0 & 52.0 & 149.0 & 44.2 & 27.7 & 3.1 & 26.1 & 37.1 & 57.3 & 159.4 \\
\hline POP.1500 & 40.3 & 22.6 & 3.0 & 26.0 & 35.0 & 49.0 & 100.0 & 42.0 & 25.0 & 4.5 & 25.7 & 35.3 & 55.5 & 143.4 \\
\hline POP.2000 & 37.1 & 19.5 & 5.0 & 24.0 & 32.0 & 49.0 & 100.0 & 38.5 & 21.3 & 5.4 & 24.4 & 33.0 & 50.7 & 112.7 \\
\hline POP.2500 & 34.6 & 17.8 & 6.0 & 21.0 & 30.0 & 46.0 & 80.0 & 36.0 & 19.2 & 6.7 & 22.5 & 30.4 & 47.2 & 91.4 \\
\hline OPEN.300 & 2.7 & 5.4 & 0.0 & 0.0 & 0.3 & 2.0 & 25.0 & 4.0 & 4.9 & 0.0 & 0.7 & 1.9 & 5.3 & 25.0 \\
\hline OPEN.400 & 4.9 & 9.4 & 0.0 & 0.1 & 0.9 & 3.9 & 44.5 & 7.4 & 8.2 & 0.0 & 2.5 & 4.5 & 10.3 & 44.6 \\
\hline OPEN.500 & 7.6 & 14.0 & 0.0 & 0.5 & 2.1 & 6.2 & 68.7 & 11.9 & 12.5 & 0.3 & 4.2 & 7.2 & 15.8 & 68.9 \\
\hline OPEN.750 & 18.2 & 27.9 & 0.0 & 1.9 & 6.4 & 26.0 & 146.0 & 28.5 & 24.9 & 2.9 & 11.8 & 21.3 & 36.0 & 147.3 \\
\hline RES.300 & 17.7 & 7.9 & 0.0 & 0.0 & 1.9 & 8.6 & 24.8 & 19.8 & 6.4 & 3.2 & 16.9 & 21.9 & 24.7 & 28.2 \\
\hline RES.400 & 30.6 & 13.2 & 0.4 & 24.0 & 32.6 & 41.3 & 48.9 & 34.6 & 10.5 & 4.6 & 29.3 & 36.6 & 42.1 & 50.1 \\
\hline RES.500 & 46.7 & 19.6 & 3.4 & 31.2 & 50.2 & 62.2 & 71.1 & 53.1 & 16.0 & 5.8 & 45.9 & 56.6 & 64.8 & 77.2 \\
\hline RES.750 & 100.2 & 41.5 & 9.2 & 73.8 & 112.5 & 132.1 & 158.6 & 115.4 & 33.9 & 12.5 & 98.4 & 123.6 & 143.4 & 162.5 \\
\hline IND.300 & 5.0 & 6.6 & 0.0 & 0.0 & 1.9 & 8.6 & 24.8 & 2.4 & 4.4 & 0.0 & 0.0 & 0.0 & 2.9 & 21.3 \\
\hline IND.400 & 9.2 & 10.9 & 0.0 & 0.6 & 4.1 & 14.3 & 39.7 & 4.1 & 7.0 & 0.0 & 0.0 & 1.1 & 4.8 & 28.3 \\
\hline IND.500 & 14.6 & 16.1 & 0.0 & 1.6 & 7.5 & 24.6 & 59.1 & 6.3 & 10.1 & 0.0 & 0.0 & 2.2 & 6.7 & 44.4 \\
\hline IND.750 & 33.7 & 33.2 & 0.0 & 5.7 & 20.5 & 50.7 & 125.3 & 14.6 & 20.4 & 0.0 & 1.8 & 6.1 & 17.7 & 101.8 \\
\hline
\end{tabular}




\begin{tabular}{|c|c|c|c|c|c|c|c|c|c|c|c|c|c|c|}
\hline \multicolumn{8}{|c|}{ Distribution of variables in 2003} & \multicolumn{7}{|c|}{ Distribution of variables in 2010} \\
\hline $\begin{array}{c}\text { Variable } \\
\text { description }\end{array}$ & Mean & SD & Min & $25 \%$ ile & Med & $75 \%$ ile & Max & Mean & SD & Min & $25 \%$ ile & Med & $75 \%$ ile & Max \\
\hline GOV.300 & 0.4 & 1.1 & 0.0 & 0.0 & 0.0 & 0.0 & 5.9 & 1.0 & 1.9 & 0.0 & 0.0 & 0.0 & 1.4 & 11.1 \\
\hline GOV.400 & 0.8 & 1.7 & 0.0 & 0.0 & 0.0 & 0.9 & 7.6 & 2.0 & 2.6 & 0.0 & 0.0 & 1.2 & 3.1 & 14.3 \\
\hline GOV.500 & 1.4 & 2.7 & 0.0 & 0.0 & 0.0 & 1.7 & 11.7 & 3.1 & 3.6 & 0.0 & 0.0 & 1.9 & 4.8 & 17.6 \\
\hline GOV.750 & 3.1 & 4.5 & 0.0 & 0.0 & 1.3 & 3.6 & 19.5 & 6.5 & 6.3 & 0.0 & 2.0 & 4.5 & 9.2 & 25.4 \\
\hline COMM.300 & 0.6 & 1.1 & 0.0 & 0.0 & 0.0 & 0.8 & 4.9 & 0.7 & 1.5 & 0.0 & 0.0 & 0.0 & 0.8 & 7.8 \\
\hline COMM.400 & 0.9 & 1.6 & 0.0 & 0.0 & 0.1 & 1.4 & 6.9 & 1.2 & 2.2 & 0.0 & 0.0 & 0.1 & 1.6 & 11.8 \\
\hline COMM.500 & 1.5 & 2.2 & 0.0 & 0.0 & 0.3 & 2.3 & 8.8 & 1.9 & 3.2 & 0.0 & 0.0 & 0.3 & 2.4 & 16.5 \\
\hline COMM.750 & 3.4 & 4.0 & 0.0 & 0.2 & 2.0 & 5.4 & 19.1 & 4.6 & 6.7 & 0.0 & 0.2 & 2.2 & 6.0 & 37.7 \\
\hline AD.100 & 177.8 & 286.5 & 0.0 & 0.0 & 47.1 & 187.9 & 1196.9 & 190.9 & 291.5 & 0.0 & 0.0 & 37.0 & 209.6 & 1227.4 \\
\hline AD. 200 & 144.0 & 167.8 & 0.0 & 27.2 & 77.3 & 216.1 & 638.3 & 152.5 & 178.2 & 0.0 & 26.2 & 80.0 & 207.1 & 721.2 \\
\hline AD. 300 & 137.1 & 136.8 & 0.0 & 42.1 & 77.1 & 192.3 & 585.3 & 145.5 & 146.1 & 0.0 & 44.8 & 86.5 & 215.8 & 628.9 \\
\hline AD. 500 & 132.7 & 118.2 & 0.5 & 45.4 & 92.9 & 178.6 & 563.9 & 137.9 & 126.5 & 0.1 & 44.2 & 94.9 & 183.6 & 596.7 \\
\hline AD. 750 & 122.2 & 104.3 & 0.8 & 46.2 & 92.9 & 169.1 & 592.1 & 128.6 & 113.2 & 0.4 & 47.6 & 95.3 & 185.9 & 652.0 \\
\hline AD. 1000 & 120.4 & 93.5 & 1.3 & 47.1 & 92.6 & 183.0 & 531.7 & 126.8 & 101.1 & 4.4 & 48.3 & 92.8 & 191.0 & 584.7 \\
\hline TD.100 & 3.0 & 5.9 & 0.0 & 0.0 & 0.4 & 3.3 & 34.1 & 6.9 & 11.8 & 0.0 & 0.0 & 1.0 & 9.9 & 52.5 \\
\hline TD. 200 & 2.3 & 3.7 & 0.0 & 0.2 & 0.8 & 3.0 & 22.2 & 5.1 & 6.5 & 0.0 & 0.6 & 2.4 & 6.9 & 28.0 \\
\hline TD. 300 & 2.0 & 2.8 & 0.0 & 0.4 & 1.0 & 2.6 & 18.9 & 4.8 & 5.3 & 0.0 & 1.0 & 2.7 & 7.5 & 23.6 \\
\hline TD. 500 & 1.9 & 2.0 & 0.0 & 0.4 & 1.4 & 2.5 & 9.0 & 4.6 & 4.7 & 0.0 & 1.4 & 3.0 & 6.4 & 24.3 \\
\hline TD. 750 & 1.8 & 1.8 & 0.0 & 0.5 & 1.3 & 2.4 & 9.8 & 4.4 & 4.1 & 0.0 & 1.8 & 3.3 & 6.4 & 19.1 \\
\hline TD. 1000 & 1.9 & 1.6 & 0.0 & 0.5 & 1.3 & 3.0 & 7.7 & 4.6 & 3.9 & 0.1 & 1.8 & 3.1 & 6.6 & 16.8 \\
\hline
\end{tabular}

